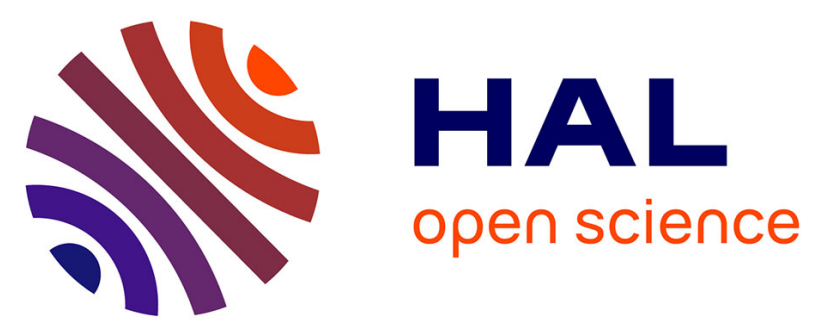

\title{
Synthesis and in vitro evaluation of new fluorinated quinoline derivatives with high affinity for PDE5: Towards the development of new PET neuroimaging probes
}

Jianrong Liu, Aurelie Maisonial-Besset, Barbara Wenzel, Damien Canitrot, Ariane Baufond, Jean-Michel Chezal, Peter Brust, Emmanuel Moreau

\section{To cite this version:}

Jianrong Liu, Aurelie Maisonial-Besset, Barbara Wenzel, Damien Canitrot, Ariane Baufond, et al.. Synthesis and in vitro evaluation of new fluorinated quinoline derivatives with high affinity for PDE5: Towards the development of new PET neuroimaging probes. European Journal of Medicinal Chemistry, 2017, 136, pp.548 - 560. 10.1016/j.ejmech.2017.03.091 . hal-01671041

\author{
HAL Id: hal-01671041 \\ https://hal.science/hal-01671041
}

Submitted on 21 Dec 2017

HAL is a multi-disciplinary open access archive for the deposit and dissemination of scientific research documents, whether they are published or not. The documents may come from teaching and research institutions in France or abroad, or from public or private research centers.
L'archive ouverte pluridisciplinaire HAL, est destinée au dépôt et à la diffusion de documents scientifiques de niveau recherche, publiés ou non, émanant des établissements d'enseignement et de recherche français ou étrangers, des laboratoires publics ou privés. 


\title{
Synthesis and in vitro evaluation of new fluorinated quinoline derivatives with high affinity for PDE5: towards the development of new PET neuroimaging probes.
}

\author{
Jianrong Liu, ${ }^{a}$ Aurélie Maisonial-Besset, ${ }^{* a}$ Barbara Wenzel, ${ }^{b}$ Damien Canitrot, ${ }^{a}$ Ariane \\ Baufond, ${ }^{a}$ Jean-Michel Chezal, ${ }^{a}$ Peter Brust, ${ }^{b}$ and Emmanuel Moreau ${ }^{a}$
}

'Univ. Clermont Auvergne, INSERM, UMR 1240, IMOST, F-63005 Clermont-Ferrand, France; liujianrong2005@163.com; aurelie.maisonial@ucamail.fr; damien.canitrot@ucamail.fr; ariane.baufond@ucamail.fr; j-michel.chezal@ucamail.fr; emmanuel.moreau@ucamail.fr.

${ }^{b}$ Helmholtz-Zentrum Dresden-Rossendorf, Institute of Radiopharmaceutical Cancer Research, Research Site Leipzig, Dept. of Neuroradiopharmaceuticals, Permoserstrasse 15, 04318 Leipzig, Germany; b.wenzel@hzdr.de; p.brust@hzdr.de.

* Corresponding author: Aurélie Maisonial-Besset, aurelie.maisonial@ucamail.fr; UMR 1240, IMOST, Univ. Clermont Auvergne, INSERM, BP 184, 58 rue Montalembert, F-63005 Clermont-Ferrand, France.

\section{Keywords:}

Quinoline ; fluorination; Phosphodiesterase 5 ; radiotracer ; positron emission tomography.

\begin{abstract}
Abbreviations used: $A D$ : alzheimer's disease; AllocCl: allyl chloroformate; ATR: attenuated total reflectance; cAMP: cyclic adenosine 3',5'-monophosphate; cGMP: cyclic guanosine 3',5'-monophosphate; CNS: central nervous system; CREB: responsive element binding protein; DAST: (diethylamino)sulfur trifluoride; DIBALH: diisobutylaluminium hydride; DIPEA: $\mathrm{N}, \mathrm{N}$-diisopropylethylamine; $\quad$ DMAP: $\quad \mathrm{N}, \mathrm{N}$-dimethylaminopyridine; $\quad$ DMF: $\quad \mathrm{N}, \mathrm{N}$ dimethylformamide; DMSO: dimethylsulfoxide; EMME: ethoxy methylene malonic diethyl ester; ESI-MS: electrospray ionization mass spectra; HMBC: heteronuclear multiple bond correlation; HRMS: high resolution mass spectroscopy; HSQC: heteronuclear single quantum correlation; $\mathrm{IC}_{50}$ : inhibition concentration 50; IR: infrared spectroscopy; Mp: melting point; $n$ BuLi: $n$-butyl lithium; NDs: neurodegenerative disorders; NMR: nuclear magnetic resonance; PDE: phosphodiesterase; PDE5Is: phosphodiesterase 5 inhibitors; PET: positron emission tomography; $\mathrm{R}_{\mathrm{f}}$ : retention factor; rt: room temperature; SAR: structure-activity relationship; SPR: structure-property relationship; THF: tetrahydrofuran; TLC: thin layer chromatography; UK: United Kingdom; UV: ultra-violet.
\end{abstract}




\section{Highlights}

New fluorinated inhibitors of the PDE5 enzyme were synthesised and evaluated in vitro

Small fluoro-containing alkyl side chains did not alter the inhibitory potency

Compounds 24a, b appeared to be most promising regarding affinity and selectivity

Compounds 24a, b were selected for radiolabelling with fluorine-18 and PET imaging 


\begin{abstract}
The increasing incidence of Alzheimer's disease (AD) worlwide is a major public health problem. Current treatments provide only palliative solutions with significant side effects. Therefore, new efficient treatment options and novel early diagnosis tools are urgently needed. Recently, strong pre-clinical evidences suggested that phosphodiesterase 5 (PDE5) may be clinically relevant both as biomarker and drug-target in AD. In this study, we intended to develop a new radiofluorinated tracer for the visualisation of PDE5 in brain using PET imaging. Based on currently known PDE5 inhibitors, a series of novel fluorinated compounds bearing a quinoline core have been synthesised via multi-steps reaction pathways. Their affinity for PDE5 and selectivity over other PDE families have been investigated. According to the data collected from this in vitro screening, fluorinated derivatives $24 \mathbf{a}, \mathbf{b}$ bearing $\mathbf{a}$ fluoroethoxy group at the C-3 position of the quinoline core appeared to be the most promising structures and will be further radiolabelled with fluorine-18 for in vitro and in vivo evaluations as PET radiotracer for neuroimaging of PDE5.
\end{abstract}




\section{Introduction}

In the last decades, the neurodegenerative disorders (NDs) became a major concern of public health in industrialized countries. The risk of developing diseases like Alzheimer's, Parkinson's, Huntington's diseases or amyotrophic lateral sclerosis, is clearly increasing with advancing age [1]. The common feature of these pathologies is the progressive deterioration of neuronal activity leading for example to dementia, cognitive and mental degeneration and/or movement disorders and changes in individual personality. Among NDs, Alzheimer's disease (AD) accounts for around 50$75 \%$ of diagnosed dementias in elderly people [2, 3]. Currently, 35 million patients are identified worldwide [3] and one case of $A D$ is revealed every 7 second [1, 4]. Early diagnosis of $A D$ is highly challenging $[3,5]$ and there is no remedial treatment for this pathology. The medical care and treatment of AD patients at the earliest stage of the pathology can considerably reduce the progression rate of the disease and delay the hospitalisation necessity, but most of the time the treatment often begins far too late [3]. Due to the inefficiency of current strategies focused on $\beta$-amyloid plaques or neurofibrillary tangles, the identification of new biological targets to offer innovative diagnostic and therapeutic options are urgently needed.

The phosphodiesterases (PDEs) are a large family of enzymes that regulate the intracellular levels of two important second messengers: cyclic adenosine 3',5'monophosphate (cAMP) and cyclic guanosine 3',5'-monophosphate (cGMP), by cleaving their phosphodiester bond. To date, 11 subtypes of these enzymes have been identified and classified mainly according to their amino acid sequences [6]. Phosphodiesterase 5 (PDE5) is specific for cGMP and is located in some peripheral organs such as heart, lungs and smooth muscle cells but also in the central nervous system (CNS) and particularly in cerebellar Purkinje cells, hippocampus, caudate and substantia nigra [7-10]. There is currently a growing interest in using inhibitors of PDE5 such as Sildenafil $\left(\right.$ Viagra $^{\circledR}$ ) or Tadalafil $\left(\right.$ Cialis ${ }^{\circledR}$ ), commonly used as treatment for erectile dysfunction or chronic pulmonary hypertension, to reverse or decrease memory damages caused by AD [7, 11]. There are strong pre-clinical evidences suggesting that PDE5 may be both a clinically relevant biomarker and a diseaserelevant drug-target in $A D$. For example, the crucial nitric oxide/cGMP/CREB (responsive element binding protein) signalling pathway is known to be altered in several processes including neurotransmission, synaptic plasticity and memory [1216]. Restoring normal cGMP levels in the CNS of AD patients by action of PDE5 inhibitors (PDE5Is) could decrease neuroinflammation, improve cerebral blood flow, long-term memory consolidation, and synaptic plasticity [12, 17, 18]. However, the 
level of expression, exact role and involvement of this enzyme in $A D$ are still quite unclear and controversial. Therefore we aim at developing radiotracers for clinical positron emission tomography (PET) imaging of PDE5 in brain under normal and pathological conditions. By use of radiotracers with optimal pharmacokinetic profiles in combination with high accuracy, PET imaging should proof valuable in at least two principle areas of interest for basic scientists and clinical investigators: i) the timely availability of diagnostic information i.e. the upfront prediction of disease states, which involve impairments and/or deregulation of the cGMP-PDE5 pathway, and ii) for monitoring and evaluating the disease-progression and response to therapy. Moreover, dynamic PET imaging of PDE5 in intact living subjects should strongly foster the paths to new therapeutic strategies and to new mechanistic insights into the role of PDE5 for biology and pathophysiology of NDs such as AD. To date, there is no radiopharmaceutical approved for the visualisation of PDE5 in clinic [19, 20]. Most of the radiotracers developed at the preclinical level are labelled with carbon-11 and suffer from a lack of specificity toward others PDEs. Only one compound radiolabelled with fluorine-18, which is the best radionuclide for PET imaging purposes, has been reported to date and warrant further preclinical investigations [21-23]. In such a context, we envisaged to develop and evaluate new fluorinated analogues of PDE5 inhibitors as candidates for PET imaging of PDE5 in the CNS.

An extensive study of the literature shows that, on the basis of their structural similarities, PDE5 inhibitors can be grouped as follows: i) cGMP-based derivatives, represented by Sildenafil and Vardenafil [24-26]; ii) $\beta$-carboline-derived molecules, represented by Tadalafil; iii) pyrazolopyridine, phtalazine, pyrazolopyridopyridazine, quinoline-based inhibitors; iv) isoquinoline, naphthyridinone and pyridopyrazinone derivatives [27-33]. As the work presented herein is directed toward the development of new radiofluorinated inhibitors for PET imaging of PDE5 in brain, we decided to focus our attention on the heterocyclic scaffold quinoline which presents a high PDE5 potency and selectivity over mainly PDE6 and PDE11 and is described to cross readily the blood-brain barrier (Figure 1) [12]. This lead compound is the result of considerable structure-activity (SAR) and structure-property relationship (SPR) studies which revealed important structural features of this family of PDE5 inhibitors [12, 31]. The quinoline scaffold bearing a hydroxymethyl group at the C-3 position ("east region") improves the solubility compared to the other core ring systems tested. The binding to the protein is highly dependent on the presence of the benzylamino moiety at the C-4 position ("north region"). Moreover the combination of a cyano or a trifluoromethyl group at the C-6 position ("west region") and ethyl or cyclopropyl substituents at the C-8 position ("south region") enhance PDE5 potency and appear to 
be the optimal parameters for a high selectivity over others PDEs (based on $\mathrm{IC}_{50}$ values).

Figure 1. Strategy of introduction of a fluorine atom on the lead heterocyclic quinoline scaffold presenting a high PDE5 potency and selectivity.

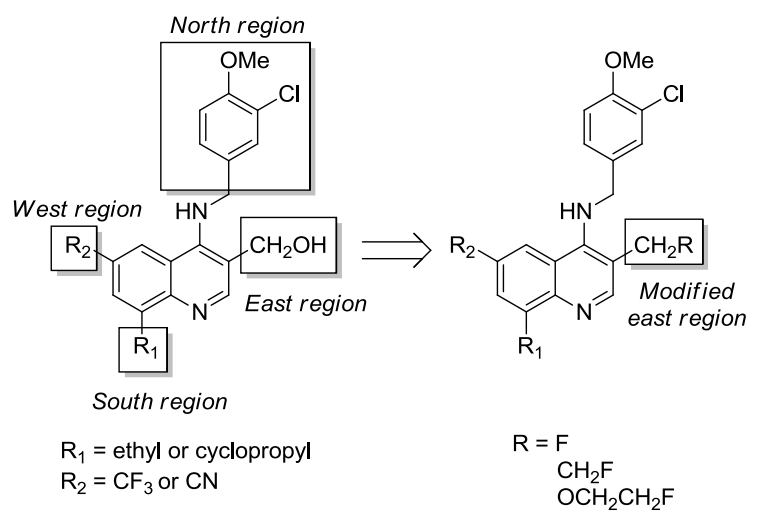

In order to develop a radiotracer for PET imaging of PDE5 according to the SAR studies described above and knowing that fluorine can be considered as a bioisostere of both hydrogen and hydroxyl groups, we firstly decided to slightly modify this lead structure by introducing a fluorine atom on the "east region" of the molecule (Figure 1, see substituents for R). Herein we report, the chemical syntheses and first in vitro biological evaluation of a series of new fluorinated PDE5 ligands and the selection of the most promising ones for further labelling with fluorine-18 and evaluation in vivo.

\section{Results and discussion}

\subsection{Chemistry: introduction of fluorine at the "east region"}

To obtain compounds modified at the "east region" of the quinoline core, we firstly decided to replace the hydroxyl group of the two key compounds $\mathbf{4 a}, \mathbf{b}$ directly by a fluorine atom (Scheme 1). The synthesis of derivative 4a was previously described by Fiorito et al. [12] in three steps starting from intermediate quinoline 1 (Scheme 1). This synthetic approach was used to produce the second reference alcohol $\mathbf{4 b}$. Briefly, a nucleophilic aromatic substitution of the chlorine atom at the C-4 position of the quinoline core of 1 using (3-chloro-4-methoxyphenyl)methanamine hydrochloride [29] in $n$-propanol yielded compound 2. Then, the ethyl and cyclopropyl substituents were introduced at the C-8 position via a classical Suzuki coupling in the presence of tetrakis(triphenylphosphine)palladium[0] and caesium carbonate under thermal heating. When using 1.5 equivalents of cyclopropylboronic acid, 3a was efficiently produced in $70 \%$ yield. However, in the case of $\mathbf{3 b}$, bearing an ethyl group, the concomitant formation of the corresponding debrominated compound $\mathbf{3 b 1}$ was observed. Interestingly, a large excess of ethylboronic acid (16 eq.) was mandatory to 
avoid the formation of the by-product and produce preferentially $\mathbf{3 b}$ in $63 \%$ yield. To successfully afford $\mathbf{4 a}, \mathbf{b}$, reduction of the ester group at the C-3 position into the corresponding hydroxymethyl group was performed using $\mathrm{LiAlH}(\mathrm{O} t \mathrm{Bu})_{3}$ as a mild reducing agent to avoid the hydrolysis of the cyano group.

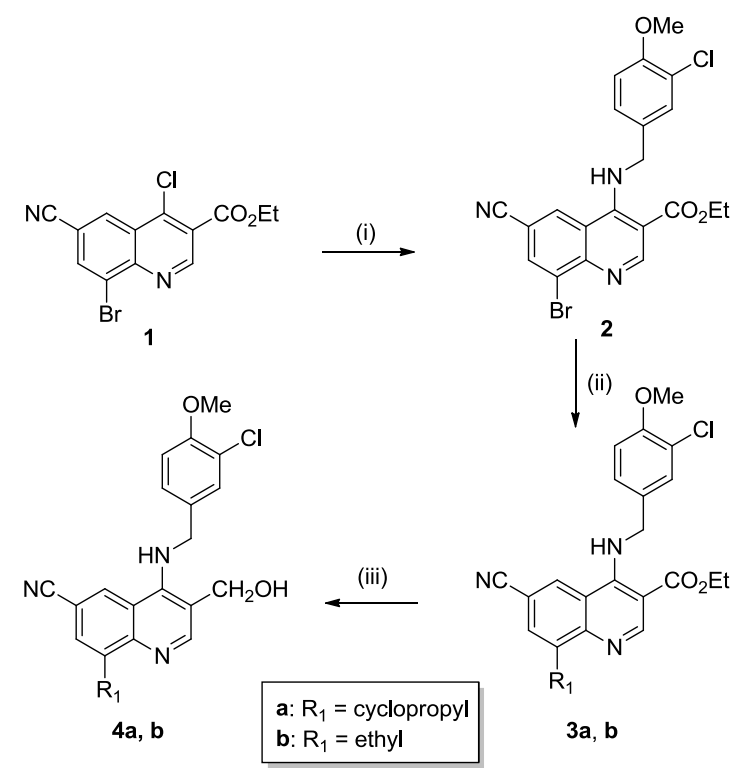

Scheme 1. Synthesis of key alcohols intermediates $\mathbf{4 a}, \mathbf{b} .^{a}$

${ }^{a}$ Reagents and conditions: (i) (3-Chloro-4-methoxyphenyl)methanamine hydrochloride, DIPEA, $n$-propanol, reflux, $3 \mathrm{~h}$; (ii) Cyclopropylboronic acid or ethylboronic acid, $\mathrm{Pd}\left(\mathrm{PPh}_{3}\right)_{4}$, $\mathrm{Cs}_{2} \mathrm{CO}_{3}$, reflux, toluene, $24 \mathrm{~h}$; (iii) $\mathrm{LiAlH}(\text { tOBu})_{3}$, THF, $60^{\circ} \mathrm{C}, 16 \mathrm{~h}$ for $\mathbf{4 a}$ or $50^{\circ} \mathrm{C}, 27 \mathrm{~h}$ for $\mathbf{4 b}$.

To introduce the fluorine atom at the C-3 position, we investigated the fluorination of compound $4 \mathrm{a}$ using diethylaminosulfur trifluoride (DAST) which is a classical reagent to convert straightforward aliphatic alcohols into their corresponding fluorinated derivatives. Under these conditions, the desired fluorinated compound 5 a could not be isolated. Unfortunately, this reaction led to the major imine by-product 6 a bearing a methyl group at the C-3 position (Scheme 2). This was confirmed by NMR analyses $\left({ }^{1} \mathrm{H},{ }^{13} \mathrm{C}, \mathrm{HMBC}, \mathrm{HSQC}\right)$ and HRMS analysis ( $\mathrm{m} / \mathrm{z}$ 376.1214, calculated for $\mathrm{C}_{22} \mathrm{H}_{19} \mathrm{CIN}_{3} \mathrm{O} \mathrm{m} / \mathrm{z}$ 376.1217) (See supplementary material, Figure 1S).

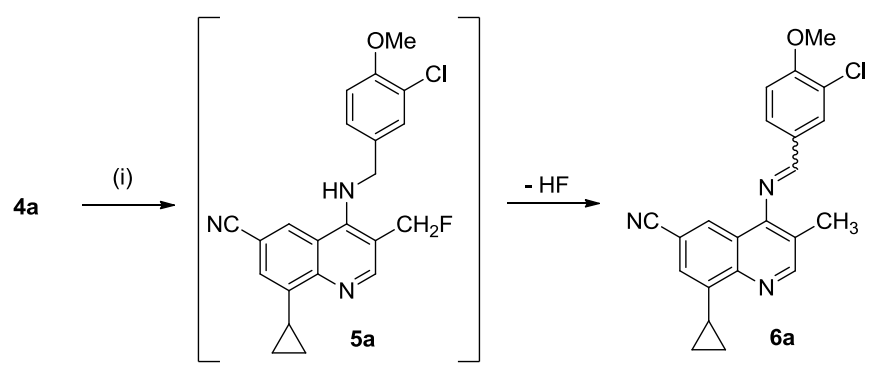

Scheme 2. Formation of $6 a^{a}$

${ }^{a}$ Reagents and conditions: (i) DAST, dichloromethane, $-60^{\circ} \mathrm{C}$. 
We assume that compound 6a was formed during the purification step of 5 a via column chromatography. Indeed, the analysis of the ${ }^{1} \mathrm{H}$ NMR spectrum of the crude product confirmed the presence of $5 \mathrm{a}$ with a doublet at $5.46 \mathrm{ppm}$, integrating for two protons and presenting a spin-spin coupling between $\mathrm{H}$ and $\mathrm{F}$ with a coupling constant of $49.2 \mathrm{~Hz}$, typical of a fluoromethyl group (See supplementary material, Figure 2S). To avoid the formation of 6a, different stationary phases (silica, alumina, RP C18, filtration through a pad of Celite ${ }^{\circledR} 545$ ) were tested with various combinations of solvents for elution but remained unsuccessful. Moreover, we observed after one day that the crude compound $\mathbf{5 a}$ was completely converted into 6a ( ${ }^{1} \mathrm{H}$ NMR kinetic studies; data not shown). These results clearly demonstrated that the desired compound $\mathbf{5 a}$ is highly unstable. As possible mechanism we propose the elimination of HF as depicted in Figure 2.

Figure 2. Possible mechanism proposed for the formation of $\mathbf{6 a}$.

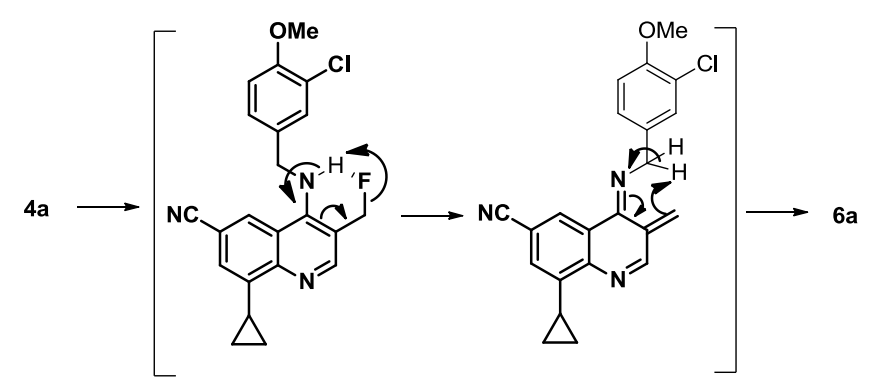

We then tested an alternative synthetic route using a tosylate leaving group. Compound $4 a$ was treated with 4-toluenesulfonyl chloride in the presence of $\mathrm{Et}_{3} \mathrm{~N}$ and DMAP in dry dichloromethane at room temperature. As expected, the total conversion of the tosylate into 6a was observed (See supplementary material, Figure 2S). These findings support our assumption of the instability of these derivatives bearing either a fluoromethyl group (for the reference compounds) or a tosylate leaving group (corresponding precursors for fluorine-18 radiolabelling) at the C-3 position. Consequently, we focused our efforts on the development of quinoline structures bearing a longer alkyl chain such as a fluoroethyl moiety at the C-3 position (Figure 1).

We designed a synthetic pathway based on a Gould-Jacobs reaction as previously developed for the synthesis of starting material 1 (Scheme 3). Firstly, quinolone 10 was obtained in three steps via formylation of diethyl succinate 7 according to the procedure described by Holmes et al. [34] followed by a condensation with 2-bromo-4-cyanoaniline and a thermal cyclisation in Dowtherm $\mathrm{A}$ at $250{ }^{\circ} \mathrm{C}$. Treatment of compound 10 with $\mathrm{POCl}_{3}$ gave the corresponding 4-chloroquinoline $\mathbf{1 1}$ in $90 \%$ yield. The next step was the aromatic 
nucleophilic substitution of the chlorine atom to graft the benzylamino moiety at the C-4 position.

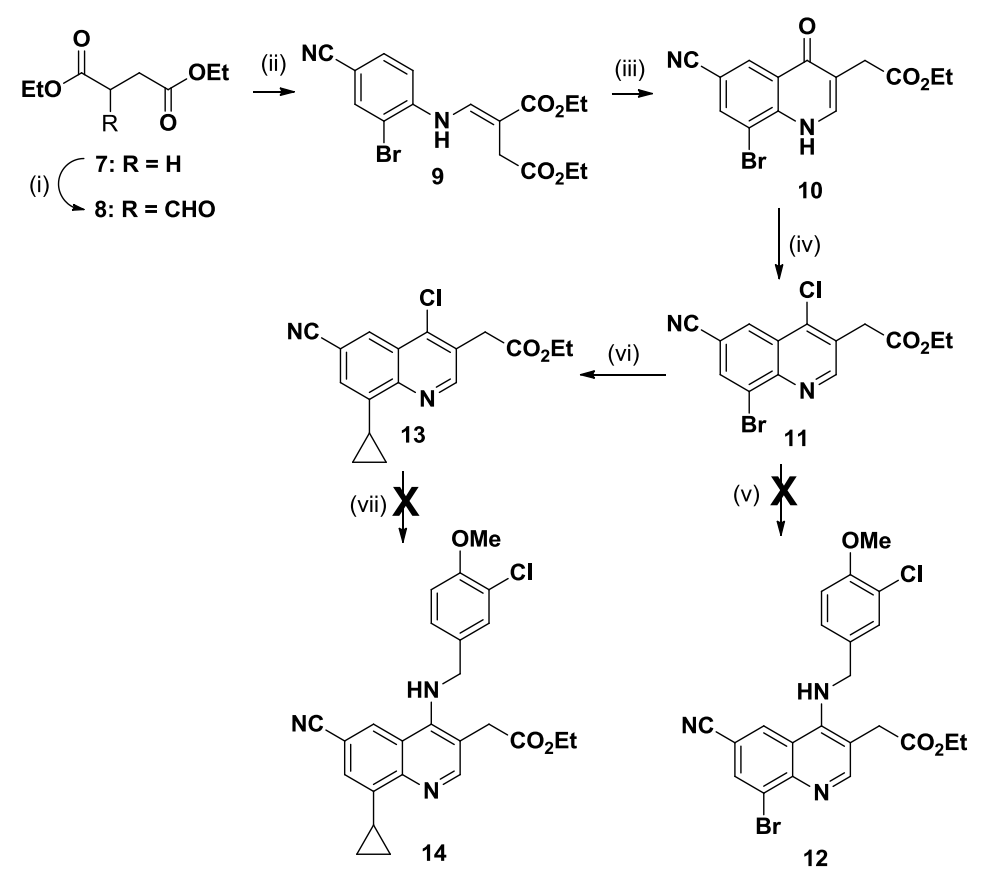

Scheme 3. First synthetic approach tested to introduce a fluoroethyl side chain at the C-3 position of the quinoline scaffold. ${ }^{a}$

${ }^{a}$ Reagents and conditions: (i) Ethyl formate, sodium, $\mathrm{Et}_{2} \mathrm{O}, 0{ }^{\circ} \mathrm{C}$ to rt, $20 \mathrm{~h}$; (ii) 2-bromo-4cyanoaniline, toluene, reflux, $8 \mathrm{~h}$; (iii) Dowtherm A, $250^{\circ} \mathrm{C}, 2 \mathrm{~h}$; (iv) $\mathrm{POCl}_{3}$, reflux, $7 \mathrm{~h}$; (v) nucleophilic aromatic substitution under thermal conditions; (vi) Cyclopropylboronic acid, $\mathrm{Pd}\left(\mathrm{PPh}_{3}\right)_{4}, \mathrm{Cs}_{2} \mathrm{CO}_{3}$, reflux, toluene, $22 \mathrm{~h}$; (vii) buchwald reaction under thermal or microwave conditions.

The experimental conditions previously used to obtain compound 2 (Scheme 1) failed to produce 12 even with further modifications of reaction parameters (solvents, temperatures, nature of the base). Obviously, due to the addition of a methylene group between the ester function and the carbon C-3 of the quinoline core, the electron withdrawing effect necessary for the nucleophilic substitution at the C-4 position was suppressed. Therefore, we focused our effort to insert the benzylamino moiety via a Buchwald-Hartwig coupling. Given that compound 11 possesses both a chlorine and a bromine atom at C-4 and C-8 positions respectively, we firstly performed the regioselective Suzuki reaction to obtain compound $\mathbf{1 3}$ from 11 with a good yield (62\%). Then, the Buchwald-Hartwig reaction was performed with compound 13 to introduce the benzylamine derivative at the C-4 position. Despite using several combinations of catalyst, ligand, base and activation via thermal or microwave heating, only the degradation of $\mathbf{1 3}$ was observed.

Therefore, we were forced to reconsider our synthetic approach and designed a new strategy depicted in Scheme 4. Compound 4a previously synthesised, was oxidised into its 
corresponding aldehyde 15a. Then, we performed a Wittig reaction in the presence of (methoxymethyl)triphenylphosphonium chloride to obtain the mixture of $(E, Z)-16 a$. The cleavage of the methoxy group of 16a using hydrochloric acid (4 M) unfortunately afforded the cyclic compound 17a rather than the expected aldehyde 18a. The formation of the fivemembered cycle of $\mathbf{1 7 a}$ is probably due to the nucleophilic character of the secondary amine at the C-4 position of the quinoline scaffold. Keeping in mind that this amine is an important feature for the binding to the PDE5 enzyme [28] and cannot be blocked as a tertiary amine, we decided to protect this function to avoid the cyclisation. We chose the allyloxycarbonyl protecting group, because of its stability under acidic conditions needed to convert intermediates 19a, b to the corresponding aldehydes 20a, b. Afterwards, the aldehyde function was reduced using $\mathrm{LiAlH}(\mathrm{OtBu})_{3}$ to give the alcohols 21a, b which were finally treated with DAST affording the desired fluorinated compounds $22 \mathrm{a}, \mathbf{b}$ in $46 \%$ and $15 \%$ yield respectively. However, during this reaction we observed the formation of major by-products, identified as the cyclic compounds 23a, $\mathbf{b}$.
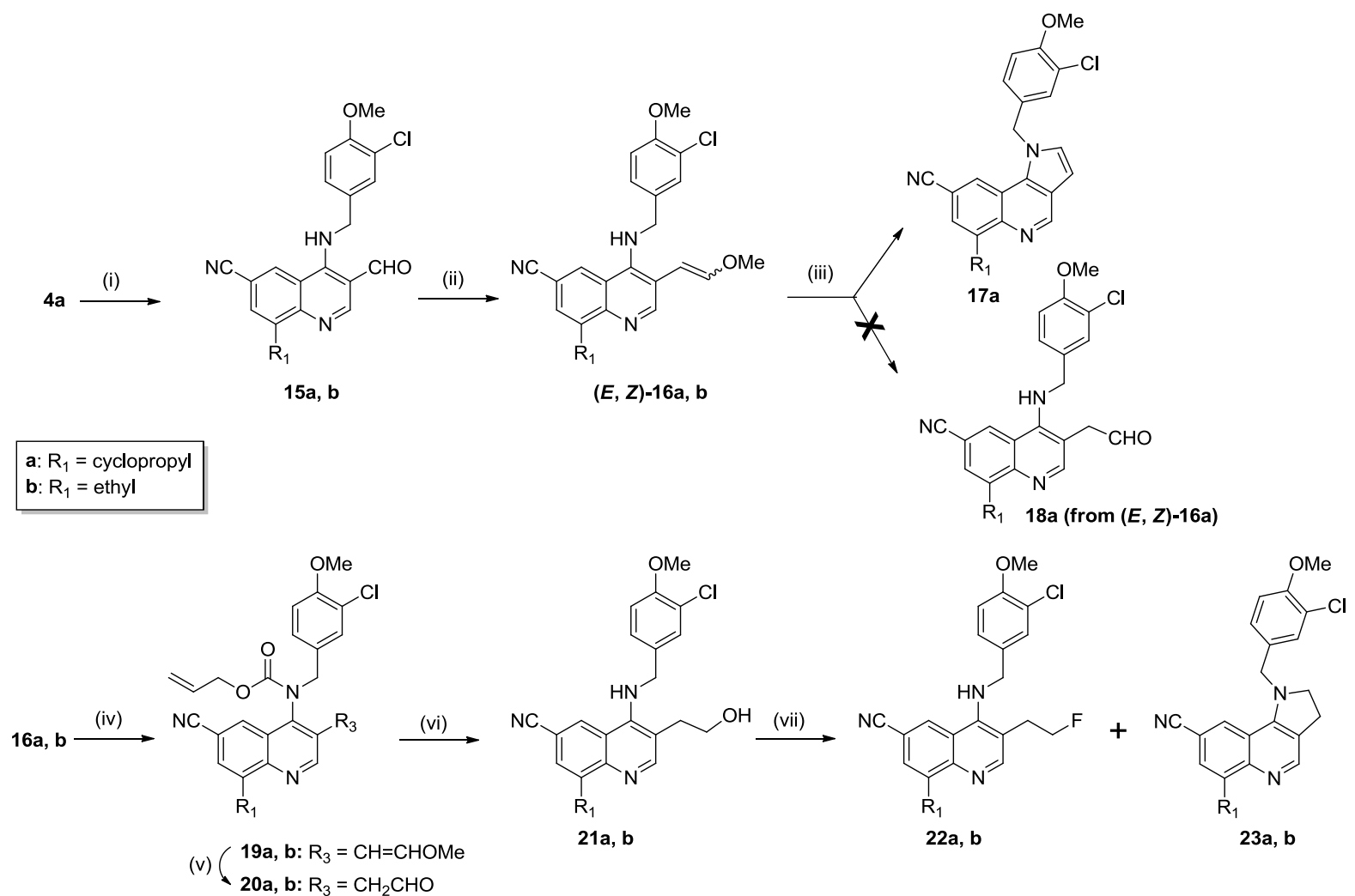

Scheme 4. Modified synthetic approach starting from $\mathbf{4 a}$ and efficiently producing derivatives 22a, b bearing a fluoroethyl side chain at the C-3 position of the quinoline scaffold. ${ }^{a}$

${ }^{a}$ Reagents and conditions: (i) $\mathrm{MnO}_{2}, \mathrm{CH}_{2} \mathrm{Cl}_{2}, \mathrm{rt}, 5 \mathrm{~h}$ for 15a or $20 \mathrm{~h}$ for 15b; (ii) (Methoxymethyl)triphenylphosphonium chloride, $n$-Buli, THF, $-15^{\circ} \mathrm{C}$ to rt, $2 \mathrm{~h}$; (iii) $4 \mathrm{M} \mathrm{HCl}$ in $\mathrm{H}_{2} \mathrm{O} / \mathrm{THF}(1 / 3, \mathrm{v} / \mathrm{v}), 50^{\circ} \mathrm{C}, 4 \mathrm{~h}$; (iv) AllocCl, NaH, DMF, rt, $1 \mathrm{~h}$ for $19 \mathrm{a}$ and $2 \mathrm{~h}$ for 19b; (v) $\mathrm{HCO}_{2} \mathrm{H}, 50{ }^{\circ} \mathrm{C}, 20 \mathrm{~h}$; (vi) $\mathrm{LiAlH}(\mathrm{OtBu})_{3}, \mathrm{THF}, 60^{\circ} \mathrm{C}, 20 \mathrm{~h}$; (vii) DAST, $\mathrm{CH}_{2} \mathrm{Cl}_{2},-78^{\circ} \mathrm{C}$ to rt, $3 \mathrm{~h}$ for $22 \mathrm{a}$ and $1.5 \mathrm{~h}$ for $\mathbf{2 2 b}$. 
To further exemplify this series of candidates modified at the "east region", we intended to develop fluorinated derivatives (24a, b and 29a, b) via O-alkylation of the hydroxymethyl substituent by a 2-fluoroethyl group (Schemes 5 and 6). We firstly intended the direct reaction of $\mathbf{4 a}$ and 2-fluoroethyl-4-methylbenzenesulfonate [35] to obtain 24a (Scheme 5). However, we observed that the hydroxymethyl group was not reactive enough to substitute the tosylate leaving group, despite modifying experimental conditions (temperature, solvents, bases). Therefore, as we already proved that a halogen atom on the methylene moiety at the C-3 position of the quinoline core is a good leaving group (See Scheme 1 and Figure 2), we decided to convert the alcohol function of $\mathbf{4 a}$ into the corresponding chloromethyl function using thionyl chloride. This chlorinated intermediate was used without purification for the nucleophilic substitution with 2-fluoroethanol to obtain the desired compound $24 a$ in moderate yield over two steps (37\%). These conditions were then applied to compound $\mathbf{4 b}$ to synthesise the fluorinated derivative $\mathbf{2 4 b}$.

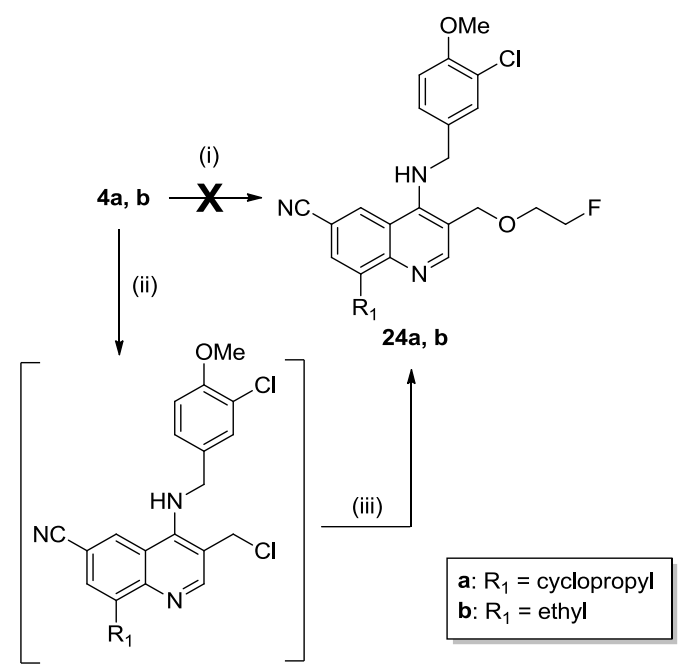

Scheme 5 . Syntheses of compounds $24 a, b$ starting from $\mathbf{4 a}, \mathbf{b}^{a}$

${ }^{a}$ Reagents and conditions: (i) 2-fluoroethyl-4-methylbenzenesulfonate, basic conditions, THF, rt or reflux; (ii) $\mathrm{SOCl}_{2}$, rt, $30 \mathrm{~min}$; (iii) 2-fluoroethanol, DMF, $80^{\circ} \mathrm{C}, 27 \mathrm{~h}$ for $24 \mathrm{a}$ and $30 \mathrm{~h}$ for 24b.

After the first in vitro evaluation of these new fluorinated derivatives (see section "biology: inhibitory effects on selected PDEs") and identification of $\mathbf{2 4 a}$, b as most potent analogues, we explored the effect of replacing the cyano function of $\mathbf{2 4 a}$, b by a trifluoromethyl group at the "west region" (32a, b in Scheme 6). 


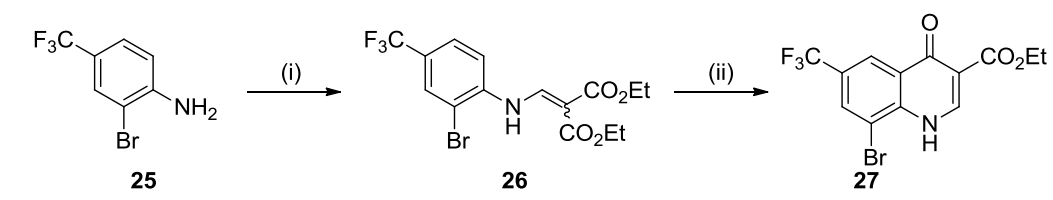<smiles>[R16]c1cc(C(F)(F)F)cc2c(NCc3ccc(OC)c(Cl)c3)c(C(=O)OCC)cnc12</smiles>

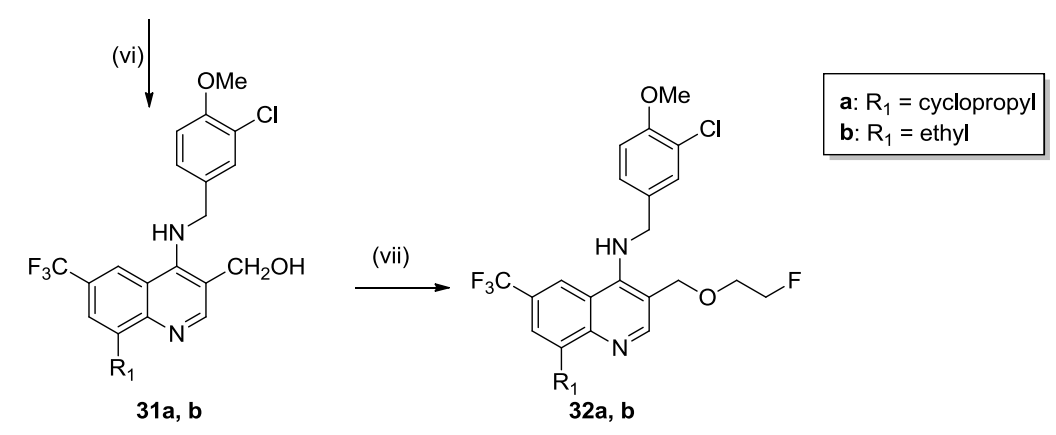

Scheme 6. Syntheses of analogues $32 \mathbf{a}$, b bearing a trifluoromethyl group at the C-6 position of the quinoline ring. ${ }^{a}$

${ }^{a}$ Reagents and conditions: (i) EMME, toluene, reflux, $11 \mathrm{~h}$; (ii) diphenyl ether, $240{ }^{\circ} \mathrm{C}, 3 \mathrm{~h}$; (iii) $\mathrm{POCl}_{3}, 120^{\circ} \mathrm{C}, 6 \mathrm{~h}$; (iv) (3-chloro-4-methoxyphenyl)methanamine hydrochloride, DIPEA, $n$ propanol, reflux, $16 \mathrm{~h}$; (v) cyclopropylboronic acid or ethylboronic acid, $\mathrm{Pd}\left(\mathrm{PPh}_{3}\right)_{4}, \mathrm{Cs}_{2} \mathrm{CO}_{3}$, reflux, toluene, $20 \mathrm{~h}$; (vi) DIBALH, $\mathrm{CH}_{2} \mathrm{Cl}_{2},-70{ }^{\circ} \mathrm{C}$ to $-30{ }^{\circ} \mathrm{C}, 3 \mathrm{~h}$ for 31a and DIBALH, THF, $60{ }^{\circ} \mathrm{C}$ to rt, $16 \mathrm{~h}$ for $\mathbf{3 1 b}$; (vii) (a) $\mathrm{SOCl}_{2}$, rt, $40 \mathrm{~min}$ for $\mathbf{3 2 a}$ or $30 \mathrm{~min}$ for $\mathbf{3 2 b}$; (b) 2fluoroethanol, DMF, $80^{\circ} \mathrm{C}, 30 \mathrm{~h}$ for $32 \mathrm{a}$ and $22 \mathrm{~h}$ for $\mathbf{3 2 b}$.

The corresponding alcohols $\mathbf{3 1 a}$, b were synthesised according to the procedure previously optimised for alcohols 4a, b (Scheme 6). Quinoline 28 was produced in three steps from commercially available 2-bromo-4-trifluoromethylaniline (26) [30]. Then, the aromatic nucleophilic substitution of the chlorine atom at the C-4 position of 28 using (3-chloro-4methoxyphenyl)methanamine hydrochloride [29] efficiently produced compound 29. The Suzuki coupling was performed to introduce either ethyl or cyclopropyl group at the C-8 position to obtain $\mathbf{3 0 a}, \mathbf{b}$. The ester function at the C-3 position was classically reduced using DIBALH to afford alcohols 31a, b which were converted into their corresponding chlorinated derivatives. The latter were not isolated and reacted immediately with 2-fluoroethanol to yield the desired fluorinated derivatives $32 \mathbf{a}$, $\mathbf{b}$ in $22-29 \%$ yields. 


\subsection{Biology: inhibitory effects on selected PDEs}

In order to study the influence of the introduction of a fluorine atom into the lead structures 4a, $\mathbf{b}$ and select the most potent derivative for further development as new radiotracer for PET imaging of PDE5, we evaluated the inhibitory effects of the synthesised fluorinated ligands on human PDE5A1 and a panel of other human PDEs (SB drug discovery, Glasgow, UK). Table 1 summarises the percentage of inhibition of compounds $\mathbf{2 2} \mathbf{a}, \mathbf{b}, \mathbf{2 4 a}, \mathbf{b}$ and $\mathbf{3 2} \mathbf{a}$, b compared to lead alcohols $\mathbf{4 a}$, b. At the beginning, all experiments were performed at ligand concentrations of $100 \mathrm{nM}$. However, only inhibitory effects on the PDE5 enzyme could be observed under these conditions. Therefore, for all other PDEs the ligand concentration had to be increased to $1 \mu \mathrm{M}$ in order to achieve analyzable signals. This behaviour already indicated the high specificity of the new derivatives for PDE5. Compounds $\mathbf{2 2} \mathbf{a}, \mathbf{b}$, and $\mathbf{2 4 a} \mathbf{a} \mathbf{b}$ showed a high and selective inhibitory activity on PDE5A1 (>88\% at $100 \mathrm{nM}$ vs. $0 \%-77 \%$ at 1 $\mu \mathrm{M}$ for other PDEs). Similar values were obtained with reference alcohols $\mathbf{4 a}, \mathbf{b}$ highlighting that the introduction of a fluorine atom at the "east region", i.e. at the C-3 position of the quinoline scaffold, did not significantly affect the affinity of the ligands for the PDE5 enzyme. Only a slightly lower inhibitory activity was observed for products $\mathbf{3 2 a}$, b obviously caused by the substitution of a trifluoromethyl group instead of the cyano group at the C-6 position of the quinoline scaffold.

Table 1: Percentage inhibition of selected PDEs by the synthesised compounds; the compounds were studied using a concentration of $100 \mathrm{nM}$ for inhibition of human PDE5A1 and a concentration of $1 \mu \mathrm{M}$ for inhibition of PDE2A3, PDE3A, PDE4A1, PDE4C2, PDE6AB, PDE9A1, PDE10A1 and PDE11A1; NI: no inhibition observed.

\begin{tabular}{cccccccccc}
\hline & \multicolumn{9}{c}{ \% Inhibition of PDEs } \\
\hline & PDE2 & PDE3 & PDE4 & PDE4 & PDE5 & PDE6 & PDE9 & PDE10 & PDE11 \\
& A3 & A & A1 & C2 & A1 & AB & A1 & A1 & A1 \\
\hline 4a & 15.3 & $\mathrm{NI}$ & 36.9 & 22.4 & 84.2 & 32.4 & $\mathrm{NI}$ & 22.9 & 24.1 \\
4b & 22.4 & $\mathrm{NI}$ & 45.4 & 40.9 & 90.3 & 49.8 & $\mathrm{NI}$ & 40.0 & 27.2 \\
$\mathbf{2 2 a}$ & 65.5 & $\mathrm{NI}$ & 44.5 & 27.3 & 96.1 & 26.0 & 18.0 & 43.0 & 17.6 \\
$\mathbf{2 2 b}$ & 68.4 & $\mathrm{NI}$ & 74.7 & 40.3 & 100 & 26.3 & 22.5 & 77.1 & 42.1 \\
$\mathbf{2 4 a}$ & 16.0 & 6.12 & 13.2 & 35.9 & 89.9 & 54.8 & 14.8 & 18.8 & 15.1 \\
$\mathbf{2 4 b}$ & 7.49 & 18.2 & 9.03 & 32.4 & 88.4 & 60.4 & $\mathrm{NI}$ & 14.1 & 5.21 \\
$\mathbf{3 2 a}$ & 12.1 & $\mathrm{NI}$ & 6.5 & 17.3 & 57.1 & 2.36 & $\mathrm{NI}$ & 13.0 & 3.51 \\
$\mathbf{3 2 b}$ & 9.74 & $\mathrm{NI}$ & 4.74 & 21.4 & 74.6 & 26.4 & 40.9 & 8.5 & 8.84 \\
\hline
\end{tabular}

The compounds bearing a fluoroethyl chain at the C-3 position of the quinoline appeared to be less selective than derivatives with a fluoroethoxymethyl moiety. For example, 24a presented a 4-fold lower inhibitory activity on PDE2A3 compared to 22a. Therefore we focused our attention on compounds $\mathbf{2 4 a}, \mathbf{b}$ and $\mathbf{3 2} \mathbf{a}, \mathbf{b}$ and determined their $\mathrm{IC}_{50}$ values for inhibition of PDE5A1. The values obtained were 7.39, 1.86, 358 and $192 \mathrm{nM}$ for $\mathbf{2 4 a}$, b and 32a, b respectively. These results clearly highlight that the substituent at the C-6 position of the quinoline heterocycle influences the binding to the enzyme. As already indicated by the percentage of inhibition values in Table 1 , when bearing a trifluoromethyl substituent, the $\mathrm{IC}_{50}$ 
values reflect a significantly lower affinity for the PDE5A1 enzyme compared to the compounds with a cyano group (358 and $192 \mathrm{nM}$ for $\mathbf{3 2 a}$, b vs. 7.39 and $1.86 \mathrm{nM}$ for $\mathbf{2 4 a}$, b respectively). Under identical conditions, Sildenafil presented an IC50 value of $6.23 \mathrm{nM}$.

\section{Conclusion}

A new series of fluorinated inhibitors of the PDE5 enzyme was synthesised and evaluated in vitro. The organic synthesis of six new derivatives was successfully performed. In vitro inhibition experiments revealed that the introduction of small fluoro-containing alkyl side chains on the "east region" of the selected lead structures $\mathbf{4 a}$, b did not alter the inhibitory potency of these compounds towards PDE5. According to the data obtained, the fluorinated derivatives $\mathbf{2 4 a}$, $\mathbf{b}$ appeared to be most promising regarding affinity and selectivity and were selected for radiolabelling with fluorine-18 and biological evaluations in vitro and in vivo for PET imaging of PDE5 in the brain [36]. The data collected for $\left[{ }^{18} \mathrm{~F}\right] 24 \mathrm{a}$ revealed that this compound was fastly metabolized in vivo and formed brain penetrable radiometabolites making it unsuitable for PET imaging of the PDE5 enzyme in the brain [36]. However, all these findings revealed useful for the design of metabolically more stable fluorinated quinoline analogs for further development of PET probes for imaging of PDE5 in brain. This work is currently undertaken in our laboratory.

\section{Experimental section}

\subsection{Materials for Chemical Syntheses}

All commercially available reagents and solvents were purchased from the following commercial suppliers: Sigma Aldrich, Acros Organics, Carlo Erba, and Alfa Aesar and were used without further purification. Room temperature $(\mathrm{rt})$ refers to $20-25{ }^{\circ} \mathrm{C}$. All solvents were dried using common techniques. Air and moisture sensitive reactions were carried out under anhydrous argon atmosphere. Magnesium sulfate $\left(\mathrm{MgSO}_{4}\right)$ and sodium sulfate $\left(\mathrm{Na}_{2} \mathrm{SO}_{4}\right)$ were used as drying agents. Monitoring of the reaction progresses was performed using thin layer chromatography (TLC) on silica (60 F254) or alumina (gel 60A + F254) plates and visualised with UV light (UV lamp Fisher Bioblock Scientific, $365 \mathrm{~nm}$ or $254 \mathrm{~nm}$ ) or with an appropriate staining agent. Column chromatography was performed on silica gel (Chromagel 60 ACC, 40-63 $\mu \mathrm{m}$, Carlo Erba Reagents) or on alumina gel (Merck, column chromatographic adsorption analysis ACC. to Brockmann, neutral aluminium oxide 90, standardise, 63-200 $\mu \mathrm{m}$ ). Uncorrected melting points (Mp) were measured on an IA9100 Digital Melting Point Apparatus. Infrared spectra (IR) were recorded in the range of $4000-600 \mathrm{~cm}^{-1}$ on a 
Nicolet IS10 with attenuated total reflectance (ATR) accessory (v: stretch, as: asymmetric, s: symmetric, $\delta$ : deformation; op: out of plane). Nuclear magnetic resonance (NMR) spectra were recorded on a Bruker Avance 500 instrument (500 $\mathrm{MHz}$ for ${ }^{1} \mathrm{H}, 125 \mathrm{MHz}$ for ${ }^{13} \mathrm{C}$ ), a Bruker Avance 400 instrument $\left(400 \mathrm{MHz}\right.$ for ${ }^{1} \mathrm{H}, 100$ $\mathrm{MHz}$ for ${ }^{13} \mathrm{C}$ ) or a Bruker Avance 200 instrument $\left(200 \mathrm{MHz}\right.$ for ${ }^{1} \mathrm{H}, 50 \mathrm{MHz}$ for $\left.{ }^{13} \mathrm{C}\right)$. All chemical shifts $(\delta)$ are reported in parts per million (ppm). Coupling constants $(\mathcal{J})$ are given in Hertz $(\mathrm{Hz})$. Spectral coupling patterns are indicated as follow: s: singlet; d: doublet; t: triplet; q: quartet; m: multiplet, brt: broad triplet and brs: broad singlet. All new compounds were analysed by HRMS (High-Resolution Mass Spectrometry, Waters ${ }^{\circledR}$ Micromass ${ }^{\circledR}$ Q-Tof micro ${ }^{\mathrm{TM}}$ Mass Spectrometer, UBP- START, Blaise Pascal University, Clermont-Ferrand, France). The isotope peaks for chlorine and bromine atoms are given with their relative intensities.

\subsubsection{Ethyl 4-[(3-chloro-4-methoxybenzyl)amino]-6-cyano-8-ethylquinoline -3-} carboxylate (3b). Ethylboronic acid $(1.25 \mathrm{~g}, 16.8 \mathrm{mmol}, 16.0$ eq.), tetrakis(triphenylphosphine)palladium (0) (122 mg, $0.11 \mathrm{mmol}, 0.1$ eq.), caesium carbonate (858 mg, $2.63 \mathrm{mmol}, 2.5$ eq.) were added, under argon and stirring, to a solution of 212 (0.5 $\mathrm{g}, 1.05 \mathrm{mmol}, 1.0 \mathrm{eq}$ ) in anhydrous toluene $(20 \mathrm{~mL})$. The resulting mixture was refluxed for $24 \mathrm{~h}$. After cooling to rt, the mixture was filtered on celite ${ }^{\circledR} 545$, washed with ethyl acetate $(100 \mathrm{~mL})$. The filtrate was concentrated under reduced pressure. The crude product was purified by column chromatography $\left(\mathrm{SiO}_{2}\right.$, gradient: ethyl acetate/cyclohexane, $1 / 9$ to $5 / 5, v / v)$ to give, by order of elution: the desired product 3b (270 mg, $0.64 \mathrm{mmol}, 60 \%)$ as a yellow solid and ethyl 4-[(3-chloro-4methoxybenzyl)amino]-6-cyanoquinoline-3-carboxylate (3b1) (150 mg, 0.38 mmol, $36 \%$ as a yellow solid. Ethyl 4-[(3-chloro-4-methoxybenzyl)amino]-6-cyano-8ethylquinoline-3-carboxylate (3b) [30]. $\mathrm{R}_{\mathrm{f}}\left(\mathrm{SiO}_{2}\right.$, cyclohexane/ethyl acetate, 7/3, v/v): 0.38; Mp: 159-161 ํㅜ; IR ( $\left.\mathrm{cm}^{-1}\right): 2230\left(\mathrm{v}_{\mathrm{C} \equiv \mathrm{N}}\right), 1681\left(\mathrm{v}_{\mathrm{C}=\mathrm{O}}\right), 1577\left(\delta_{\mathrm{N}-\mathrm{H}}\right), 1507\left(\mathrm{v}_{\mathrm{C}=\mathrm{C}}\right), 1289\left(\mathrm{v}_{\mathrm{C}-\mathrm{O}}\right)$, $1190\left(\mathrm{v}_{\mathrm{C}-\mathrm{O}}\right), 1114\left(\mathrm{v}_{\mathrm{C}-\mathrm{o}}\right), 1029\left(\mathrm{v}_{\mathrm{C}-\mathrm{O}}\right) ;{ }^{1} \mathrm{H}$ NMR $\left(\mathrm{CDCl}_{3}, 400 \mathrm{MHz}\right) \delta 9.60$ (brs, $\left.1 \mathrm{H}, \mathrm{NH}\right), 9.26$ (s, $\left.1 \mathrm{H}, \mathrm{H}_{2}\right), 8.39\left(\mathrm{~d}, 1 \mathrm{H},{ }^{4} J_{\mathrm{H}_{5}-\mathrm{H}_{7}}=1.4 \mathrm{~Hz}, \mathrm{H}_{5}\right), 7.67\left(\mathrm{~d}, 1 \mathrm{H},{ }^{4} J_{\mathrm{H}_{7}-\mathrm{H}_{5}}=1.4 \mathrm{~Hz}, \mathrm{H}_{7}\right), 7.40\left(\mathrm{~d}, 1 \mathrm{H},{ }^{4} J_{\mathrm{H}^{\prime}-}\right.$ $\left.\mathrm{H}_{6^{\prime}}=2.2 \mathrm{~Hz}, \mathrm{H}_{2^{\prime}}\right), 7.26\left(\mathrm{dd}, 1 \mathrm{H},{ }^{3} \mathrm{~J}_{\mathrm{H}^{\prime} \mathrm{H}^{\prime} \mathrm{H}^{\prime}}=8.5 \mathrm{~Hz},{ }^{4} \mathrm{~J}_{\mathrm{H}_{6^{\prime}}-\mathrm{H}_{2^{\prime}}}=2.2 \mathrm{~Hz}, \mathrm{H}_{6^{\prime}}\right), 6.97\left(\mathrm{~d}, 1 \mathrm{H},{ }^{3} J_{\mathrm{H}_{5^{\prime}}-\mathrm{H}_{6^{\prime}}}=\right.$ $\left.8.5 \mathrm{~Hz}, \mathrm{H}_{5^{\prime}}\right), 4.87\left(\mathrm{~d}, 2 \mathrm{H},{ }^{3} \mathrm{~J}_{\mathrm{H}_{\mathrm{d}} \mathrm{NH}}=5.5 \mathrm{~Hz}, \mathrm{H}_{\mathrm{d}}\right), 4.38\left(\mathrm{q}, 2 \mathrm{H},{ }^{3} \mathrm{~J}_{\mathrm{H}_{\mathrm{b}}-\mathrm{H}_{\mathrm{c}}}=7.1 \mathrm{~Hz}, \mathrm{H}_{\mathrm{b}}\right), 3.92(\mathrm{~s}, 3 \mathrm{H}$, $\mathrm{H}_{\mathrm{e}}$ ), $3.23\left(\mathrm{q}, 2 \mathrm{H},{ }^{3} \mathrm{~J}_{\mathrm{H}_{\mathrm{f}} \mathrm{H}_{\mathrm{g}}}=7.5 \mathrm{~Hz}, \mathrm{H}_{\mathrm{f}}\right), 1.40\left(\mathrm{t}, 3 \mathrm{H},{ }^{3} \mathrm{~J}_{\mathrm{H}_{\mathrm{c}}-\mathrm{H}_{\mathrm{b}}}=7.1 \mathrm{~Hz}, \mathrm{H}_{\mathrm{c}}\right), 1.35\left(\mathrm{t}, 3 \mathrm{H},{ }^{3} \mathrm{~J}_{\mathrm{H}_{\mathrm{g}}-\mathrm{H}_{\mathrm{f}}}=7.5\right.$ $\left.\mathrm{Hz}, \mathrm{H}_{\mathrm{g}}\right)$. Ethyl 4-[(3-chloro-4-methoxybenzyl)amino]-6-cyanoquinoline-3-carboxylate (3b1). $\mathrm{R}_{\mathrm{f}}$ $\left(\mathrm{SiO}_{2}\right.$, cyclohexane/ethyl acetate, 3/7, v/v): 0.20; Mp: 155-157 ${ }^{\circ} \mathrm{C} ; \mathrm{IR}\left(\mathrm{cm}^{-1}\right): 2226\left(\mathrm{v}_{\mathrm{C} \equiv \mathrm{N}}\right)$, $1671\left(\mathrm{v}_{\mathrm{C}=\mathrm{O}}\right), 1572\left(\delta_{\mathrm{N}-\mathrm{H}}\right), 1504\left(\mathrm{v}_{\mathrm{C}=\mathrm{C}}\right), 1280\left(\mathrm{v}_{\mathrm{C}-\mathrm{O}}\right), 1185\left(\mathrm{v}_{\mathrm{C}-\mathrm{O}}\right), 1064\left(\mathrm{v}_{\mathrm{C}-\mathrm{O}}\right) ;{ }^{1} \mathrm{H}$ NMR $\left(\mathrm{CDCl}_{3}\right.$, 
$400 \mathrm{MHz}) \delta 9.85\left(\mathrm{t}, 1 \mathrm{H},{ }^{3} J_{\mathrm{NH}-\mathrm{H}_{\mathrm{d}}}=5.1 \mathrm{~Hz}, \mathrm{NH}\right), 9.19\left(\mathrm{~s}, 1 \mathrm{H}, \mathrm{H}_{2}\right), 8.54\left(\mathrm{~d}, 1 \mathrm{H},{ }^{4} J_{\mathrm{H}_{5}-\mathrm{H}_{7}}=1.5 \mathrm{~Hz}\right.$, $\left.\mathrm{H}_{5}\right), 8.02\left(\mathrm{~d}, 1 \mathrm{H},{ }^{3} \mathrm{~J}_{\mathrm{H}_{8}-\mathrm{H}_{7}}=8.7 \mathrm{~Hz}, \mathrm{H}_{8}\right), 7.79\left(\mathrm{dd}, 1 \mathrm{H},{ }^{3} \mathrm{~J}_{\mathrm{H}_{7}-\mathrm{H}_{8}}=8.7 \mathrm{~Hz},{ }^{4} \mathrm{~J}_{\mathrm{H}_{7}-\mathrm{H}_{5}}=1.5 \mathrm{~Hz}, \mathrm{H}_{7}\right)$, $7.41\left(\mathrm{~d}, 1 \mathrm{H},{ }^{4} J_{\mathrm{H}_{2^{\prime}-\mathrm{H}_{6^{\prime}}}}=2.2 \mathrm{~Hz}, \mathrm{H}_{2^{\prime}}\right), 7.27\left(\mathrm{dd}, 1 \mathrm{H},{ }^{3} \mathrm{~J}_{\mathrm{H}_{6^{\prime}} \mathrm{H}_{5^{\prime}}}=8.5 \mathrm{~Hz},{ }^{4} J_{\mathrm{H}_{6^{\prime}}-\mathrm{H}_{2^{\prime}}}=2.2 \mathrm{~Hz}, \mathrm{H}_{6^{\prime}}\right), 6.98$ $\left(\mathrm{d}, 1 \mathrm{H},{ }^{3} \mathrm{~J}_{\mathrm{H}^{\prime}-\mathrm{H}_{6^{\prime}}}=8.5 \mathrm{~Hz}, \mathrm{H}_{5^{\prime}}\right), 4.90\left(\mathrm{~d}, 2 \mathrm{H},{ }^{3} \mathrm{~J}_{\mathrm{H}^{-} \mathrm{NH}}=5.5 \mathrm{~Hz}, \mathrm{H}_{\mathrm{d}}\right), 4.38\left(\mathrm{q}, 2 \mathrm{H},{ }^{3} \mathrm{~J}_{\mathrm{H}_{\mathrm{b}}-\mathrm{H}_{\mathrm{c}}}=7.1 \mathrm{~Hz}\right.$, $\left.\mathrm{H}_{\mathrm{b}}\right), 3.92\left(\mathrm{~s}, 3 \mathrm{H}, \mathrm{H}_{\mathrm{e}}\right), 1.41\left(\mathrm{t}, 3 \mathrm{H},{ }^{3} \mathrm{~J}_{\mathrm{H}_{\mathrm{c}}-\mathrm{H}_{\mathrm{b}}}=7.1 \mathrm{~Hz}, \mathrm{H}_{\mathrm{c}}\right)$.

\subsubsection{4-[(3-Chloro-4-methoxybenzyl)amino]-8-ethyl-3-(hydroxymethyl)quinoline-6-} carbonitrile (4b). An anhydrous $1.1 \mathrm{M}$ solution of lithium tri-tert-butoxyaluminum hydride in tetrahydrofuran (10.5 mL, $11.55 \mathrm{mmol}, 7.0$ eq.) was added, under stirring and argon, to a solution of $3 \mathbf{b}(700 \mathrm{mg}, 1.65 \mathrm{mmol}, 1.0$ eq.) in anhydrous tetrahydrofuran (30 mL). The resulting mixture was heated at $50{ }^{\circ} \mathrm{C}$ for 27 hours. After cooling to rt, methanol $(2 \mathrm{~mL})$ was added slowly. This mixture was then diluted with dichloromethane $(100 \mathrm{~mL})$ before addition of a $1.0 \mathrm{M}$ aqueous sodium hydroxide solution $(100 \mathrm{~mL})$. After decantation, the aqueous layer was then extracted with dichloromethane $(2 \times 100 \mathrm{~mL})$. The combined organic layers were washed successively with a $1.0 \mathrm{M}$ aqueous sodium hydroxide solution $(100 \mathrm{~mL})$ and brine $(100 \mathrm{~mL})$, dried over anhydrous magnesium sulfate, filtered and then concentrated under reduced pressure. The crude product was purified by column chromatography $\left(\mathrm{SiO}_{2}\right.$, ethyl acetate/cyclohexane, 4/6, v/v) to give the desired product $4 \mathbf{b}^{30}(500 \mathrm{mg}, 1.31 \mathrm{mmol}$, $79 \%)$ as a yellow solid. $\mathrm{R}_{\mathrm{f}}\left(\mathrm{SiO}_{2}\right.$, cyclohexane/ethyl acetate, $\left.1 / 9, \mathrm{v} / \mathrm{v}\right): 0.32 ; \mathrm{Mp}: 177-179 \stackrel{\circ}{\circ} \mathrm{C}$; IR $\left(\mathrm{cm}^{-1}\right)$ : $3413\left(\mathrm{v}_{\mathrm{N}-\mathrm{H}}\right), 2922\left(\mathrm{v}_{\mathrm{CH}_{3}}\right), 2230\left(\mathrm{v}_{\mathrm{C} \equiv \mathrm{N}}\right), 1548\left(\delta_{\mathrm{N}-\mathrm{H}}\right), 1504\left(\mathrm{v}_{\mathrm{C}=\mathrm{C}}\right), 1260\left(\mathrm{v}_{\mathrm{C}-\mathrm{O}}\right), 1068\left(\mathrm{v}_{\mathrm{C}-}\right.$ o); ${ }^{1} \mathrm{H}$ NMR (DMSO-d 6 , $\left.400 \mathrm{MHz}\right) \delta 8.79\left(\mathrm{~d}, 1 \mathrm{H},{ }^{4} J_{\mathrm{H}_{5}-\mathrm{H}_{7}}=1.5 \mathrm{~Hz}, \mathrm{H}_{5}\right), 8.49\left(\mathrm{~s}, 1 \mathrm{H}, \mathrm{H}_{2}\right), 7.75$ $\left(\mathrm{d}, 1 \mathrm{H},{ }^{4} \mathrm{~J}_{\mathrm{H}_{7}-\mathrm{H}_{5}}=1.4 \mathrm{~Hz}, \mathrm{H}_{7}\right), 7.44\left(\mathrm{t}, 1 \mathrm{H},{ }^{3} \mathrm{~J}_{\mathrm{NH}-\mathrm{H}_{\mathrm{b}}}=6.7 \mathrm{~Hz}, \mathrm{NH}\right), 7.39\left(\mathrm{~d}, 1 \mathrm{H},{ }^{4} \mathrm{~J}_{\mathrm{H}_{2}-\mathrm{H}^{\prime}}=2.0 \mathrm{~Hz}\right.$, $\left.\mathrm{H}_{2^{\prime}}\right), 7.24\left(\mathrm{dd}, 1 \mathrm{H},{ }^{3} \mathrm{~J}_{\mathrm{H}^{\prime}-\mathrm{H}_{5^{\prime}}}=8.5 \mathrm{~Hz},{ }^{4} J_{\mathrm{H}_{6^{\prime}}-\mathrm{H}_{2^{\prime}}}=2.0 \mathrm{~Hz}, \mathrm{H}_{6^{\prime}}\right), 7.11\left(\mathrm{~d}, 1 \mathrm{H},{ }^{3} \mathrm{~J}_{\mathrm{H}^{\prime}{ }^{\prime} \mathrm{H}_{6^{\prime}}}=8.5 \mathrm{~Hz}, \mathrm{H}_{5^{\prime}}\right)$, $5.38\left(\mathrm{t}, 1 \mathrm{H},{ }^{3} \mathrm{~J}_{\mathrm{OH}-\mathrm{H}_{\mathrm{a}}}=5.2 \mathrm{~Hz}, \mathrm{OH}\right), 4.81\left(\mathrm{~d}, 2 \mathrm{H},{ }^{3} \mathrm{~J}_{\mathrm{H}-\mathrm{NH}}=6.7 \mathrm{~Hz}, \mathrm{H}_{\mathrm{b}}\right), 4.44\left(\mathrm{~d}, 2 \mathrm{H},{ }^{3} \mathrm{~J}_{\mathrm{H}-\mathrm{OH}}=5.2\right.$ $\mathrm{Hz}, \mathrm{H}_{\mathrm{a}}$ ), $3.81\left(\mathrm{~s}, 3 \mathrm{H}, \mathrm{H}_{\mathrm{c}}\right.$ ), $3.13\left(\mathrm{q}, 2 \mathrm{H},{ }^{3} \mathrm{~J}_{\mathrm{H}_{\mathrm{d}}-\mathrm{H}_{\mathrm{e}}}=7.5 \mathrm{~Hz}, \mathrm{H}_{\mathrm{d}}\right), 1.25\left(\mathrm{t}, 3 \mathrm{H},{ }^{3} \mathrm{~J}_{\mathrm{H}_{\mathrm{e}}-\mathrm{H}_{\mathrm{d}}}=7.5 \mathrm{~Hz}, \mathrm{H}_{\mathrm{e}}\right.$ ).

\subsubsection{4-[(3-Chloro-4-methoxybenzyl)amino]-8-cyclopropyl-3-(fluoromethyl)quinoline-6-} carbonitrile (5a). Diethylaminosulfur trifluoride $(58 \mathrm{mg}, 0.36 \mathrm{mmol}, 2.0$ eq.) was added dropwise, at $-60^{\circ} \mathrm{C}$ and under stirring to a solution of $4 \mathrm{a}^{12}$ (70 mg, $0.18 \mathrm{mmol}, 1.0$ eq.) in anhydrous dichloromethane $(20 \mathrm{~mL})$. The temperature increased slowly to rt over 2 hours and the mixture was stirred at this temperature for additional 2 hours. Then, a saturated aqueous sodium hydrogen carbonate solution $(30 \mathrm{~mL})$ was added to the mixture cooled at $20 \stackrel{\circ}{\circ}(\mathrm{pH}=7-8)$. After return back to $\mathrm{rt}$ and decantation, the aqueous layer was extracted with dichloromethane $(2 \times 30 \mathrm{~mL})$. The combined organic layers were washed with water (50 $\mathrm{mL}$ ) and brine $(50 \mathrm{~mL})$, dried over anhydrous sodium sulfate, filtered and evaporated under reduced pressure to afford a highly unstable white solid 5 a (60 mg, $0.15 \mathrm{mmol}, 83 \%$ ). Mp: 
121-123 $\stackrel{\circ}{\circ}$; IR $\left(\mathrm{cm}^{-1}\right): 3405\left(\mathrm{v}_{\mathrm{N}-\mathrm{H}}\right), 2230\left(\mathrm{v}_{\mathrm{C} \equiv \mathrm{N}}\right), 1504\left(\mathrm{v}_{\mathrm{C}=\mathrm{C}}\right), 1260\left(\mathrm{v}_{\mathrm{C}-\mathrm{O}}\right), 1068\left(\mathrm{v}_{\mathrm{C}-\mathrm{O}}\right) ;{ }^{1} \mathrm{H}$ NMR $\left(\mathrm{CDCl}_{3}, 400 \mathrm{MHz}\right) \delta 8.65\left(\mathrm{~d}, 1 \mathrm{H},{ }^{4} \mathrm{~J}_{\mathrm{H}_{2}-\mathrm{F}}=1.7 \mathrm{~Hz}, \mathrm{H}_{2}\right), 8.23\left(\mathrm{~m}, 1 \mathrm{H}, \mathrm{H}_{5}\right), 7.36\left(\mathrm{~d}, 1 \mathrm{H},{ }^{4} \mathrm{~J}_{\mathrm{H}_{2} \cdot \mathrm{H}^{\prime}}=\right.$ $\left.2.1 \mathrm{~Hz}, \mathrm{H}_{2^{\prime}}\right), 7.27\left(\mathrm{~m}, 1 \mathrm{H}, \mathrm{H}_{7}\right), 7.20\left(\mathrm{dd}, 1 \mathrm{H},{ }^{3} J_{\mathrm{H}_{6^{\prime}}-\mathrm{H}_{5^{\prime}}}=8.4 \mathrm{~Hz},{ }^{4} J_{\mathrm{H}^{\prime}} \mathrm{H}_{2^{\prime}}=2.1 \mathrm{~Hz}, \mathrm{H}_{6^{\prime}}\right), 6.94(\mathrm{~d}$, $\left.1 \mathrm{H},{ }^{3} J_{\mathrm{H}^{-} \mathrm{H}^{\prime}}=8.4 \mathrm{~Hz}, \mathrm{H}_{5^{\prime}}\right), 5.46\left(\mathrm{~d}, 2 \mathrm{H},{ }^{3} J_{\mathrm{H}_{\mathrm{a}} \mathrm{F}}=49.2 \mathrm{~Hz}, \mathrm{H}_{\mathrm{a}}\right), 4.78\left(\mathrm{~d}, 2 \mathrm{H},{ }^{3} \mathrm{~J}_{\mathrm{H}_{\mathrm{b}}-\mathrm{NH}}=5.7 \mathrm{~Hz}, \mathrm{H}_{\mathrm{b}}\right)$, $3.91\left(\mathrm{~s}, 3 \mathrm{H}, \mathrm{H}_{\mathrm{c}}\right), 3.08\left(\mathrm{~m}, 1 \mathrm{H}, \mathrm{H}_{\mathrm{d}}\right), 1.23\left(\mathrm{~m}, 2 \mathrm{H}, \mathrm{H}_{\mathrm{e}}\right.$ or $\left.\mathrm{H}_{\mathrm{e}^{\prime}}\right), 0.83\left(\mathrm{~m}, 2 \mathrm{H}, \mathrm{H}_{\mathrm{e}}\right.$ or $\left.\mathrm{H}_{\mathrm{e}^{\prime}}\right) ;{ }^{13} \mathrm{C} \mathrm{NMR}$ $\left(\mathrm{CDCl}_{3}, 100 \mathrm{MHz}\right) \delta 155.0\left(\mathrm{C}_{4^{\prime}}\right), 154.6\left(\mathrm{C}_{2}\right), 152.2\left(\mathrm{C}_{4}\right), 150.2\left(\mathrm{C}_{8 \mathrm{a}}\right), 145.4\left(\mathrm{C}_{8}\right), 131.6\left(\mathrm{C}_{1^{\prime}}\right)$, $129.4\left(\mathrm{C}_{2^{\prime}}\right), 126.8\left(\mathrm{C}_{6^{\prime}}\right), 125.8\left(\mathrm{C}_{5}\right), 124.7\left(\mathrm{C}_{7}\right), 123.2\left(\mathrm{C}_{3^{\prime}}\right), 119.7\left(\mathrm{C}_{4 \mathrm{a}}\right), 119.4(\mathrm{CN}), 112.7$ $\left(\mathrm{C}_{5^{\prime}}\right), 111.5\left(\mathrm{~d},{ }^{2} \mathrm{~J}_{\mathrm{C}_{3}-\mathrm{F}}=18 \mathrm{~Hz}, \mathrm{C}_{3}\right), 108.4\left(\mathrm{C}_{6}\right), 81.4\left(\mathrm{~d},{ }^{1} \mathrm{~J}_{\mathrm{C}_{\mathrm{a}} \mathrm{F}}=164 \mathrm{~Hz}, \mathrm{C}_{\mathrm{a}}\right), 56.4\left(\mathrm{C}_{\mathrm{c}}\right), 50.9$ $\left(\mathrm{C}_{\mathrm{b}}\right), 11.2\left(\mathrm{C}_{\mathrm{d}}\right), 10.1\left(2 \mathrm{C}, \mathrm{C}_{\mathrm{e}}, \mathrm{C}_{\mathrm{e}}\right)$; ESI-MS calculated for $\mathrm{C}_{22} \mathrm{H}_{19}{ }^{35} \mathrm{CIFN}_{3} \mathrm{O}[\mathrm{M}+\mathrm{H}]^{+} \mathrm{m} / \mathrm{z} 396.12$, found $\mathrm{C}_{22} \mathrm{H}_{19}{ }^{35} \mathrm{CIFN}_{3} \mathrm{O}[\mathrm{M}+\mathrm{H}]^{+} \mathrm{m} / \mathrm{z} 396.12$ (100\%); $\mathrm{C}_{22} \mathrm{H}_{19}{ }^{37} \mathrm{CIFN}_{3} \mathrm{O}[\mathrm{M}+\mathrm{H}]^{+} \mathrm{m} / \mathrm{z} 398.09$ (33\%). If the crude product was purified over silica gel, alumina or C-18, $(Z, E)-4-[((3-c h l o r o-4-$ methoxyphenyl)methylene)amino]-8-cyclopropyl-3-methylquinoline-6-carbonitrile (6a) was obtained. $\mathrm{R}_{\mathrm{f}}\left(\mathrm{SiO}_{2}\right.$, ethyl acetate/cyclohexane, 3/7, v/v): 0.24; $\mathrm{Mp}: 216-218{ }^{\circ} \mathrm{C} ; \mathrm{IR}\left(\mathrm{cm}^{-1}\right)$ : $2227\left(\mathrm{v}_{\mathrm{C} \equiv \mathrm{N}}\right), 1502\left(\mathrm{v}_{\mathrm{C}=\mathrm{C}}\right), 1276\left(\mathrm{v}_{\text {as C-O-C}}\right), 1187\left(\mathrm{v}_{\mathrm{s}} \mathrm{C}-\mathrm{O}-\mathrm{C}\right) ;{ }^{1} \mathrm{H}$ NMR $\left(\mathrm{CDCl}_{3}, 400 \mathrm{MHz}\right) \delta 8.91(\mathrm{~s}$, $\left.1 \mathrm{H}, \mathrm{H}_{2}\right), 8.20\left(\mathrm{~s}, 1 \mathrm{H}, \mathrm{H}_{\mathrm{b}}\right) 8.09\left(\mathrm{~d}, 1 \mathrm{H},{ }^{4} \mathrm{~J}_{\mathrm{H}^{\prime} \mathrm{H}_{6^{\prime}}}=2.0 \mathrm{~Hz}, \mathrm{H}_{2^{\prime}}\right), 7.95\left(\mathrm{~d}, 1 \mathrm{H},{ }^{4} J_{\mathrm{H}_{5}-\mathrm{H}_{7}}=1.7 \mathrm{~Hz}, \mathrm{H}_{5}\right)$, $\left.7.82\left(\mathrm{dd}, 1 \mathrm{H},{ }^{3} J_{\mathrm{H}_{6^{\prime}} \mathrm{H}_{5^{\prime}}}=8.5 \mathrm{~Hz}\right),{ }^{4} J_{\mathrm{H}_{6^{\prime}-\mathrm{H}_{2}}}=2.0 \mathrm{~Hz}, \mathrm{H}_{6^{\prime}}\right), 7.23\left(\mathrm{~m}, 1 \mathrm{H}, \mathrm{H}_{7}\right), 7.09\left(\mathrm{~d}, 1 \mathrm{H},{ }^{4} J_{\mathrm{H}^{\prime}-\mathrm{H}_{6^{\prime}}}=\right.$ $\left.8.5 \mathrm{~Hz}, \mathrm{H}_{5^{\prime}}\right), 4.03\left(\mathrm{~s}, 3 \mathrm{H}, \mathrm{H}_{\mathrm{c}}\right), 3.17\left(\mathrm{~m}, 1 \mathrm{H}, \mathrm{H}_{\mathrm{d}}\right), 2.34\left(\mathrm{~s}, 3 \mathrm{H}, \mathrm{H}_{\mathrm{a}}\right), 1.25\left(\mathrm{~m}, 2 \mathrm{H}, \mathrm{H}_{\mathrm{e}}\right.$ or $\left.\mathrm{H}_{\mathrm{e}^{\prime}}\right), 0.86$ $\left(\mathrm{m}, 2 \mathrm{H}, \mathrm{H}_{\mathrm{e}}\right.$ or $\left.\mathrm{H}_{\mathrm{e}^{\prime}}\right) ;{ }^{13} \mathrm{C} \mathrm{NMR}\left(\mathrm{CDCl}_{3}, 100 \mathrm{MHz}\right) \delta 162.6\left(\mathrm{C}_{\mathrm{b}}\right), 158.8\left(\mathrm{C}_{4}\right), 155.6\left(\mathrm{C}_{4}\right), 154.6$ $\left(\mathrm{C}_{2}\right), 147.4\left(\mathrm{C}_{8 \mathrm{a}}\right), 144.8\left(\mathrm{C}_{8}\right), 130.6\left(\mathrm{C}_{2^{\prime}}\right), 129.9\left(\mathrm{C}_{6^{\prime}}\right), 128.5\left(\mathrm{C}_{1^{\prime}}\right), 127.0\left(\mathrm{C}_{5}\right), 124.0\left(\mathrm{C}_{7}\right), 123.4$ $\left(\mathrm{C}_{3^{\prime}}\right), 121.4\left(\mathrm{C}_{4 \mathrm{a}}\right), 119.4(\mathrm{CN}), 118.7\left(\mathrm{C}_{3}\right), 112.1\left(\mathrm{C}_{5^{\prime}}\right), 109.6\left(\mathrm{C}_{6}\right), 56.7\left(\mathrm{C}_{\mathrm{c}}\right), 15.2\left(\mathrm{C}_{\mathrm{a}}\right), 11.0$ $\left(\mathrm{C}_{\mathrm{d}}\right), 10.1$ (2C, $\mathrm{C}_{\mathrm{e}}, \mathrm{C}_{\mathrm{e}^{\prime}}$ ); HRMS calculated for $\mathrm{C}_{22} \mathrm{H}_{18}{ }^{35} \mathrm{CIN}_{3} \mathrm{O}[\mathrm{M}+\mathrm{H}]^{+} \mathrm{m} / \mathrm{z} 376.1217$, found $\mathrm{C}_{22} \mathrm{H}_{18}{ }^{35} \mathrm{CIN}_{3} \mathrm{O}[\mathrm{M}+\mathrm{H}]^{+} \mathrm{m} / \mathrm{z} 376.1214$ (100\%); $\mathrm{C}_{22} \mathrm{H}_{18}{ }^{37} \mathrm{CIN}_{3} \mathrm{O}[\mathrm{M}+\mathrm{H}]^{+} \mathrm{m} / \mathrm{z} 378.1169$ (33\%).

4.1.4. (E)-Diethyl 2-[((2-bromo-4-cyanophenyl)amino)methylene]succinate (9). 4-Amino3-bromobenzonitrile (2.0 g, $10.2 \mathrm{mmol}, 1.0 \mathrm{eq}$ ) was added to a mixture of $8^{34}(5.16 \mathrm{~g}, 25.5$ mmol, 2.0 eq.) in anhydrous toluene $(24 \mathrm{~mL})$ under stirring. The resulting mixture was refluxed for 8 hours. After cooling to rt, the solvent was evaporated under reduced pressure. The crude product was purified by column chromatography $\left(\mathrm{Al}_{2} \mathrm{O}_{3}\right.$, ethyl acetate/cyclohexane, 4/6, v/v) to give the desired product $9(3.0 \mathrm{~g}, 7.87 \mathrm{mmol}, 77 \%)$ as a white solid. $\mathrm{R}_{\mathrm{f}}\left(\mathrm{SiO}_{2}\right.$, cyclohexane/ethyl acetate, 6/4, v/v): 0.62; $\mathrm{Mp}: 138-140 \stackrel{\circ}{\circ} \mathrm{C} ; \mathrm{IR}\left(\mathrm{cm}^{-1}\right)$ : $2223\left(\mathrm{v}_{\mathrm{C} \equiv \mathrm{N}}\right), 1677\left(\mathrm{v}_{\mathrm{C}=\mathrm{O}}\right), 1625\left(\mathrm{v}_{\mathrm{C}=\mathrm{C}}\right), 1596\left(\delta_{\mathrm{N}-\mathrm{H}}\right), 1191\left(\mathrm{v}_{\mathrm{as}} \mathrm{C}-\mathrm{O}-\mathrm{C}\right), 1023\left(\mathrm{v}_{\mathrm{s}} \mathrm{C}-\mathrm{O}-\mathrm{C}\right) ;{ }^{1} \mathrm{H}$ NMR $\left(\mathrm{CDCl}_{3}, 400 \mathrm{MHz}\right) \delta 10.68\left(\mathrm{~d}, 1 \mathrm{H},{ }^{3} J_{\mathrm{NH}-\mathrm{H}_{\mathrm{a}}}=11.6 \mathrm{~Hz}, \mathrm{NH}\right), 7.82\left(\mathrm{~d}, 1 \mathrm{H},{ }^{4} J_{\mathrm{H}_{3}-\mathrm{H}_{5}}=1.8 \mathrm{~Hz}, \mathrm{H}_{3}\right)$, $7.54\left(\mathrm{dd}, 1 \mathrm{H},{ }^{3} \mathrm{~J}_{\mathrm{H}_{5}-\mathrm{H}_{6}}=8.6 \mathrm{~Hz},{ }^{4} \mathrm{~J}_{\mathrm{H}_{5}-\mathrm{H}_{3}}=1.8 \mathrm{~Hz}, \mathrm{H}_{5}\right), 7.22\left(\mathrm{~d}, 1 \mathrm{H},{ }^{3} J_{\mathrm{H}_{\mathrm{a}} \mathrm{NH}}=11.6 \mathrm{~Hz}, \mathrm{H}_{\mathrm{a}}\right), 7.10$

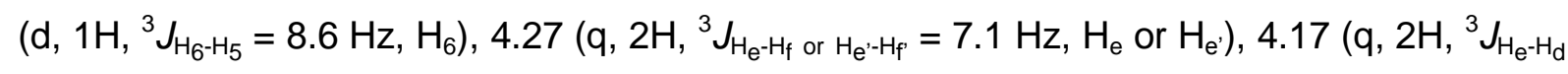
or $\mathrm{H}_{\mathrm{e}^{\prime}-\mathrm{H}_{\mathrm{d}^{\prime}}}=7.1 \mathrm{~Hz}, \mathrm{H}_{\mathrm{e}}$ or $\left.\mathrm{H}_{\mathrm{e}^{\prime}}\right), 3.24\left(\mathrm{~s}, 2 \mathrm{H}, \mathrm{H}_{\mathrm{c}}\right), 1.30\left(\mathrm{t}, 3 \mathrm{H},{ }^{3} J_{\mathrm{H}_{\mathrm{f}}-\mathrm{H}_{\mathrm{e}}}\right.$ or $\mathrm{H}_{\mathrm{f}}-\mathrm{H}_{\mathrm{e}^{\prime}}=7.1 \mathrm{~Hz}, \mathrm{H}_{\mathrm{e}}$ or $\left.\mathrm{H}_{\mathrm{e}^{\prime}}\right)$,

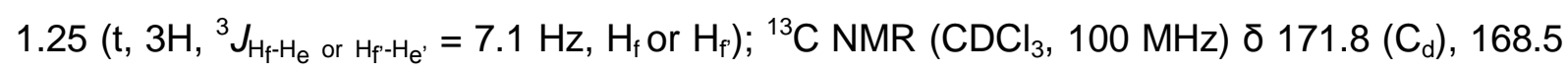


$\left(\mathrm{C}_{\mathrm{d}^{\prime}}\right), 142.5\left(\mathrm{C}_{1}\right), 139.1\left(\mathrm{C}_{\mathrm{a}}\right), 136.7\left(\mathrm{C}_{3}\right), 132.5\left(\mathrm{C}_{5}\right), 117.8(\mathrm{CN}), 112.7\left(\mathrm{C}_{6}\right), 111.2\left(\mathrm{C}_{2}\right.$ or $\left.\mathrm{C}_{4}\right)$, $104.9\left(\mathrm{C}_{2}\right.$ or $\left.\mathrm{C}_{4}\right)$, $99.6\left(\mathrm{C}_{\mathrm{b}}\right), 60.9\left(\mathrm{C}_{\mathrm{e}}\right.$ or $\left.\mathrm{C}_{\mathrm{e}^{\prime}}\right), 60.6\left(\mathrm{C}_{\mathrm{e}}\right.$ or $\left.\mathrm{C}_{\mathrm{e}^{\prime}}\right), 36.0\left(\mathrm{C}_{\mathrm{c}}\right), 14.2\left(2 \mathrm{C}, \mathrm{C}_{\mathrm{f}}, \mathrm{C}_{\mathrm{f}}\right)$; HRMS calculated for $\mathrm{C}_{16} \mathrm{H}_{17}{ }^{79} \mathrm{BrN}_{2} \mathrm{O}_{4}[\mathrm{M}+\mathrm{H}]^{+} \mathrm{m} / \mathrm{z} 381.0450$, found $\mathrm{C}_{16} \mathrm{H}_{17}{ }^{79} \mathrm{BrN}_{2} \mathrm{O}_{4}[\mathrm{M}+\mathrm{H}]^{+}$ $\mathrm{m} / \mathrm{z} 381.0476$ (100\%); $\mathrm{C}_{16} \mathrm{H}_{17}{ }^{81} \mathrm{BrN}_{2} \mathrm{O}_{4}[\mathrm{M}+\mathrm{H}]^{+} \mathrm{m} / \mathrm{z} 383.0457$ (98\%).

\subsubsection{Ethyl 2-(8-bromo-6-cyano-4-oxo-1,4-dihydroquinolin-3-yl)acetate (10). A} suspension of 9 (510 mg, $1.34 \mathrm{mmol}, 1.0$ eq.) in DowTherm $A(10 \mathrm{~mL})$ was placed into a bath beforehand heated at $240-250{ }^{\circ} \mathrm{C}$. The mixture was stirred at this temperature for 2 hours. After cooling to rt and decantation overnight, the formed precipitate was collected by filtration, washed with diethyl ether $(30 \mathrm{~mL})$ and dried to give the desired product 10 (230 mg, $0.69 \mathrm{mmol}, 51 \%)$ as a brown solid. Mp: 134-136 우 $\mathrm{CIR}\left(\mathrm{cm}^{-1}\right): 2232\left(\mathrm{v}_{\mathrm{C} \equiv \mathrm{N}}\right), 1740\left(\mathrm{v}_{\mathrm{C}=\mathrm{O}}\right), 1548$ $\left(\delta_{\mathrm{N}-\mathrm{H}}\right), 1505\left(\mathrm{v}_{\mathrm{C}=\mathrm{C}}\right), 1166\left(\mathrm{v}_{\mathrm{C}-\mathrm{O}}\right) ;{ }^{1} \mathrm{H}$ NMR (DMSO-d $\left.\mathrm{d}_{6}, 400 \mathrm{MHz}\right) \delta 11.55\left(\mathrm{~d}, 1 \mathrm{H},{ }^{3} \mathrm{~J}_{\mathrm{NH}-\mathrm{H}_{2}}=5.9\right.$

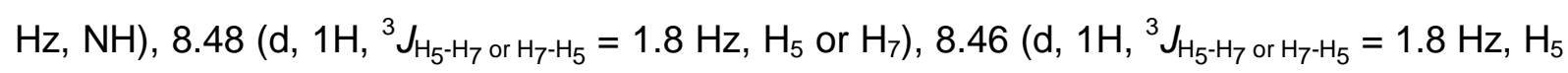
or $\left.\mathrm{H}_{7}\right), 8.02\left(\mathrm{~d}, 1 \mathrm{H},{ }^{3} \mathrm{~J}_{\mathrm{H}_{2}-\mathrm{NH}}=5.9 \mathrm{~Hz}, \mathrm{H}_{2}\right), 4.06\left(\mathrm{q}, 2 \mathrm{H},{ }^{3} \mathrm{~J}_{\mathrm{H}_{\mathrm{c}}-\mathrm{H}_{\mathrm{d}}}=7.1 \mathrm{~Hz}, \mathrm{H}_{\mathrm{c}}\right), 3.51\left(\mathrm{~s}, 2 \mathrm{H}, \mathrm{H}_{\mathrm{a}}\right)$, $1.18\left(\mathrm{t}, 3 \mathrm{H},{ }^{3} \mathrm{~J}_{\mathrm{H}_{\mathrm{d}}-\mathrm{H}_{\mathrm{C}}}=7.1 \mathrm{~Hz}, \mathrm{H}_{\mathrm{d}}\right.$ ); HRMS calculated for $\mathrm{C}_{14} \mathrm{H}_{11}{ }^{79} \mathrm{BrN}_{2} \mathrm{O}_{3}[\mathrm{M}+\mathrm{H}]^{+} \mathrm{m} / \mathrm{z} 335.0031$, found $\mathrm{C}_{14} \mathrm{H}_{11}{ }^{79} \mathrm{BrN}_{2} \mathrm{O}_{3}[\mathrm{M}+\mathrm{H}]^{+} \mathrm{m} / \mathrm{z} 335.0034$ (100\%); $\mathrm{C}_{14} \mathrm{H}_{11}{ }^{81} \mathrm{BrN}_{2} \mathrm{O}_{3}[\mathrm{M}+\mathrm{H}]^{+} \mathrm{m} / \mathrm{z} 337.0004$ (98\%).

4.1.6. Ethyl 2-(8-bromo-4-chloro-6-cyanoquinolin-3-yl)acetate (11). A mixture of 10 (0.53 g, $1.58 \mathrm{mmol}, 1.0$ eq.) in phosphorous oxychloride $(15 \mathrm{~mL})$ was stirred at reflux for 5 hours. After cooling to rt, the solvent was evaporated. Then, ice $(10 \mathrm{~mL})$ and a saturated aqueous sodium carbonate solution $(30 \mathrm{~mL})$ were slowly added. The aqueous layer was extracted with dichloromethane $(2 \times 50 \mathrm{~mL})$. The combined organic layers were washed with brine $(80$ $\mathrm{mL}$ ), dried over anhydrous magnesium sulfate, filtered and concentrated under reduced pressure. The brown residue was purified by column chromatography $\left(\mathrm{SiO}_{2}\right.$, ethyl acetate/cyclohexane, 3/7, v/v) to give the desired product 11 as a brown solid $(0.45 \mathrm{~g}, 1.27$ $\mathrm{mmol}, 81 \%) . \mathrm{R}_{\mathrm{f}}\left(\mathrm{SiO}_{2}\right.$, cyclohexane/ethyl acetate, 5/5, v/v): 0.71; Mp: 179-181 ${ }^{\circ} \mathrm{C} ; \mathrm{IR}\left(\mathrm{cm}^{-1}\right)$ : $2235\left(\mathrm{v}_{\mathrm{C} \equiv \mathrm{N}}\right), 1721\left(\mathrm{v}_{\mathrm{C}=\mathrm{O}}\right), 1213\left(\mathrm{v}_{\mathrm{as}} \mathrm{C}-\mathrm{O}-\mathrm{C}\right), 1151$ ( $\left.\mathrm{v}_{\mathrm{s}} \mathrm{C}-\mathrm{O}-\mathrm{c}\right) ;{ }^{1} \mathrm{H} \mathrm{NMR}\left(\mathrm{CDCl}_{3}, 400 \mathrm{MHz}\right) \delta 8.99$ (s, $\left.1 \mathrm{H}, \mathrm{H}_{2}\right), 8.60\left(\mathrm{~d}, 1 \mathrm{H},{ }^{4} \mathrm{~J}_{\mathrm{H}^{-} \mathrm{H}_{7}}=1.7 \mathrm{~Hz}, \mathrm{H}_{5}\right), 8.20\left(\mathrm{~d}, 1 \mathrm{H},{ }^{4} \mathrm{~J}_{\mathrm{H}_{7}-\mathrm{H}_{5}}=1.7 \mathrm{~Hz}, \mathrm{H}_{7}\right), 4.20\left(\mathrm{q}, 2 \mathrm{H},{ }^{3} \mathrm{~J}_{\mathrm{H}^{-}}\right.$ $\left.\mathrm{H}_{\mathrm{d}}=7.1 \mathrm{~Hz}, \mathrm{H}_{\mathrm{c}}\right), 4.02\left(\mathrm{~s}, 2 \mathrm{H}, \mathrm{H}_{\mathrm{a}}\right), 1.26\left(\mathrm{t}, 3 \mathrm{H},{ }^{3} \mathrm{~J}_{\mathrm{H}_{\mathrm{d}}-\mathrm{H}_{\mathrm{c}}}=7.1 \mathrm{~Hz}, \mathrm{H}_{\mathrm{d}}\right) ;{ }^{3} \mathrm{C} \mathrm{NMR}\left(\mathrm{CDCl}_{3}, 100\right.$ $\mathrm{MHz}) \delta 168.7\left(\mathrm{C}_{\mathrm{b}}\right), 155.2\left(\mathrm{C}_{2}\right), 146.4\left(\mathrm{C}_{8 \mathrm{a}}\right), 143.0\left(\mathrm{C}_{4}\right), 133.9\left(\mathrm{C}_{7}\right), 130.2\left(\mathrm{C}_{5}\right), 128.6\left(\mathrm{C}_{3}\right)$, $126.9\left(\mathrm{C}_{4 \mathrm{a}}\right.$ or $\left.\mathrm{C}_{8}\right), 126.8\left(\mathrm{C}_{4 \mathrm{a}}\right.$ or $\left.\mathrm{C}_{8}\right), 116.9(\mathrm{CN}), 112.1\left(\mathrm{C}_{6}\right), 61.8\left(\mathrm{C}_{\mathrm{c}}\right), 37.1\left(\mathrm{C}_{\mathrm{a}}\right), 14.2\left(\mathrm{C}_{\mathrm{d}}\right)$; HRMS calculated for $\mathrm{C}_{14} \mathrm{H}_{10}{ }^{79} \mathrm{Br}^{35} \mathrm{CIN}_{2} \mathrm{O}_{2}[\mathrm{M}+\mathrm{H}]^{+} \mathrm{m} / \mathrm{z} 352.9692$, found $\mathrm{C}_{14} \mathrm{H}_{10}{ }^{79} \mathrm{Br}^{35} \mathrm{CIN}_{2} \mathrm{O}_{2}$ $[\mathrm{M}+\mathrm{H}]^{+} \mathrm{m} / \mathrm{z} 352.9671$ (77\%); $\mathrm{C}_{14} \mathrm{H}_{10}{ }^{81} \mathrm{Br}^{35} \mathrm{CIN}_{2} \mathrm{O}_{2}$ or $\mathrm{C}_{14} \mathrm{H}_{10}{ }^{79} \mathrm{Br}^{37} \mathrm{CIN}_{2} \mathrm{O}_{2}[\mathrm{M}+\mathrm{H}]^{+} \mathrm{m} / \mathrm{z} 354.9647$ (100\%); $\mathrm{C}_{14} \mathrm{H}_{10}{ }^{81} \mathrm{Br}^{37} \mathrm{CIN}_{2} \mathrm{O}_{2}[\mathrm{M}+\mathrm{H}]^{+} \mathrm{m} / \mathrm{z} 356.9632$ (24\%). 


\subsubsection{Ethyl 2-(4-chloro-6-cyano-8-cyclopropylquinolin-3-yl)acetate (13).}

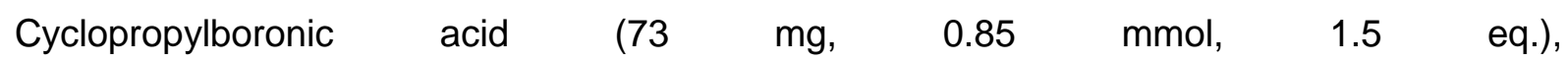
tetrakis(triphenylphosphine)palladium(0) (39 mg, $33.7 \mu \mathrm{mol}, 0.06$ eq.), caesium carbonate (460 mg, $1.41 \mathrm{mmol}, 2.5$ eq.) were added, under stirring and argon, to a solution of 11 (200 $\mathrm{mg}, 0.57 \mathrm{mmol}, 1.0$ eq.) in anhydrous toluene $(10 \mathrm{~mL})$. The resulting mixture was refluxed for $22 \mathrm{~h}$. After cooling to rt, the reaction mixture was filtered over Celite ${ }^{\circledR} 545$, washed with ethyl acetate $(40 \mathrm{~mL})$. The filtrate was concentrated under reduced pressure. The crude product was purified by column chromatography $\left(\mathrm{SiO}_{2}\right.$, ethyl acetate/cyclohexane, 3/7, v/v) to give the desired product $13(110 \mathrm{mg}, 0.35 \mathrm{mmol}, 62 \%)$ as a light yellow solid. $\mathrm{R}_{\mathrm{f}}\left(\mathrm{Al}_{2} \mathrm{O}_{3}\right.$, cyclohexane/ethyl acetate, 8/2, v/v): 0.40; Mp: 126-128 ${ }^{\circ} \mathrm{C}$; IR $\left(\mathrm{cm}^{-1}\right): 2232\left(\mathrm{v}_{\mathrm{C} \equiv \mathrm{N}}\right), 1742$ $\left(\mathrm{v}_{\mathrm{C}=\mathrm{O}}\right), 1482\left(\mathrm{v}_{\mathrm{C}=\mathrm{C}}\right), 1151$ ( $\left.\mathrm{v}_{\text {as }} \mathrm{c}-\mathrm{O}-\mathrm{c}\right), 1043$ ( $\left.\mathrm{v}_{\mathrm{s}} \mathrm{c}-\mathrm{O}-\mathrm{c}\right) ;{ }^{1} \mathrm{H}$ NMR (DMSO-d $\left.\mathrm{d}_{6}, 400 \mathrm{MHz}\right) \delta 8.93$ (s, $\left.1 \mathrm{H}, \mathrm{H}_{2}\right), 8.45\left(\mathrm{~d}, 1 \mathrm{H},{ }^{4} J_{\mathrm{H}_{5}-\mathrm{H}_{7}}=1.6 \mathrm{~Hz}, \mathrm{H}_{5}\right), 7.31\left(\mathrm{~d}, 1 \mathrm{H},{ }^{4} J_{\mathrm{H}_{7}-\mathrm{H}_{5}}=1.6 \mathrm{~Hz}, \mathrm{H}_{7}\right), 4.21\left(\mathrm{q}, 2 \mathrm{H},{ }^{3} J_{\mathrm{H}_{\mathrm{c}^{-}}}\right.$ $\left.H_{d}=7.1 \mathrm{~Hz}, \mathrm{H}_{\mathrm{c}}\right), 4.01\left(\mathrm{~s}, 2 \mathrm{H}, \mathrm{H}_{\mathrm{a}}\right), 3.19\left(\mathrm{~m}, 1 \mathrm{H}, \mathrm{H}_{\mathrm{e}}\right), 1.26\left(\mathrm{~m}, 5 \mathrm{H}, \mathrm{H}_{\mathrm{d}}, \mathrm{H}_{\mathrm{f}}\right.$ or $\left.\mathrm{H}_{\mathrm{f}}\right), 0.89\left(\mathrm{~m}, 2 \mathrm{H}, \mathrm{H}_{\mathrm{f}}\right.$ or $\left.\mathrm{H}_{\mathrm{f}}\right) ;{ }^{13} \mathrm{C}$ NMR (DMSO-d $\left.\mathrm{d}_{6}, 100 \mathrm{MHz}\right) \delta 169.0\left(\mathrm{C}_{\mathrm{b}}\right), 153.1\left(\mathrm{C}_{2}\right), 148.0\left(\mathrm{C}_{8 \mathrm{a}}\right), 145.8\left(\mathrm{C}_{8}\right), 142.4$ $\left(\mathrm{C}_{4}\right), 127.2\left(\mathrm{C}_{3}\right), 127.0\left(\mathrm{C}_{5}\right), 125.5\left(\mathrm{C}_{4 \mathrm{a}}\right), 123.9\left(\mathrm{C}_{7}\right), 118.4(\mathrm{CN}), 111.2\left(\mathrm{C}_{6}\right), 61.4\left(\mathrm{C}_{\mathrm{c}}\right), 36.8$ $\left(\mathrm{C}_{\mathrm{a}}\right), 14.0\left(\mathrm{C}_{\mathrm{d}}\right), 10.6\left(\mathrm{C}_{\mathrm{e}}\right), 10.5\left(2 \mathrm{C}, \mathrm{C}_{\mathrm{f}}, \mathrm{C}_{\mathrm{f}}\right)$; HRMS calculated for $\mathrm{C}_{17} \mathrm{H}_{15}{ }^{35} \mathrm{CIN}_{2} \mathrm{O}_{2}[\mathrm{M}+\mathrm{H}]^{+} \mathrm{m} / \mathrm{z}$ 315.0900, found $\mathrm{C}_{17} \mathrm{H}_{15}{ }^{35} \mathrm{CIN}_{2} \mathrm{O}_{2}[\mathrm{M}+\mathrm{H}]^{+} \mathrm{m} / \mathrm{z} 315.0915$ (100\%); $\mathrm{C}_{17} \mathrm{H}_{15}{ }^{37} \mathrm{CIN}_{2} \mathrm{O}_{2}[\mathrm{M}+\mathrm{H}]^{+} \mathrm{m} / \mathrm{z}$ $317.0922(33 \%)$.

\subsubsection{4-[(3-Chloro-4-methoxybenzyl)amino]-8-cyclopropyl-3-formylquinoline-6-}

carbonitrile (15a). Manganese oxide (331 mg, $3.81 \mathrm{mmol}, 10 \mathrm{eq}$.) was added to a solution of $4 \mathbf{a}$ [12] (150 mg, $0.38 \mathrm{mmol}, 1.0$ eq.) in dichloromethane $(20 \mathrm{~mL})$. The resulting mixture was stirred at rt for 5 hours, filtered on Celite ${ }^{\circledR} 545$ and washed with dichloromethane (40 $\mathrm{mL}$ ). The filtrate was evaporated under reduced pressure. The residue was purified by column chromatography $\left(\mathrm{SiO}_{2}\right.$, ethanol/dichloromethane, $\left.3 / 97, \mathrm{v} / \mathrm{v}\right)$ to give the desired product $15 \mathrm{a}(140 \mathrm{mg}, 0.36 \mathrm{mmol}, 95 \%)$ as a light yellow solid. $\mathrm{R}_{\mathrm{f}}\left(\mathrm{SiO}_{2}\right.$, ethanol/dichloromethane, 1/9, v/v): 0.49; Mp: 209-211 으; $I R\left(\mathrm{~cm}^{-1}\right): 2228\left(\mathrm{v}_{\mathrm{C} \equiv \mathrm{N}}\right), 1642\left(\mathrm{v}_{\mathrm{C}=\mathrm{O}}\right)$, $1571\left(\delta_{\mathrm{N}-\mathrm{H}}\right), 1501\left(\mathrm{v}_{\mathrm{C}=\mathrm{C}}\right), 1181\left(\mathrm{v}_{\mathrm{C}-\mathrm{O}}\right), 1022\left(\mathrm{v}_{\mathrm{C}-\mathrm{O}}\right) ;{ }^{1} \mathrm{H} \mathrm{NMR}\left(\mathrm{CDCl}_{3}, 400 \mathrm{MHz}\right) \delta 10.56(\mathrm{t}, 1 \mathrm{H}$, $\left.{ }^{3} J_{\mathrm{NH}-\mathrm{H}_{\mathrm{b}}}=5.5 \mathrm{~Hz}, \mathrm{NH}\right), 9.91\left(\mathrm{~s}, 1 \mathrm{H}, \mathrm{H}_{\mathrm{a}}\right), 8.74\left(\mathrm{~s}, 1 \mathrm{H}, \mathrm{H}_{2}\right), 8.34\left(\mathrm{~d}, 1 \mathrm{H},{ }^{4} J_{\mathrm{H}_{5}-\mathrm{H}_{7}}=1.7 \mathrm{~Hz}, \mathrm{H}_{5}\right), 7.38$ $\left(\mathrm{d}, 1 \mathrm{H},{ }^{4} J_{\mathrm{H}^{\prime} \mathrm{H}^{-} \mathrm{H}_{6^{\prime}}}=2.2 \mathrm{~Hz}, \mathrm{H}_{2^{\prime}}\right), 7.26\left(\mathrm{~m}, 2 \mathrm{H}, \mathrm{H}_{7}, \mathrm{H}_{6^{\prime}}\right), 6.95\left(\mathrm{~d}, 1 \mathrm{H},{ }^{3} J_{\mathrm{H}_{5^{\prime}}-\mathrm{H}_{6^{\prime}}}=8.5 \mathrm{~Hz}, \mathrm{H}_{5^{\prime}}\right), 4.92(\mathrm{~d}$, $\left.2 \mathrm{H},{ }^{3} \mathrm{~J}_{\mathrm{H}_{\mathrm{b}} \mathrm{NH}}=5.5 \mathrm{~Hz}, \mathrm{H}_{\mathrm{b}}\right), 3.89\left(\mathrm{~s}, 3 \mathrm{H}, \mathrm{H}_{\mathrm{c}}\right), 3.08\left(\mathrm{~m}, 1 \mathrm{H}, \mathrm{H}_{\mathrm{d}}\right), 1.19\left(\mathrm{~m}, 2 \mathrm{H}, \mathrm{H}_{\mathrm{e}}\right.$ or $\left.\mathrm{H}_{\mathrm{e}}\right), 0.78(\mathrm{~m}$, $2 \mathrm{H}, \mathrm{H}_{\mathrm{e}}$ or $\left.\mathrm{H}_{\mathrm{e}^{\prime}}\right) ;{ }^{13} \mathrm{C} \mathrm{NMR}\left(\mathrm{CDCl}_{3}, 100 \mathrm{MHz}\right) \delta 192.7\left(\mathrm{C}_{\mathrm{a}}\right), 157.0\left(\mathrm{C}_{2}\right), 155.5\left(\mathrm{C}_{4}\right), 155.3\left(\mathrm{C}_{4}\right)$, $151.8\left(\mathrm{C}_{8 \mathrm{a}}\right), 145.5\left(\mathrm{C}_{8}\right), 129.5\left(\mathrm{C}_{1^{\prime}}\right), 129.5\left(\mathrm{C}_{5}\right), 129.4\left(\mathrm{C}_{2^{\prime}}\right), 127.0\left(\mathrm{C}_{6^{\prime}}\right), 126.9\left(\mathrm{C}_{7}\right), 123.4$ $\left(\mathrm{C}_{3^{\prime}}\right), 119.0(\mathrm{CN}), 118.0\left(\mathrm{C}_{3}\right), 112.7\left(\mathrm{C}_{5^{\prime}}\right), 111.6\left(\mathrm{C}_{4 \mathrm{a}}\right), 107.7\left(\mathrm{C}_{6}\right), 56.3\left(\mathrm{C}_{\mathrm{c}}\right), 51.1\left(\mathrm{C}_{\mathrm{b}}\right), 11.4$ $\left(\mathrm{C}_{\mathrm{d}}\right), 10.1\left(2 \mathrm{C}, \mathrm{C}_{\mathrm{e}}, \mathrm{C}_{\mathrm{e}}\right)$; HRMS calculated for $\mathrm{C}_{22} \mathrm{H}_{18}{ }^{35} \mathrm{CIN}_{3} \mathrm{O}_{2}[\mathrm{M}+\mathrm{H}]^{+} \mathrm{m} / \mathrm{z}$ 392.1166, found $\mathrm{C}_{22} \mathrm{H}_{18}{ }^{35} \mathrm{CIN}_{3} \mathrm{O}_{2}[\mathrm{M}+\mathrm{H}]^{+} \mathrm{m} / \mathrm{z} 392.1151$ (100\%); $\mathrm{C}_{22} \mathrm{H}_{18}{ }^{37} \mathrm{CIN}_{3} \mathrm{O}_{2}[\mathrm{M}+\mathrm{H}]^{+} \mathrm{m} / \mathrm{z} 394.1126$ (33\%). 


\subsubsection{4-[(3-Chloro-4-methoxybenzyl)amino]-8-ethyl-3-formylquinoline-6-carbonitrile}

(15b). Manganese oxide (1.4 g, $16.1 \mathrm{mmol}, 10.0$ eq.) was added to a solution of $4 \mathrm{~b}(0.6 \mathrm{~g}$, $1.57 \mathrm{mmol}, 1.0$ eq.) in dichloromethane $(40 \mathrm{~mL})$. The resulting mixture was stirred at rt for 20 hours before filtration on celite ${ }^{\circledR} 545$ and washing with dichloromethane $(2 \times 40 \mathrm{~mL})$. The filtrate was concentrated under reduced pressure. The residue was purified by column chromatography $\left(\mathrm{SiO}_{2}\right.$, cyclohexane/ethyl acetate, $\left.7 / 3, \mathrm{v} / \mathrm{v}\right)$ to give the desired product $\mathbf{1 5 b}$ $(0.27 \mathrm{~g}, 0.71 \mathrm{mmol}, 45 \%)$ as a yellow solid. $\mathrm{R}_{\mathrm{f}}\left(\mathrm{SiO}_{2}\right.$, cyclohexane/ethyl acetate, $\left.7 / 3, \mathrm{v} / \mathrm{v}\right)$ : 0.25; Mp: 168-170 ํㅜ; IR $\left(\mathrm{cm}^{-1}\right)$ : $2226\left(\mathrm{v}_{\mathrm{C} \equiv \mathrm{N}}\right), 1651\left(\mathrm{v}_{\mathrm{C}=\mathrm{O}}\right), 1576\left(\delta_{\mathrm{NH}}\right), 1505\left(\mathrm{v}_{\mathrm{C}=\mathrm{C}}\right), 1266\left(\mathrm{v}_{\mathrm{C}-}\right.$ o), $1069\left(\mathrm{v}_{\mathrm{C}-\mathrm{o}}\right) ;{ }^{1} \mathrm{H}$ NMR $\left(\mathrm{CDCl}_{3}, 400 \mathrm{MHz}\right) \delta 10.57\left(\mathrm{t}, 1 \mathrm{H},{ }^{3} \mathrm{~J}_{\mathrm{NH}-\mathrm{H}_{\mathrm{b}}}=5.5 \mathrm{~Hz}, \mathrm{NH}\right), 9.91(\mathrm{~s}, 1 \mathrm{H}$, $\left.\mathrm{H}_{\mathrm{a}}\right), 8.72\left(\mathrm{~s}, 1 \mathrm{H}, \mathrm{H}_{2}\right), 8.43\left(\mathrm{~d}, 1 \mathrm{H},{ }^{4} J_{\mathrm{H}_{5}-\mathrm{H}_{7}}=1.7 \mathrm{~Hz}, \mathrm{H}_{5}\right), 7.70\left(\mathrm{~m}, 1 \mathrm{H}, \mathrm{H}_{7}\right), 7.40\left(\mathrm{~d}, 1 \mathrm{H},{ }^{4} J_{\mathrm{H}_{2} 2^{-} \mathrm{H}_{6^{\prime}}}=\right.$ $\left.2.3 \mathrm{~Hz}, \mathrm{H}_{2^{\prime}}\right), 7.27\left(\mathrm{dd}, 1 \mathrm{H},{ }^{4} \mathrm{~J}_{\mathrm{H}^{\prime} \mathrm{H}_{\mathrm{H}^{\prime}}}=2.3 \mathrm{~Hz},{ }^{3} \mathrm{~J}_{\mathrm{H}^{\prime} \mathrm{H}^{\prime}}=8.6 \mathrm{~Hz}, \mathrm{H}_{6^{\prime}}\right), 6.97\left(\mathrm{~d}, 1 \mathrm{H},{ }^{3} \mathrm{~J}_{\mathrm{H}^{\prime}{ }^{-} \mathrm{H}_{6^{\prime}}}=8.6\right.$ $\mathrm{Hz}, \mathrm{H}_{5^{\prime}}$ ), $4.94\left(\mathrm{~d}, 2 \mathrm{H},{ }^{3} \mathrm{~J}_{\mathrm{H}_{\mathrm{b}} \mathrm{NH}}=5.5 \mathrm{~Hz}, \mathrm{H}_{\mathrm{b}}\right), 3.90\left(\mathrm{~s}, 3 \mathrm{H}, \mathrm{H}_{\mathrm{c}}\right.$ ), 3.20 (q, 2H, ${ }^{3} \mathrm{~J}_{\mathrm{H}_{\mathrm{d}}-\mathrm{H}_{\mathrm{e}}}=7.5 \mathrm{~Hz}, \mathrm{H}_{\mathrm{d}}$ ), $1.33\left(\mathrm{t}, 3 \mathrm{H},{ }^{3} \mathrm{~J}_{\mathrm{H}_{\mathrm{e}} \mathrm{H}_{\mathrm{d}}}=7.5 \mathrm{~Hz}, \mathrm{H}_{\mathrm{e}}\right) ;{ }^{13} \mathrm{C} \mathrm{NMR}\left(\mathrm{CDCl}_{3}, 100 \mathrm{MHz}\right) \delta 192.7\left(\mathrm{C}_{\mathrm{a}}\right), 157.0\left(\mathrm{C}_{2}\right), 155.4$ $\left(\mathrm{C}_{4^{\prime}}\right), 155.3\left(\mathrm{C}_{4}\right), 151.2\left(\mathrm{C}_{8 \mathrm{a}}\right), 145.4\left(\mathrm{C}_{8}\right), 131.5\left(\mathrm{C}_{7}\right), 130.5\left(\mathrm{C}_{5}\right), 129.5\left(\mathrm{C}_{1^{\prime}}\right), 129.4\left(\mathrm{C}_{2^{\prime}}\right), 126.9$ $\left(\mathrm{C}_{6^{\prime}}\right), 123.4\left(\mathrm{C}_{3^{\prime}}\right), 119.0(\mathrm{CN}), 118.0\left(\mathrm{C}_{4 \mathrm{a}}\right), 112.7\left(\mathrm{C}_{5^{\prime}}\right), 111.5\left(\mathrm{C}_{3}\right), 107.6\left(\mathrm{C}_{6}\right), 56.3\left(\mathrm{C}_{\mathrm{c}}\right), 51.1$ $\left(\mathrm{C}_{\mathrm{b}}\right), 25.3\left(\mathrm{C}_{\mathrm{d}}\right), 14.5\left(\mathrm{C}_{\mathrm{e}}\right)$; HRMS calculated for $\mathrm{C}_{21} \mathrm{H}_{18}{ }^{35} \mathrm{CIN}_{3} \mathrm{O}_{2}[\mathrm{M}+\mathrm{H}]^{+} \mathrm{m} / \mathrm{z} 380.1166$, found $\mathrm{C}_{21} \mathrm{H}_{18}{ }^{35} \mathrm{CIN}_{3} \mathrm{O}_{2}[\mathrm{M}+\mathrm{H}]^{+} \mathrm{m} / \mathrm{z} 380.1159$ (100\%); $\mathrm{C}_{21} \mathrm{H}_{18}{ }^{37} \mathrm{CIN}_{3} \mathrm{O}_{2}[\mathrm{M}+\mathrm{H}]^{+} \mathrm{m} / \mathrm{z} 382.1113$ (33\%).

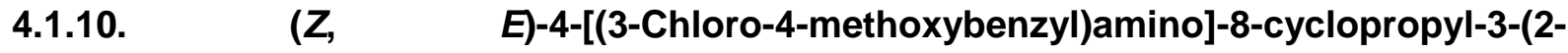
methoxyvinyl)quinoline-6-carbonitrile (16a). A $1.6 \mathrm{M}$ solution of $n$-butyllithium $(4.1 \mathrm{~mL}$, $6.56 \mathrm{mmol}, 9.9$ eq.) in hexane was slowly added at $-7{ }^{\circ} \mathrm{C}$, under argon and stirring, to a suspension of (methoxymethyl)triphenylphosphonium chloride $(2.28 \mathrm{~g}, 6.65 \mathrm{mmol}, 10.0 \mathrm{eq}$.) in anhydrous tetrahydrofuran $(20 \mathrm{~mL})$. The resulting mixture was then stirred at $\mathrm{rt}$ for 20 minutes. After cooling to $-15^{\circ} \mathrm{C}$, a solution of $15 \mathrm{a}(260 \mathrm{mg}, 0.66 \mathrm{mmol}, 1.0 \mathrm{eq}$.) in anhydrous tetrahydrofuran $(20 \mathrm{~mL})$ was slowly added. The resulting mixture was stirred at it for 2 hours before addition of a saturated aqueous ammonium chloride solution $(40 \mathrm{~mL})$ at $-5{ }^{\circ} \mathrm{C}$. This aqueous layer was extracted with ethyl acetate $(3 \times 30 \mathrm{~mL})$. The combined organic layers were washed with brine $(50 \mathrm{~mL})$, dried over anhydrous magnesium sulfate, filtered, and concentrated under reduced pressure. The residue obtained was purified by column chromatography $\left(\mathrm{SiO}_{2}\right.$, cyclohexane/ethyl acetate, $\left.5 / 5, \mathrm{v} / \mathrm{v}\right)$ to give the desired product $(\boldsymbol{Z}, \boldsymbol{E})$ 16a $(0.19 \mathrm{~g}, 0.45 \mathrm{mmol}, 68 \%)$ as a yellow solid (ratio $Z / E=1 / 0.4) . \mathrm{R}_{\mathrm{f}}\left(\mathrm{SiO}_{2}\right.$, cyclohexane/ethyl acetate, 5/5, v/v): 0.32, 0.23; Mp: 140-142 ${ }^{\circ} \mathrm{C}$; IR $\left(\mathrm{cm}^{-1}\right): 3405\left(\mathrm{v}_{\mathrm{N}-\mathrm{H}}\right), 2226$ $\left(\mathrm{v}_{\mathrm{C} \equiv \mathrm{N}}\right), 1651\left(\mathrm{v}_{\mathrm{C}=\mathrm{C}}\right), 1498\left(\mathrm{v}_{\mathrm{C}=\mathrm{C}}\right), 1255\left(\mathrm{v}_{\mathrm{C}-\mathrm{o}}\right), 1099\left(\mathrm{v}_{\mathrm{C}-\mathrm{o}}\right), 1061\left(\mathrm{v}_{\mathrm{C}-\mathrm{O}}\right) ;{ }^{1} \mathrm{H}$ NMR $\left(\mathrm{CDCl}_{3}, 400\right.$ $\mathrm{MHz}) \delta 8.96\left(\mathrm{~s}, 1 \mathrm{H}, \mathrm{H}_{2(\mathrm{z})}\right), 8.69\left(\mathrm{~s}, 1 \mathrm{H}, \mathrm{H}_{2(\mathrm{E})}\right), 8.15\left(\mathrm{~d}, 1 \mathrm{H},{ }^{4} J_{\mathrm{H}_{5(\mathrm{Z})}-\mathrm{H}_{7(\mathrm{Z})}}=1.6 \mathrm{~Hz}, \mathrm{H}_{5(\mathrm{Z})}\right), 8.12(\mathrm{~d}$, $\left.1 \mathrm{H},{ }^{4} J_{\mathrm{H}_{5(E)}-\mathrm{H}_{7(E)}}=1.6 \mathrm{~Hz}, \mathrm{H}_{5(E)}\right), 7.32\left(\mathrm{~d}, 1 \mathrm{H},{ }^{4} J_{\mathrm{H}^{\prime}(\mathrm{Z} / \mathrm{E}) \mathrm{H}^{\prime} \mathrm{H}^{\prime}(\mathrm{Z} / E)}=2.2 \mathrm{~Hz}, \mathrm{H}_{2^{\prime}(E / Z)}\right), 7.16(\mathrm{~m}, 1 \mathrm{H}$, $\left.\mathrm{H}_{7(\mathrm{Z} / \mathrm{E})}\right), 7.12\left(\mathrm{dd}, 1 \mathrm{H},{ }^{4} J_{\mathrm{H}_{6^{\prime}}(\mathrm{Z})^{-} \mathrm{H}_{2^{\prime}(\mathrm{Z})}}=2.2 \mathrm{~Hz},{ }^{3} J_{\mathrm{H}_{6^{\prime}}(\mathrm{Z})^{-} \mathrm{H}_{5^{\prime}(\mathrm{Z})}}=8.4 \mathrm{~Hz}, \mathrm{H}_{6^{\prime}(\mathrm{Z})}\right), 7.11\left(\mathrm{dd}, 1 \mathrm{H},{ }^{4} J_{\mathrm{H}_{6^{\prime}}(\mathrm{E})^{-}}\right.$ 
$\left.H_{2^{\prime}(E)}=2.2 \mathrm{~Hz},{ }^{3} J_{H_{6^{\prime}}(E)-H_{5^{\prime}(E)}}=8.4 \mathrm{~Hz}, H_{6^{\prime}(E)}\right), 6.88\left(\mathrm{~d}, 1 \mathrm{H},{ }^{3} J_{\mathrm{H}^{\prime}(\mathrm{Z} / E)-H_{6^{\prime}(Z / E)}}=8.4 \mathrm{~Hz}, \mathrm{H}_{5^{\prime}(Z / E)}\right), 6.85$ $\left(\mathrm{d}, 1 \mathrm{H},{ }^{3} \mathrm{~J}_{\left.\mathrm{Hb}_{\mathrm{b}(\mathrm{E})}\right)_{\mathrm{H}(\mathrm{E})}}=12.8 \mathrm{~Hz}, \mathrm{H}_{\mathrm{b}(\mathrm{E})}\right), 6.27\left(\mathrm{~d}, 1 \mathrm{H},{ }^{3} \mathrm{~J}_{\left.\mathrm{Hb}_{\mathrm{Z}}\right)^{-} \mathrm{H}_{\mathrm{a}(\mathrm{Z})}}=6.8 \mathrm{~Hz}, \mathrm{H}_{\mathrm{b}(\mathrm{Z})}\right), 5.72\left(\mathrm{~d}, 1 \mathrm{H},{ }^{3} \mathrm{~J}_{\mathrm{H}_{\mathrm{a}(\mathrm{E})}}\right.$ $\left.\mathrm{H}_{\mathrm{b}(\mathrm{E})}=12.8 \mathrm{~Hz}, \mathrm{H}_{\mathrm{a}(\mathrm{E})}\right), 5.28\left(\mathrm{~d}, 1 \mathrm{H},{ }^{3} \mathrm{~J}_{\mathrm{H}_{\mathrm{a}(\mathrm{Z})}-\mathrm{H}_{\mathrm{b}(\mathrm{Z})}}=6.8 \mathrm{~Hz}, \mathrm{H}_{\mathrm{a}(\mathrm{Z})}\right), 4.58\left(\mathrm{~s}, 2 \mathrm{H}, \mathrm{H}_{\mathrm{d}(\mathrm{E})}\right), 4.55(\mathrm{~s}, 2 \mathrm{H}$, $\left.\mathrm{H}_{\mathrm{d}(\mathrm{Z})}\right), 3.88\left(\mathrm{~s}, 3 \mathrm{H}, \mathrm{H}_{\mathrm{e}(\mathrm{Z} / \mathrm{E})}\right), 3.73\left(\mathrm{~s}, 3 \mathrm{H}, \mathrm{H}_{\mathrm{c}(\mathrm{Z})}\right), 3.65\left(\mathrm{~s}, 3 \mathrm{H}, \mathrm{H}_{\mathrm{c}(\mathrm{E})}\right), 3.10\left(\mathrm{~m}, 1 \mathrm{H}, \mathrm{H}_{\mathrm{f}(\mathrm{Z} / \mathrm{E})}\right), 1.19(\mathrm{~m}$, $2 \mathrm{H}, \mathrm{H}_{\mathrm{g}(\mathrm{Z} / \mathrm{E})}$ or $\left.\mathrm{H}_{\mathrm{g}^{\prime}(\mathrm{Z} / \mathrm{E})}\right), 0.81\left(\mathrm{~m}, 2 \mathrm{H}, \mathrm{H}_{\mathrm{g}(\mathrm{Z} / \mathrm{E})}\right.$ or $\left.\mathrm{H}_{\mathrm{g}^{\prime}(\mathrm{Z} / \mathrm{E})}\right) ;{ }^{13} \mathrm{C} \mathrm{NMR}\left(\mathrm{CDCl}_{3}, 100 \mathrm{MHz}\right) \delta 154.8$ $\left(\mathrm{C}_{4^{\prime}(\mathrm{E})}\right), 154.7\left(\mathrm{C}_{4^{\prime}(\mathrm{Z})}\right), 154.0\left(\mathrm{C}_{2(\mathrm{Z})}\right), 152.0\left(\mathrm{C}_{2(\mathrm{E})}\right), 151.3\left(\mathrm{C}_{\mathrm{b}(\mathrm{E})}\right), 149.1\left(2 \mathrm{C}, \mathrm{C}_{\mathrm{b}(\mathrm{Z})}, \mathrm{C}_{4(\mathrm{Z} / \mathrm{E})}\right), 148.6$ $\left(\mathrm{C}_{8 \mathrm{a}(\mathrm{E})}\right), 148.4\left(\mathrm{C}_{8 \mathrm{a}(\mathrm{Z})}\right), 145.3\left(\mathrm{C}_{8(\mathrm{E})}\right), 144.9\left(\mathrm{C}_{8(\mathrm{Z})}\right), 132.4\left(\mathrm{C}_{1^{\prime}(\mathrm{Z})}\right), 132.3\left(\mathrm{C}_{1^{\prime}(\mathrm{E})}\right), 129.5\left(\mathrm{C}_{2^{\prime}(\mathrm{Z})}\right)$, $129.4\left(\mathrm{C}_{2^{\prime}(\mathrm{E})}\right), 127.0\left(\mathrm{C}_{6^{\prime}(\mathrm{Z})}\right), 126.9\left(\mathrm{C}_{6^{\prime}(\mathrm{E})}\right), 126.6\left(\mathrm{C}_{5(\mathrm{Z})}\right), 125.8\left(\mathrm{C}_{5(\mathrm{E})}\right), 123.3\left(\mathrm{C}_{7(\mathrm{Z})}\right), 123.1$ $\left(\mathrm{C}_{7(\mathrm{E})}\right), 123.0\left(\mathrm{C}_{3^{\prime}(\mathrm{E})}\right), 122.9\left(\mathrm{C}_{3^{\prime}(\mathrm{E})}\right), 121.0\left(\mathrm{C}_{4 \mathrm{a}(\mathrm{Z})}\right), 120.7\left(\mathrm{C}_{4 \mathrm{a}(\mathrm{E})}\right), 119.7\left(\mathrm{CN}_{(\mathrm{Z})}\right), 119.6\left(\mathrm{CN}_{(\mathrm{E})}\right)$, $117.4\left(\mathrm{C}_{3(\mathrm{E})}\right), 116.7\left(\mathrm{C}_{3(\mathrm{Z})}\right), 112.4\left(\mathrm{C}_{5^{\prime}(\mathrm{E})}\right), 112.4\left(\mathrm{C}_{5^{\prime}(\mathrm{Z})}\right), 108.4\left(\mathrm{C}_{6(\mathrm{E})}\right), 108.0\left(\mathrm{C}_{6(\mathrm{Z})}\right), 99.4\left(\mathrm{C}_{\mathrm{a}(\mathrm{Z})}\right)$, $98.6\left(\mathrm{C}_{\mathrm{a}(\mathrm{E})}\right), 60.8\left(\mathrm{C}_{\mathrm{c}(\mathrm{Z})}\right), 56.9\left(\mathrm{C}_{\mathrm{c}(\mathrm{E})}\right), 56.3\left(\mathrm{C}_{\mathrm{e}(\mathrm{Z} / \mathrm{E})}\right), 52.5\left(\mathrm{C}_{\mathrm{d}(\mathrm{Z})}\right), 52.0\left(\mathrm{C}_{\mathrm{d}(\mathrm{E})}\right), 11.2\left(\mathrm{C}_{\mathrm{f}(\mathrm{Z})}\right), 11.1$ $\left(\mathrm{C}_{\mathrm{f}(\mathrm{E})}\right), 10.0\left(2 \mathrm{C}, \mathrm{C}_{\mathrm{g}(\mathrm{E})} / \mathrm{C}_{\mathrm{g}^{\prime}(\mathrm{E})}\right), 9.9\left(2 \mathrm{C}, \mathrm{C}_{\mathrm{g}(\mathrm{Z})} / \mathrm{C}_{\mathrm{g}^{\prime}(\mathrm{Z})}\right)$; HRMS calculated for $\mathrm{C}_{24} \mathrm{H}_{22}{ }^{35} \mathrm{CIN}_{3} \mathrm{O}_{2}[\mathrm{M}+\mathrm{H}]^{+}$ $\mathrm{m} / \mathrm{z} 420.1479$, found $\mathrm{C}_{24} \mathrm{H}_{22}{ }^{35} \mathrm{CIN}_{3} \mathrm{O}_{2}[\mathrm{M}+\mathrm{H}]^{+} \mathrm{m} / \mathrm{z} 420.1505$ (100\%); $\mathrm{C}_{24} \mathrm{H}_{22}{ }^{37} \mathrm{ClN}_{3} \mathrm{O}_{2}[\mathrm{M}+\mathrm{H}]^{+}$ $\mathrm{m} / \mathrm{z} 422.1455$ (33\%).

\subsubsection{1. (Z)-4-[(3-Chloro-4-methoxybenzyl)amino]-8-ethyl-3-(2-methoxyvinyl)quinoline-6-} carbonitrile (16b). A solution of $1.6 \mathrm{M} \mathrm{n}$-butyllithium $(4.1 \mathrm{~mL}, 6.56 \mathrm{mmol}, 9.2 \mathrm{eq})$ in hexane was added slowly to a suspension of (methoxymethyl)triphenylphosphonium chloride $(2.4 \mathrm{~g}$, $7.00 \mathrm{mmol}, 9.9 \mathrm{eq})$ in anhydrous tetrahydrofuran $(20 \mathrm{~mL})$ under argon and stirring at $-15^{\circ} \mathrm{C}$. The resulting mixture was then stirred at $\mathrm{rt}$ for 20 minutes before addition of a solution of $\mathbf{1 5 b}$ (270 mg, $0.71 \mathrm{mmol}, 1.0 \mathrm{eq})$ in anhydrous tetrahydrofuran $(15 \mathrm{~mL})$ at $-10{ }^{\circ} \mathrm{C}$ over 15 minutes. The resulting mixture was stirred at $r$ for another 2 hours before addition of a saturated aqueous solution of ammonium chloride $(40 \mathrm{~mL})$ at a temperature between $-5^{\circ} \mathrm{C}$ and $0{ }^{\circ} \mathrm{C}$. The resulting solution was extracted with ethyl acetate $(3 \times 30 \mathrm{~mL})$ and the combined organic layers were washed with brine $(100 \mathrm{~mL})$, dried over anhydrous magnesium sulfate, filtered, and concentrated under reduced pressure. The residue was purified by column chromatography $\left(\mathrm{SiO}_{2}\right.$, cyclohexane/ethyl acetate, $\left.5 / 5, \mathrm{v} / \mathrm{v}\right)$ to give the desired product (Z)16b (140 mg, $0.34 \mathrm{mmol}, 48 \%)$ as a yellow solid. $\mathrm{R}_{\mathrm{f}}\left(\mathrm{SiO}_{2}\right.$, cyclohexane/ethyl acetate, 5/5, $\mathrm{v} / \mathrm{v})$ : 0.24; Mp: $151-153 \stackrel{\circ}{\circ} \mathrm{C} ; \mathrm{IR}\left(\mathrm{cm}^{-1}\right): 3405\left(\mathrm{v}_{\mathrm{N}-\mathrm{H}}\right), 2228\left(\mathrm{v}_{\mathrm{C}=\mathrm{N}}\right), 1499\left(\delta_{\mathrm{N}-\mathrm{H}}\right), 1390\left(\delta_{\mathrm{CH}_{3}}\right), 1255$ $\left(\mathrm{v}_{\mathrm{C}-\mathrm{o}}\right), 1099\left(\mathrm{v}_{\mathrm{C}-\mathrm{o}}\right), 1060\left(\mathrm{v}_{\mathrm{C}-\mathrm{o}}\right) ;{ }^{1} \mathrm{H}$ NMR $\left(\mathrm{CDCl}_{3}, 400 \mathrm{MHz}\right) \delta 8.88\left(\mathrm{~s}, 1 \mathrm{H}, \mathrm{H}_{2}\right), 8.14(\mathrm{~d}, 1 \mathrm{H}$, $\left.{ }^{4} J_{\mathrm{H}_{5}-\mathrm{H}_{7}}=1.8 \mathrm{~Hz}, \mathrm{H}_{5}\right), 7.49\left(\mathrm{~m}, 1 \mathrm{H}, \mathrm{H}_{7}\right), 7.27\left(\mathrm{~d}, 1 \mathrm{H},{ }^{4} J_{\mathrm{H}_{2}{ }^{-} \mathrm{H}_{6^{\prime}}}=2.2 \mathrm{~Hz}, \mathrm{H}_{2^{\prime}}\right), 7.07\left(\mathrm{dd}, 1 \mathrm{H}^{3}{ }^{3} J_{\mathrm{H}^{\prime}-\mathrm{H}_{5^{\prime}}}\right.$ $\left.=8.4 \mathrm{~Hz},{ }^{4} J_{\mathrm{H}_{6^{\prime}}-\mathrm{H}_{2^{\prime}}}=2.2 \mathrm{~Hz}, \mathrm{H}_{6^{\prime}}\right), 6.82\left(\mathrm{~d}, 1 \mathrm{H},{ }^{3} J_{\mathrm{H}^{\prime}-\mathrm{H}_{6^{\prime}}}=8.4 \mathrm{~Hz}, \mathrm{H}_{5^{\prime}}\right), 6.21\left(\mathrm{~d}, 1 \mathrm{H},{ }^{3} J_{\mathrm{H}_{\mathrm{b}}-\mathrm{H}_{\mathrm{a}}}=6.9\right.$ $\left.\mathrm{Hz}, \mathrm{H}_{\mathrm{b}}\right), 5.22\left(\mathrm{~d}, 1 \mathrm{H},{ }^{3} \mathrm{~J}_{\mathrm{H}_{\mathrm{a}}-\mathrm{H}_{\mathrm{b}}}=6.9 \mathrm{~Hz}, \mathrm{H}_{\mathrm{a}}\right), 4.64\left(\mathrm{t}, 1 \mathrm{H},{ }^{3} J_{\mathrm{NH}-\mathrm{H}_{\mathrm{d}}}=6.2 \mathrm{~Hz}, \mathrm{NH}\right), 4.47\left(\mathrm{~d}, 2 \mathrm{H},{ }^{3} J_{\mathrm{H}^{-}}\right.$ $\left.\mathrm{NH}=6.2 \mathrm{~Hz}, \mathrm{H}_{\mathrm{d}}\right), 3.82\left(\mathrm{~s}, 3 \mathrm{H}, \mathrm{H}_{\mathrm{e}}\right), 3.67\left(\mathrm{~s}, 3 \mathrm{H}, \mathrm{H}_{\mathrm{c}}\right), 3.17\left(\mathrm{q}, 2 \mathrm{H},{ }^{3} \mathrm{~J}_{\mathrm{H}_{\mathrm{f}}-\mathrm{H}_{\mathrm{g}}}=7.5 \mathrm{~Hz}, \mathrm{H}_{\mathrm{f}}\right), 1.29(\mathrm{t}$, $\left.3 \mathrm{H},{ }^{3} \mathrm{~J}_{\mathrm{H}_{\mathrm{g}} \mathrm{H}_{\mathrm{f}}}=7.5 \mathrm{~Hz}, \mathrm{H}_{\mathrm{g}}\right) ;{ }^{13} \mathrm{C} \mathrm{NMR}\left(\mathrm{CDCl}_{3}, 100 \mathrm{MHz}\right) \delta 154.7\left(\mathrm{C}_{4}\right), 154.2\left(\mathrm{C}_{2}\right), 149.0\left(\mathrm{C}_{\mathrm{b}}\right)$, 
$148.9\left(\mathrm{C}_{4}\right), 147.9\left(\mathrm{C}_{8 \mathrm{a}}\right), 145.1\left(\mathrm{C}_{8}\right), 132.5\left(\mathrm{C}_{1^{\prime}}\right), 129.5\left(\mathrm{C}_{2^{\prime}}\right), 127.5\left(\mathrm{C}_{7}\right), 127.4\left(\mathrm{C}_{6^{\prime}}\right), 127.0\left(\mathrm{C}_{5}\right)$, $122.9\left(\mathrm{C}_{3^{\prime}}\right), 121.1\left(\mathrm{C}_{4 \mathrm{a}}\right), 119.8(\mathrm{CN}), 116.7\left(\mathrm{C}_{3}\right), 112.4\left(\mathrm{C}_{5^{\prime}}\right), 107.9\left(\mathrm{C}_{6}\right), 99.5\left(\mathrm{C}_{\mathrm{a}}\right), 60.7\left(\mathrm{C}_{\mathrm{c}}\right)$, $56.3\left(\mathrm{C}_{\mathrm{e}}\right), 52.6\left(\mathrm{C}_{\mathrm{d}}\right), 24.9\left(\mathrm{C}_{\mathrm{f}}\right), 14.6\left(\mathrm{C}_{\mathrm{g}}\right)$; HRMS calculated for $\mathrm{C}_{23} \mathrm{H}_{22}{ }^{35} \mathrm{CIN}_{3} \mathrm{O}_{2}[\mathrm{M}+\mathrm{H}]^{+} \mathrm{m} / \mathrm{z}$ 408.1479, found $\mathrm{C}_{23} \mathrm{H}_{22}{ }^{35} \mathrm{CIN}_{3} \mathrm{O}_{2}[\mathrm{M}+\mathrm{H}]^{+} \mathrm{m} / \mathrm{z} 408.1461$ (100\%); $\mathrm{C}_{23} \mathrm{H}_{22}{ }^{37} \mathrm{CIN}_{3} \mathrm{O}_{2}[\mathrm{M}+\mathrm{H}]^{+} \mathrm{m} / \mathrm{z}$ 410.1417 (33\%).

\subsubsection{1-(3-Chloro-4-methoxybenzyl)-6-cyclopropyl-1 H-pyrrolo[3,2-c]quinoline-8-} carbonitrile (17a). A $4 \mathrm{M}$ aqueous hydrochloric acid solution $(0.1 \mathrm{~mL})$ was added to a solution of $16 \mathrm{a}(20 \mathrm{mg}, 47.6 \mu \mathrm{mol}, 1.0 \mathrm{eq}$.) in tetrahydrofuran $(0.3 \mathrm{~mL})$. The resulting mixture was stirred at $50{ }^{\circ} \mathrm{C}$ for 4 hours. After cooling to rt, an aqueous saturated sodium bicarbonate solution $(20 \mathrm{~mL})$ was added. The resulting solution was extracted with ethyl acetate $(2 \times 15$ $\mathrm{mL})$ and the combined organic layers were washed with brine $(30 \mathrm{~mL})$, dried over anhydrous magnesium sulfate, filtered, and concentrated under reduced pressure. The residue was purified by column chromatography $\left(\mathrm{SiO}_{2}\right.$, cyclohexane/ethyl acetate, $\left.7 / 3, \mathrm{v} / \mathrm{v}\right)$ to give product 17a as a white solid (10 mg, $25.8 \mu \mathrm{mol}, 54 \%) ; \mathrm{R}_{\mathrm{f}}\left(\mathrm{SiO}_{2}\right.$, cyclohexane/ethyl acetate, 7/3, v/v): 0.53; Mp: 196-198 우 IR $\left(\mathrm{cm}^{-1}\right): 2230\left(\mathrm{v}_{\mathrm{C}=\mathrm{N}}\right), 1502\left(\mathrm{v}_{\mathrm{C}=\mathrm{C}}\right), 1258\left(\mathrm{v}_{\text {as }} \mathrm{C}-\mathrm{O}\right), 1064\left(\mathrm{v}_{\mathrm{s}} \mathrm{C}-\right.$ o); ${ }^{1} \mathrm{H} \mathrm{NMR}\left(\mathrm{CDCl}_{3}, 400 \mathrm{MHz}\right) \delta 9.32\left(\mathrm{~s}, 1 \mathrm{H}, \mathrm{H}_{4}\right), 8.44\left(\mathrm{~d}, 1 \mathrm{H},{ }^{4} \mathrm{~J}_{\mathrm{H}_{9}-\mathrm{H}_{7}}=1.6 \mathrm{~Hz}, \mathrm{H}_{9}\right), 7.76(\mathrm{~d}$, $\left.1 \mathrm{H},{ }^{3} J_{\mathrm{H}_{2}-\mathrm{H}_{3}}=3.1 \mathrm{~Hz}, \mathrm{H}_{2}\right), 7.31\left(\mathrm{~d}, 1 \mathrm{H},{ }^{4} J_{\mathrm{H}_{7}-\mathrm{H}_{9}}=1.6 \mathrm{~Hz}, \mathrm{H}_{7}\right), 7.19\left(\mathrm{~d}, 1 \mathrm{H},{ }^{4} \mathrm{~J}_{\mathrm{H}^{\prime} \mathrm{H}^{\prime} \mathrm{H}^{\prime}}=2.1 \mathrm{~Hz}, \mathrm{H}_{2^{\prime}}\right)$, $7.04\left(\mathrm{~d}, 1 \mathrm{H},{ }^{3} J_{\mathrm{H}^{\prime} \mathrm{H}^{\prime}}=8.6 \mathrm{~Hz}, \mathrm{H}_{5^{\prime}}\right), 6.98\left(\mathrm{~d}, 1 \mathrm{H},{ }^{3} J_{\mathrm{H}_{3}-\mathrm{H}_{2}}=3.1 \mathrm{~Hz}, \mathrm{H}_{3}\right), 6.88\left(\mathrm{dd}, 1 \mathrm{H},{ }^{4} J_{\mathrm{H}^{\prime}-\mathrm{H}_{2}}=\right.$ $\left.2.1 \mathrm{~Hz},{ }^{3} \mathrm{~J}_{\mathrm{H}^{\prime} \mathrm{H}^{\prime}}=8.6 \mathrm{~Hz}, \mathrm{H}_{6^{\prime}}\right), 5.95\left(\mathrm{~s}, 2 \mathrm{H}, \mathrm{H}_{\mathrm{a}}\right), 3.76\left(\mathrm{~s}, 3 \mathrm{H}, \mathrm{H}_{\mathrm{b}}\right), 3.31\left(\mathrm{~m}, 1 \mathrm{H}, \mathrm{H}_{\mathrm{c}}\right), 1.10(\mathrm{~m}, 2 \mathrm{H}$, $\mathrm{H}_{\mathrm{d}}$ or $\left.\mathrm{H}_{\mathrm{d}^{\prime}}\right), 0.88\left(\mathrm{~m}, 2 \mathrm{H}, \mathrm{H}_{\mathrm{d}}\right.$ or $\left.\mathrm{H}_{\mathrm{d}^{\prime}}\right) ;{ }^{13} \mathrm{C} \operatorname{NMR}\left(\mathrm{CDCl}_{3}, 100 \mathrm{MHz}\right) \delta 153.8\left(\mathrm{C}_{4^{\prime}}\right), 147.7\left(\mathrm{C}_{4}\right), 144.9$ $\left(\mathrm{C}_{6}\right), 143.8\left(\mathrm{C}_{5 \mathrm{a}}\right), 132.6\left(\mathrm{C}_{2}\right), 132.3\left(\mathrm{C}_{9 \mathrm{~b}}\right), 130.3\left(\mathrm{C}_{1^{\prime}}\right), 127.7\left(\mathrm{C}_{2^{\prime}}\right), 126.0\left(\mathrm{C}_{6^{\prime}}\right), 124.2\left(\mathrm{C}_{9}\right)$, $123.1\left(\mathrm{C}_{3 \mathrm{a}}\right), 121.4\left(\mathrm{C}_{3^{\prime}}\right), 121.0\left(\mathrm{C}_{7}\right), 119.3(\mathrm{CN}), 117.1\left(\mathrm{C}_{9 \mathrm{a}}\right), 113.1\left(\mathrm{C}_{5^{\prime}}\right), 107.7\left(\mathrm{C}_{8}\right), 102.7$ $\left(\mathrm{C}_{3}\right), 56.1\left(\mathrm{C}_{\mathrm{b}}\right), 51.1\left(\mathrm{C}_{\mathrm{a}}\right), 11.2\left(\mathrm{C}_{\mathrm{c}}\right), 10.3\left(2 \mathrm{C}, \mathrm{C}_{\mathrm{d}}, \mathrm{C}_{\mathrm{d}^{\prime}}\right)$; HRMS calculated for $\mathrm{C}_{23} \mathrm{H}_{18}{ }^{35} \mathrm{CIN}_{3} \mathrm{O}$ $[\mathrm{M}+\mathrm{H}]^{+} \mathrm{m} / \mathrm{z} 388.1217$, found $\mathrm{C}_{23} \mathrm{H}_{18}{ }^{35} \mathrm{CIN}_{3} \mathrm{O}[\mathrm{M}+\mathrm{H}]^{+} \mathrm{m} / \mathrm{z} 388.1197(100 \%) ; \mathrm{C}_{23} \mathrm{H}_{18}{ }^{37} \mathrm{CIN}_{3} \mathrm{O}$ $[\mathrm{M}+\mathrm{H}]^{+} \mathrm{m} / \mathrm{z} 390.1178(33 \%)$.

\subsubsection{Allyl (3-chloro-4-methoxybenzyl)-[(6-cyano-8-cyclopropyl-3-(2-} methoxyvinyl))quinolin-4-yl]carbamate (19a). Sodium hydride powder (moistened with oil, $55-65 \%, 91 \mathrm{mg}, 2.26 \mathrm{mmol}, 5.0$ eq.) was added to a solution of $16 \mathrm{a}$ (190 mg, $0.45 \mathrm{mmol}, 1.0$ eq.) in anhydrous $\mathrm{N}, \mathrm{N}$-dimethylformamide $(10 \mathrm{~mL})$. The resulting mixture was stirred at $\mathrm{rt}$ for 20 minutes before careful addition of allyl chloroformate (192 $\mu \mathrm{L}, 1.81 \mathrm{mmol}, 4.0$ eq.). The mixture was then stirred at $\mathrm{rt}$ for one hour before addition of water $(20 \mathrm{~mL})$. The resulting solution was extracted with ethyl acetate $(3 \times 30 \mathrm{~mL})$ and the combined organic layers were washed with brine $(3 \times 50 \mathrm{~mL})$, dried over anhydrous magnesium sulfate, filtered, and concentrated under reduced pressure. The residue was purified by column chromatography $\left(\mathrm{SiO}_{2}\right.$, cyclohexane/ethyl acetate, 6/4, v/v) to give the desired product $19 \mathrm{a}$ as yellow oil corresponding to a mixture of $Z / E$ isomers (ratio: $Z / E=1 / 0.7,170 \mathrm{mg}, 0.34 \mathrm{mmol}, 76 \%$ ). IR 
$\left(\mathrm{cm}^{-1}\right): 2228\left(\mathrm{v}_{\mathrm{C}=\mathrm{N}}\right), 1703\left(\mathrm{v}_{\mathrm{C}=\mathrm{O}}\right), 1635\left(\mathrm{v}_{\mathrm{C}=\mathrm{C}}\right), 1501\left(\mathrm{v}_{\mathrm{C}=\mathrm{C}}\right), 1257\left(\mathrm{v}_{\mathrm{C}-\mathrm{O}}\right), 1220\left(\mathrm{v}_{\mathrm{C}-\mathrm{O}}\right), 1118\left(\mathrm{v}_{\mathrm{C}-\mathrm{O}}\right)$; HRMS calculated for $\mathrm{C}_{28} \mathrm{H}_{26}{ }^{35} \mathrm{CIN}_{3} \mathrm{O}_{4}[\mathrm{M}+\mathrm{H}]^{+} \mathrm{m} / \mathrm{z} 504.1690$, found $\mathrm{C}_{28} \mathrm{H}_{26}{ }^{35} \mathrm{CIN}_{3} \mathrm{O}_{4}[\mathrm{M}+\mathrm{H}]^{+} \mathrm{m} / \mathrm{z}$ 504.1676 (100\%); $\mathrm{C}_{28} \mathrm{H}_{26}{ }^{37} \mathrm{CIN}_{3} \mathrm{O}_{4}[\mathrm{M}+\mathrm{H}]^{+} \mathrm{m} / \mathrm{z} 506.1830$ (33\%). During the purification by column chromatography, a few fractions containing each pure isomer were obtained. The quantities isolated allowed to characterise the isomers $Z$ and $E$ by NMR analyses separately. Allyl (E)-(3-chloro-4-methoxybenzyl)-[(6-cyano-8-cyclopropyl-3-(2-methoxyvinyl))quinolin-4yl]carbamate $((\boldsymbol{E})-19 \mathrm{a}) . \mathrm{R}_{\mathrm{f}}\left(\mathrm{SiO}_{2}\right.$, cyclohexane/ethyl acetate, 5/5, v/v): 0.62; ${ }^{1} \mathrm{H} \mathrm{NMR}\left(\mathrm{CDCl}_{3}\right.$, $400 \mathrm{MHz}) \delta 9.09\left(\mathrm{~s}, 1 \mathrm{H}, \mathrm{H}_{2}\right), 7.61\left(\mathrm{~d}, 1 \mathrm{H},{ }^{4} \mathrm{~J}_{\mathrm{H}_{5}-\mathrm{H}_{7}}=1.6 \mathrm{~Hz}, \mathrm{H}_{5}\right), 7.16\left(\mathrm{~d}, 1 \mathrm{H},{ }^{3} J_{\mathrm{H}_{\mathrm{b}}-\mathrm{H}_{\mathrm{a}}}=13.1 \mathrm{~Hz}\right.$, $\left.\mathrm{H}_{\mathrm{b}}\right), 7.15\left(\mathrm{~d}, 1 \mathrm{H},{ }^{4} \mathrm{~J}_{\mathrm{H}_{2} \cdot \mathrm{H}_{6^{\prime}}}=2.2 \mathrm{~Hz}, \mathrm{H}_{2^{\prime}}\right), 7.14\left(\mathrm{~d}, 1 \mathrm{H},{ }^{4} J_{\mathrm{H}_{7}-\mathrm{H}_{5}}=1.6 \mathrm{~Hz}, \mathrm{H}_{7}\right), 7.01\left(\mathrm{dd}, 1 \mathrm{H},{ }^{3} J_{\mathrm{H}^{\prime}-\mathrm{H}_{5}}\right.$, $\left.=8.4 \mathrm{~Hz},{ }^{4} \mathrm{~J}_{\mathrm{H}^{\prime} \mathrm{H}^{\prime}}=2.2 \mathrm{~Hz}, \mathrm{H}_{6^{\prime}}\right), 6.77\left(\mathrm{~d}, 1 \mathrm{H}^{3}{ }^{3} \mathrm{~J}_{\mathrm{H}^{\prime}-\mathrm{H}_{6^{\prime}}}=8.4 \mathrm{~Hz}, \mathrm{H}_{5^{\prime}}\right), 5.66\left(\mathrm{~m}, 1 \mathrm{H}, \mathrm{H}_{\mathrm{g}}\right), 5.40(\mathrm{~d}$, $\left.1 \mathrm{H},{ }^{3} J_{\mathrm{H}_{\mathrm{a}}-\mathrm{H}_{\mathrm{b}}}=13.1 \mathrm{~Hz}, \mathrm{H}_{\mathrm{a}}\right), 5.02\left(\mathrm{~m}, 2 \mathrm{H}, \mathrm{H}_{\mathrm{h}}\right), 4.90\left(\mathrm{~d}, 1 \mathrm{H},{ }^{2} J_{\mathrm{H}^{-}-H_{\mathrm{d}^{\prime}}}=14.3 \mathrm{~Hz}, \mathrm{H}_{\mathrm{d}}\right), 4.58(\mathrm{~m}, 1 \mathrm{H}$, $\left.\mathrm{H}_{\mathrm{f}}\right), 4.53\left(\mathrm{~d}, 1 \mathrm{H},{ }^{2} \mathrm{~J}_{\mathrm{H}^{\prime} \mathrm{H}_{\mathrm{d}}}=14.3 \mathrm{~Hz}, \mathrm{H}_{\mathrm{d}^{\prime}}\right), 4.46\left(\mathrm{~m}, 1 \mathrm{H}, \mathrm{H}_{\mathrm{f}}\right), 3.86\left(\mathrm{~s}, 3 \mathrm{H}, \mathrm{H}_{\mathrm{i}}\right), 3.55\left(\mathrm{~s}, 3 \mathrm{H}, \mathrm{H}_{\mathrm{c}}\right)$, $3.17\left(\mathrm{~m}, 1 \mathrm{H}, \mathrm{H}_{\mathrm{j}}\right), 1.23\left(\mathrm{~m}, 2 \mathrm{H}, \mathrm{H}_{\mathrm{k}}\right.$ or $\left.\mathrm{H}_{\mathrm{k}^{\prime}}\right), 0.87\left(\mathrm{~m}, 2 \mathrm{H}, \mathrm{H}_{\mathrm{k}}\right.$ or $\left.\mathrm{H}_{\mathrm{k}^{\prime}}\right) ;{ }^{13} \mathrm{C} \mathrm{NMR}\left(\mathrm{CDCl}_{3}, 100 \mathrm{MHz}\right)$ ठ $162.5\left(\mathrm{C}_{\mathrm{e}}\right), 155.2\left(\mathrm{C}_{4^{\prime}}\right), 152.5\left(\mathrm{C}_{\mathrm{b}}\right), 150.5\left(\mathrm{C}_{2}\right), 147.9\left(\mathrm{C}_{8 \mathrm{a}}\right), 145.8\left(\mathrm{C}_{8}\right), 139.6\left(\mathrm{C}_{4}\right), 132.1$ $\left(\mathrm{C}_{g}\right), 131.6\left(\mathrm{C}_{2^{\prime}}\right), 129.4\left(\mathrm{C}_{6^{\prime}}\right), 129.3\left(\mathrm{C}_{1^{\prime}}\right), 125.9\left(\mathrm{C}_{5}\right), 125.7\left(\mathrm{C}_{4 \mathrm{a}}\right), 122.9\left(\mathrm{C}_{7}\right), 122.5\left(\mathrm{C}_{3^{\prime}}\right)$, $119.5\left(\mathrm{C}_{3}\right), 118.9(\mathrm{CN}), 118.2\left(\mathrm{C}_{\mathrm{h}}\right), 112.0\left(\mathrm{C}_{5^{\prime}}\right), 111.1\left(\mathrm{C}_{6}\right), 97.7\left(\mathrm{C}_{\mathrm{a}}\right), 66.9\left(\mathrm{C}_{\mathrm{f}}\right), 56.6\left(\mathrm{C}_{\mathrm{c}}\right), 56.3$ $\left(\mathrm{C}_{\mathrm{i}}\right), 52.8\left(\mathrm{C}_{\mathrm{d}}\right), 10.8\left(\mathrm{C}_{\mathrm{j}}\right), 10.5\left(2 \mathrm{C}, \mathrm{C}_{\mathrm{k}}, \mathrm{C}_{\mathrm{k}^{\prime}}\right)$. Allyl (Z)-(3-chloro-4-methoxybenzyl)-[(6-cyano-8cyclopropyl-3-(2-methoxyvinyl))quinolin-4-yl]carbamate ((Z)-19a). $\mathrm{R}_{\mathrm{f}}\left(\mathrm{SiO}_{2}\right.$, cyclohexane/ethyl acetate, 5/5, v/v): 0.55; ${ }^{1} \mathrm{H} \mathrm{NMR}\left(\mathrm{CDCl}_{3}, 400 \mathrm{MHz}\right) \delta 9.77\left(\mathrm{~s}, 1 \mathrm{H}, \mathrm{H}_{2}\right), 7.48\left(\mathrm{~d}, 1 \mathrm{H},{ }^{4} \mathrm{~J}_{\mathrm{H}_{5}-\mathrm{H}_{7}}=\right.$ $\left.1.6 \mathrm{~Hz}, \mathrm{H}_{5}\right), 7.11\left(\mathrm{~d}, 1 \mathrm{H},{ }^{4} J_{\mathrm{H}_{7}-\mathrm{H}_{5}}=1.6 \mathrm{~Hz}, \mathrm{H}_{7}\right), 7.06\left(\mathrm{dd}, 1 \mathrm{H},{ }^{3} J_{\mathrm{H}^{\prime} \cdot \mathrm{H}^{\prime}}=8.4 \mathrm{~Hz},{ }^{4} J_{\mathrm{H}^{\prime} \cdot \mathrm{H}^{\prime}}=2.1 \mathrm{~Hz}\right.$, $\left.\mathrm{H}_{6^{\prime}}\right), 7.02\left(\mathrm{~d}, 1 \mathrm{H},{ }^{4} \mathrm{~J}_{\mathrm{H}^{\prime} \mathrm{H}_{6^{\prime}}}=2.1 \mathrm{~Hz}, \mathrm{H}_{2^{\prime}}\right), 6.76\left(\mathrm{~d}, 1 \mathrm{H},{ }^{3} \mathrm{~J}_{\mathrm{H}^{\prime} \mathrm{H}^{-} \mathrm{H}^{\prime}}=8.4 \mathrm{~Hz}, \mathrm{H}_{5^{\prime}}\right), 6.26\left(\mathrm{~d}, 1 \mathrm{H},{ }^{3} \mathrm{~J}_{\mathrm{H}^{-}-\mathrm{H}_{\mathrm{a}}}\right.$ $\left.=7.1 \mathrm{~Hz}, \mathrm{H}_{\mathrm{b}}\right), 5.64\left(\mathrm{~m}, 1 \mathrm{H}, \mathrm{H}_{\mathrm{g}}\right), 5.04\left(\mathrm{~d}, 1 \mathrm{H},{ }^{3} \mathrm{~J}_{\mathrm{H}_{\mathrm{a}}-\mathrm{H}_{\mathrm{b}}}=7.1 \mathrm{~Hz}, \mathrm{H}_{\mathrm{a}}\right), 4.97\left(\mathrm{~m}, 2 \mathrm{H}, \mathrm{H}_{\mathrm{h}}\right), 4.81(\mathrm{~d}$, $\left.1 \mathrm{H},{ }^{2} J_{\mathrm{d}^{-}-H_{d^{\prime}}}=14.2 \mathrm{~Hz}, \mathrm{H}_{\mathrm{d}}\right), 4.56\left(\mathrm{~d}, 1 \mathrm{H},{ }^{2} J_{\mathrm{H}^{\prime} \mathrm{H}_{\mathrm{d}}}=14.2 \mathrm{~Hz}, \mathrm{H}_{\mathrm{d}^{\prime}}\right), 4.48\left(\mathrm{~m}, 2 \mathrm{H}, \mathrm{H}_{\mathrm{f}}\right), 3.84(\mathrm{~s}, 3 \mathrm{H}$, $\left.\mathrm{H}_{\mathrm{i}}\right), 3.82\left(\mathrm{~s}, 3 \mathrm{H}, \mathrm{H}_{\mathrm{c}}\right), 3.16\left(\mathrm{~m}, 1 \mathrm{H}, \mathrm{H}_{\mathrm{j}}\right), 1.20\left(\mathrm{~m}, 2 \mathrm{H}, \mathrm{H}_{\mathrm{k}}\right.$ or $\left.\mathrm{H}_{\mathrm{k}^{\prime}}\right), 0.84\left(\mathrm{~m}, 2 \mathrm{H}, \mathrm{H}_{\mathrm{k}}\right.$ or $\left.\mathrm{H}_{\mathrm{k}^{\prime}}\right) ;{ }^{13} \mathrm{C}$ $\operatorname{NMR}\left(\mathrm{CDCl}_{3}, 100 \mathrm{MHz}\right) \delta 155.1\left(2 \mathrm{C}, \mathrm{C}_{\mathrm{e}}, \mathrm{C}_{4^{\prime}}\right), 154.8\left(\mathrm{C}_{2}\right), 151.5\left(\mathrm{C}_{\mathrm{b}}\right), 147.4\left(\mathrm{C}_{8 \mathrm{a}}\right), 145.4\left(\mathrm{C}_{8}\right)$, $140.0\left(C_{4}\right), 132.1\left(C_{g}\right), 131.6\left(C_{2^{\prime}}\right), 129.4\left(C_{6^{\prime}}\right), 129.3\left(C_{1^{\prime}}\right), 128.7\left(C_{3}\right), 126.5\left(C_{5}\right), 125.7\left(C_{4 a}\right)$, $122.9\left(\mathrm{C}_{7}\right), 122.3\left(\mathrm{C}_{3^{\prime}}\right), 118.9(\mathrm{CN}), 117.8\left(\mathrm{C}_{\mathrm{h}}\right), 112.0\left(\mathrm{C}_{5^{\prime}}\right), 110.4\left(\mathrm{C}_{6}\right), 97.3\left(\mathrm{C}_{\mathrm{a}}\right), 66.7\left(\mathrm{C}_{\mathrm{f}}\right)$, $61.2\left(C_{c}\right), 56.3\left(C_{i}\right), 52.9\left(C_{d}\right), 10.8\left(C_{j}\right), 10.2\left(2 C, C_{k}, C_{k^{\prime}}\right)$.

\subsubsection{4.}

(Z)-Allyl

3-chloro-4-methoxybenzyl[6-cyano-8-ethyl-3-(2-

methoxyvinyl)quinoline-4-yl]carbamate (19b). Sodium hydride powder (moistened with oil, $55-65 \%, 113 \mathrm{mg}, 2.82 \mathrm{mmol}, 5.0$ eq.) was added to a solution of $16 \mathrm{~b}$ (230 mg, $0.56 \mathrm{mmol}$, 1.0 eq.) in anhydrous $\mathrm{N}, \mathrm{N}$-dimethylformamide $(10 \mathrm{~mL})$. The resulting mixture was stirred at $\mathrm{rt}$ for 20 minutes before careful addition of allyl chloroformate $(240 \mu \mathrm{L}, 2.26 \mathrm{mmol}, 4.0$ eq.). The mixture was stirred for 2 hours before addition of water $(20 \mathrm{~mL})$. The resulting solution was extracted with ethyl acetate $(3 \times 20 \mathrm{~mL})$ and the combined organic layers were washed with 
brine $(50 \mathrm{~mL})$, dried over anhydrous magnesium sulfate, filtered, and concentrated under reduced pressure. The residue was purified by column chromatography $\left(\mathrm{SiO}_{2}\right.$, cyclohexane/ethyl acetate, $7 / 3, \mathrm{v} / \mathrm{v}$ ) to give the desired product $19 \mathrm{~b}$ as yellow oil $(170 \mathrm{mg}$, $0.35 \mathrm{mmol}, 63 \%) . \mathrm{R}_{\mathrm{f}}\left(\mathrm{SiO}_{2}\right.$, cyclohexane/ethyl acetate, 7/3, v/v): 0.31; IR $\left(\mathrm{cm}^{-1}\right): 2228\left(\mathrm{v}_{\mathrm{C} \equiv \mathrm{N}}\right)$, $1707\left(\mathrm{v}_{\mathrm{C}=\mathrm{O}}\right), 1645\left(\mathrm{v}_{\mathrm{C}=\mathrm{C}}\right), 1502\left(\mathrm{v}_{\mathrm{C}=\mathrm{C}}\right), 1281\left(\mathrm{v}_{\mathrm{C}-\mathrm{O}}\right), 1258\left(\mathrm{v}_{\mathrm{C}-\mathrm{O}}\right), 1102\left(\mathrm{v}_{\mathrm{C}-\mathrm{O}}\right), 1065\left(\mathrm{v}_{\mathrm{C}-\mathrm{O}}\right) ;{ }^{1} \mathrm{H}$ $\operatorname{NMR}\left(\mathrm{CDCl}_{3}, 400 \mathrm{MHz}\right) \delta 9.75\left(\mathrm{~s}, 1 \mathrm{H}, \mathrm{H}_{2}\right), 7.53\left(\mathrm{~m}, 2 \mathrm{H}, \mathrm{H}_{5} \& \mathrm{H}_{7}\right), 7.08\left(\mathrm{dd}, 1 \mathrm{H},{ }^{3} \mathrm{~J}_{\mathrm{H}^{\prime}-\mathrm{H}_{5}}=8.4\right.$ $\left.\mathrm{Hz},{ }^{4} J_{\mathrm{H}^{\prime} \mathrm{H}^{-} \mathrm{H}^{\prime}}=2.1 \mathrm{~Hz}, \mathrm{H}_{6^{\prime}}\right), 7.01\left(\mathrm{~d}, 1 \mathrm{H},{ }^{4} J_{\mathrm{H}_{2^{\prime}-\mathrm{H}^{\prime}}}=2.1 \mathrm{~Hz}, \mathrm{H}_{2^{\prime}}\right), 6.77\left(\mathrm{~d}, 1 \mathrm{H},{ }^{3} \mathrm{~J}_{\mathrm{H}^{\prime}{ }^{-} \mathrm{H}_{6^{\prime}}}=8.4 \mathrm{~Hz}\right.$, $\left.\mathrm{H}_{5^{\prime}}\right), 6.26\left(\mathrm{~d}, 1 \mathrm{H},{ }^{3} \mathrm{~J}_{\mathrm{H}_{\mathrm{b}}-\mathrm{H}_{\mathrm{a}}}=7.1 \mathrm{~Hz}, \mathrm{H}_{\mathrm{b}}\right), 5.64\left(\mathrm{~m}, 1 \mathrm{H}, \mathrm{H}_{\mathrm{g}}\right), 5.04\left(\mathrm{~d}, 1 \mathrm{H},{ }^{3} \mathrm{~J}_{\mathrm{H}_{\mathrm{a}}-\mathrm{H}_{\mathrm{b}}}=7.1 \mathrm{~Hz}, \mathrm{H}_{\mathrm{a}}\right)$, $4.98\left(\mathrm{~m}, 2 \mathrm{H}, \mathrm{H}_{\mathrm{f}}\right), 4.82\left(\mathrm{~d}, 1 \mathrm{H},{ }^{2} J_{\mathrm{H}_{\mathrm{d}^{-}-\mathrm{H}^{\prime}}}=14.3 \mathrm{~Hz}, \mathrm{H}_{\mathrm{d}}\right), 4.54\left(\mathrm{~d}, 1 \mathrm{H},{ }^{2} J_{\mathrm{H}^{\prime} \mathrm{H}^{\prime}-H_{\mathrm{d}}}=14.3 \mathrm{~Hz}, \mathrm{H}_{\mathrm{d}^{\prime}}\right), 4.47$ $\left(\mathrm{m}, 2 \mathrm{H}, \mathrm{H}_{\mathrm{h}}\right), 3.85\left(\mathrm{~s}, 3 \mathrm{H}, \mathrm{H}_{\mathrm{i}}\right), 3.81\left(\mathrm{~s}, 3 \mathrm{H}, \mathrm{H}_{\mathrm{c}}\right), 3.27\left(\mathrm{q}, 2 \mathrm{H},{ }^{3} \mathrm{~J}_{\mathrm{H}_{\mathrm{j}} \mathrm{H}_{\mathrm{k}}}=7.5 \mathrm{~Hz}, \mathrm{H}_{\mathrm{j}}\right), 1.36(\mathrm{t}, 3 \mathrm{H}$, $\left.{ }^{3} \mathrm{~J}_{\mathrm{H}_{\mathrm{k}}-\mathrm{H}_{\mathrm{j}}}=7.5 \mathrm{~Hz}, \mathrm{H}_{\mathrm{k}}\right) ;{ }^{13} \mathrm{C} \mathrm{NMR}\left(\mathrm{CDCl}_{3}, 100 \mathrm{MHz}\right) \delta 155.1\left(\mathrm{C}_{4^{\prime}}\right.$ or $\left.\mathrm{C}_{\mathrm{e}}\right), 155.0\left(\mathrm{C}_{4^{\prime}}\right.$ or $\left.\mathrm{C}_{\mathrm{e}}\right), 154.6$ $\left(\mathrm{C}_{2}\right), 151.5\left(\mathrm{C}_{\mathrm{b}}\right), 146.7\left(\mathrm{C}_{8 \mathrm{a}}\right), 145.1\left(\mathrm{C}_{8}\right), 139.9\left(\mathrm{C}_{4}\right), 132.1\left(\mathrm{C}_{\mathrm{g}}\right), 131.6\left(\mathrm{C}_{2^{\prime}}\right), 129.4\left(\mathrm{C}_{6^{\prime}}\right), 129.3$ $\left(\mathrm{C}_{1^{1}}\right), 128.6\left(\mathrm{C}_{3}\right), 127.5\left(\mathrm{C}_{5}\right.$ or $\left.\mathrm{C}_{7}\right), 127.4\left(\mathrm{C}_{5}\right.$ or $\left.\mathrm{C}_{7}\right), 125.7\left(\mathrm{C}_{4 \mathrm{a}}\right), 122.2\left(\mathrm{C}_{3^{\prime}}\right), 118.9(\mathrm{CN})$, $117.8\left(\mathrm{C}_{\mathrm{h}}\right), 112.0\left(\mathrm{C}_{5^{\prime}}\right), 110.3\left(\mathrm{C}_{6}\right), 97.2\left(\mathrm{C}_{\mathrm{a}}\right), 66.7\left(\mathrm{C}_{\mathrm{f}}\right), 61.3\left(\mathrm{C}_{\mathrm{c}}\right), 56.3\left(\mathrm{C}_{\mathrm{i}}\right), 53.0\left(\mathrm{C}_{\mathrm{d}}\right), 24.6$ $\left(\mathrm{C}_{\mathrm{j}}\right), \quad 14.7\left(\mathrm{C}_{\mathrm{k}}\right)$; HRMS calculated for $\mathrm{C}_{27} \mathrm{H}_{26}{ }^{35} \mathrm{CIN}_{3} \mathrm{O}_{4}[\mathrm{M}+\mathrm{H}]^{+} \mathrm{m} / \mathrm{z}$ 492.1690, found $\mathrm{C}_{27} \mathrm{H}_{26}{ }^{35} \mathrm{CIN}_{3} \mathrm{O}_{4}[\mathrm{M}+\mathrm{H}]^{+} \mathrm{m} / \mathrm{z} 492.1658$ (100\%); $\mathrm{C}_{27} \mathrm{H}_{26}{ }^{37} \mathrm{CIN}_{3} \mathrm{O}_{4}[\mathrm{M}+\mathrm{H}]^{+} \mathrm{m} / \mathrm{z} 494.1739$ (33\%).

\subsubsection{Allyl 3-chloro-4-methoxybenzyl[6-cyano-8-cyclopropyl-3-(2-oxoethyl)quinoline-}

4-yl]carbamate (20a). A mixture of $19 a(170 \mathrm{mg}, 0.34 \mathrm{mmol}, 1.0$ eq.) in formic acid (10 mL) was stirred at $50{ }^{\circ} \mathrm{C}$ for 20 hours. After cooling to rt, the solvent was evaporated under reduced pressure. The residue was dissolved in ethyl acetate $(20 \mathrm{~mL})$ before addition of a saturated aqueous sodium carbonate solution $(25 \mathrm{~mL})$. After decantation, the aqueous layer was then extracted with ethyl acetate $(2 \times 20 \mathrm{~mL})$. The combined organic layers were washed with brine $(60 \mathrm{~mL})$, dried over anhydrous magnesium sulfate, filtered, and concentrated under reduced pressure. The residue was purified by column chromatography $\left(\mathrm{SiO}_{2}\right.$, cyclohexane/ethyl acetate, $\left.7 / 3, \mathrm{v} / \mathrm{v}\right)$ to give the desired product 20a (100 mg, 0.20 $\mathrm{mmol}, 60 \%)$ as yellow oil. $\mathrm{R}_{\mathrm{f}}\left(\mathrm{SiO}_{2}\right.$, cyclohexane/ethyl acetate, $\left.5 / 5, \mathrm{v} / \mathrm{v}\right): 0.33 ; \mathrm{IR}\left(\mathrm{cm}^{-1}\right): 2228$ $\left(\mathrm{v}_{\mathrm{C} \equiv \mathrm{N}}\right), 1702\left(\mathrm{v}_{\mathrm{C}=\mathrm{O}}\right), 1501\left(\mathrm{v}_{\mathrm{C}=\mathrm{C}}\right), 1387\left(\delta_{\mathrm{CH}_{3}}\right), 1257\left(\mathrm{v}_{\mathrm{C}-\mathrm{O}}\right), 1064\left(\mathrm{v}_{\mathrm{C}-\mathrm{O}}\right), 1020\left(\mathrm{v}_{\mathrm{C}-\mathrm{O}}\right)$; Analyses of NMR spectra revealed that this product was a mixture of two rotamers, named $A$ and $B$ with a ratio $\mathrm{A} / \mathrm{B}=1 / 0.3 ;{ }^{1} \mathrm{H} \mathrm{NMR}\left(\mathrm{CDCl}_{3}, 400 \mathrm{MHz}\right) \delta 9.48\left(\mathrm{~s}, 1 \mathrm{H}, \mathrm{H}_{\mathrm{b}(\mathrm{A} / \mathrm{B})}\right), 8.96\left(\mathrm{~s}, 1 \mathrm{H}, \mathrm{H}_{2(\mathrm{~B})}\right), 8.93$ (s, $\left.1 \mathrm{H}, \mathrm{H}_{2(\mathrm{~A})}\right), 7.80\left(\mathrm{~m}, 1 \mathrm{H}, \mathrm{H}_{5(\mathrm{~B})}\right), 7.72\left(\mathrm{~d}, 1 \mathrm{H},{ }^{4} \mathrm{~J}_{\left.\mathrm{H}_{5(\mathrm{~A})}\right)^{-\mathrm{H}(\mathrm{A})}}=1.6 \mathrm{~Hz}, \mathrm{H}_{5(\mathrm{~A})}\right), 7.26\left(\mathrm{~m}, 1 \mathrm{H}, \mathrm{H}_{7(\mathrm{~A} / \mathrm{B})}\right)$,

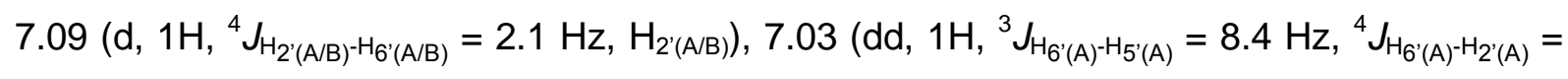
$\left.2.1 \mathrm{~Hz}, \mathrm{H}_{6^{\prime}(\mathrm{A})}\right), 6.89\left(\mathrm{~m}, 1 \mathrm{H}, \mathrm{H}_{6^{\prime}(\mathrm{B})}\right), 6.80\left(\mathrm{~d}, 1 \mathrm{H},{ }^{3} J_{\mathrm{H}_{5^{\prime}}(\mathrm{A})^{-H_{6^{\prime}}(\mathrm{A})}}=8.4 \mathrm{~Hz}, \mathrm{H}_{5^{\prime}(\mathrm{A})}\right), 6.78\left(\mathrm{~d}, 1 \mathrm{H}^{3}{ }^{3} J_{\mathrm{H}^{\prime}(\mathrm{B})^{-}}\right.$ $\left.\mathrm{H}_{6^{\prime}(B)}=8.4 \mathrm{~Hz}, \mathrm{H}_{5^{\prime}(B)}\right), 6.11\left(\mathrm{~m}, 1 \mathrm{H}, \mathrm{H}_{\mathrm{f}(\mathrm{B})}\right), 5.65\left(\mathrm{~m}, 1 \mathrm{H}, \mathrm{H}_{\mathrm{f}(\mathrm{A})}\right), 5.46\left(\mathrm{~m}, 2 \mathrm{H}, \mathrm{H}_{\mathrm{g}(\mathrm{B})}\right), 5.03(\mathrm{~m}, 3 \mathrm{H}$, $\left.\mathrm{H}_{\mathrm{g}(\mathrm{A})}, \mathrm{H}_{\mathrm{c}(\mathrm{A} / \mathrm{B})}\right), 4.80\left(\mathrm{~m}, 2 \mathrm{H}, \mathrm{H}_{\mathrm{e}(\mathrm{B})}\right), 4.49\left(\mathrm{~m}, 2 \mathrm{H}, \mathrm{H}_{\mathrm{e}(\mathrm{A})}\right), 4.39\left(\mathrm{~d}, 1 \mathrm{H},{ }^{2} J_{\left.\mathrm{H}_{\mathrm{C}^{\prime}(B)}\right)^{-H_{\mathrm{C}}(B)}}=14.7 \mathrm{~Hz}, \mathrm{H}_{\mathrm{c}^{\prime}(B)}\right)$, $4.38\left(\mathrm{~d}, 1 \mathrm{H},{ }^{2} J_{\left.\mathrm{H}_{\mathrm{c}^{\prime}}(\mathrm{A})\right)^{-H_{\mathrm{c}}(\mathrm{A})}}=14.7 \mathrm{~Hz}, \mathrm{H}_{\mathrm{c}^{\prime}(\mathrm{A})}\right), 3.87\left(\mathrm{~s}, 3 \mathrm{H}, \mathrm{H}_{\mathrm{h}(\mathrm{A} / \mathrm{B})}\right), 3.48\left(\mathrm{~m}, 2 \mathrm{H}, \mathrm{H}_{\mathrm{a}(\mathrm{A} / \mathrm{B})}\right), 3.23(\mathrm{~m}$, 
$\left.1 \mathrm{H}, \mathrm{H}_{\mathrm{i}(\mathrm{A} / \mathrm{B})}\right), 1.26\left(\mathrm{~m}, 2 \mathrm{H}, \mathrm{H}_{\mathrm{j}(\mathrm{A} / \mathrm{B})}\right.$ or $\left.\mathrm{H}_{\mathrm{j}^{\prime}(\mathrm{A} / \mathrm{B})}\right), 0.91\left(\mathrm{~m}, 2 \mathrm{H}, \mathrm{H}_{\mathrm{j}(\mathrm{A} / \mathrm{B})}\right.$ or $\left.\mathrm{H}_{\mathrm{j}^{\prime}(\mathrm{A} / \mathrm{B})}\right) ;{ }^{13} \mathrm{C} \mathrm{NMR}\left(\mathrm{CDCl}_{3}, 100\right.$ $\mathrm{MHz}) \delta 197.0\left(\mathrm{C}_{\mathrm{b}(\mathrm{B})}\right), 196.3\left(\mathrm{C}_{\mathrm{b}(\mathrm{A})}\right), 155.3\left(\mathrm{C}_{4^{\prime}(\mathrm{A} / \mathrm{B})}\right), 154.7\left(\mathrm{C}_{\mathrm{d}(\mathrm{A} / \mathrm{B})}\right), 154.6\left(\mathrm{C}_{2(\mathrm{~A} / \mathrm{B})}\right), 149.3$ $\left(\mathrm{C}_{8 \mathrm{a}(\mathrm{A} / \mathrm{B})}\right), 146.5\left(\mathrm{C}_{8(\mathrm{~A} / \mathrm{B})}\right), 144.5\left(\mathrm{C}_{4(\mathrm{~A} / \mathrm{B})}\right), 131.9\left(\mathrm{C}_{\mathrm{f}(\mathrm{B})}\right), 131.7\left(\mathrm{C}_{\mathrm{f}(\mathrm{A})}\right), 131.4\left(\mathrm{C}_{2^{\prime}(\mathrm{A})}\right), 131.3\left(\mathrm{C}_{2^{\prime}(\mathrm{B})}\right)$, $129.3\left(\mathrm{C}_{6^{\prime}(\mathrm{A} / \mathrm{B})}\right), 129.0\left(\mathrm{C}_{1^{\prime}(\mathrm{A})}\right), 128.9\left(\mathrm{C}_{1^{\prime}(\mathrm{B})}\right), 126.0\left(\mathrm{C}_{3(\mathrm{~A} / \mathrm{B})}\right), 125.9\left(\mathrm{C}_{5(\mathrm{~A} / \mathrm{B})}\right), 125.1\left(\mathrm{C}_{4 a(\mathrm{~A} / \mathrm{B})}\right)$, $124.0\left(\mathrm{C}_{7(\mathrm{~A} / \mathrm{B})}\right), 122.7\left(\mathrm{C}_{3^{\prime}(\mathrm{A} / \mathrm{B})}\right), 119.9\left(\mathrm{C}_{\mathrm{g}(\mathrm{B})}\right), 119.0\left(\mathrm{C}_{\mathrm{g}(\mathrm{A})}\right), 118.7\left(\mathrm{CN}_{(\mathrm{A} / \mathrm{B})}\right), 112.2\left(\mathrm{C}_{5^{\prime}(\mathrm{A} / \mathrm{B})}\right), 111.4$ $\left(\mathrm{C}_{6(\mathrm{~A} / \mathrm{B})}\right), 67.8\left(\mathrm{C}_{\mathrm{e}(\mathrm{B})}\right), 67.3\left(\mathrm{C}_{\mathrm{e}(\mathrm{A})}\right), 56.3\left(\mathrm{C}_{\mathrm{h}(\mathrm{A} / \mathrm{B})}\right), 53.5\left(\mathrm{C}_{\mathrm{c}(\mathrm{B})}\right), 53.3\left(\mathrm{C}_{\mathrm{c}(\mathrm{A})}\right), 43.8\left(\mathrm{C}_{\mathrm{a}(\mathrm{B})}\right), 43.5$ $\left(\mathrm{C}_{\mathrm{a}(\mathrm{A})}\right), 11.0\left(\mathrm{C}_{\mathrm{i}(\mathrm{B})}\right), 10.9\left(\mathrm{C}_{\mathrm{i}(\mathrm{A})}\right), 10.7\left(\mathrm{C}_{\mathrm{j}(\mathrm{A})}\right.$ or $\left.\mathrm{C}_{\mathrm{j}^{\prime}(\mathrm{A})}\right), 10.5\left(\mathrm{C}_{\mathrm{j}(\mathrm{B})}\right.$ or $\left.\mathrm{C}_{\mathrm{j}^{\prime}(\mathrm{B})}\right)$; ESI-MS calculated for $\mathrm{C}_{27} \mathrm{H}_{24}{ }^{35} \mathrm{CIN}_{3} \mathrm{O}_{4}[\mathrm{M}+\mathrm{H}]^{+} \mathrm{m} / \mathrm{z} \quad 490.15$, found $\mathrm{C}_{27} \mathrm{H}_{24}{ }^{35} \mathrm{CIN}_{3} \mathrm{O}_{4}[\mathrm{M}+\mathrm{H}]^{+} \mathrm{m} / \mathrm{z} \quad 490.14$ (100\%); $\mathrm{C}_{27} \mathrm{H}_{24}{ }^{37} \mathrm{CIN}_{3} \mathrm{O}_{4}[\mathrm{M}+\mathrm{H}]^{+} \mathrm{m} / \mathrm{z} 492.10$ (33\%).

\subsubsection{Allyl 3-chloro-4-methoxybenzyl[6-cyano-8-ethyl-3-(2-oxoethyl)quinoline-4-}

yl]carbamate (20b). A mixture of $19 \mathrm{~b}(170 \mathrm{mg}, 0.35 \mathrm{mmol}, 1.0$ eq.) in formic acid (10 mL) was stirred at $50{ }^{\circ} \mathrm{C}$ for 20 hours. After cooling to rt, the solvent was evaporated under reduced pressure. The residue was dissolved in ethyl acetate $(30 \mathrm{~mL})$ before addition of a saturated aqueous sodium carbonate solution $(30 \mathrm{~mL})$. After decantation, the aqueous layer was extracted ethyl acetate $(2 \times 20 \mathrm{~mL})$. The combined organic layers were washed with brine $(100 \mathrm{~mL})$, dried over anhydrous magnesium sulfate, filtered, and concentrated under reduced pressure. The residue was purified by column chromatography $\left(\mathrm{SiO}_{2}\right.$, cyclohexane/ethyl acetate, 6/4, v/v) to give the product $20 \mathrm{~b}(0.11 \mathrm{~g}, 0.23 \mathrm{mmol}, 67 \%)$ as yellow oil. $\mathrm{R}_{\mathrm{f}}\left(\mathrm{SiO}_{2}\right.$, cyclohexane/ethyl acetate, 6/4, v / v): 0.24; IR $\left(\mathrm{cm}^{-1}\right): 2224\left(\mathrm{v}_{\mathrm{C} \equiv \mathrm{N}}\right), 1705$ $\left(\mathrm{v}_{\mathrm{C}=\mathrm{O}}\right), 1260\left(\mathrm{v}_{\mathrm{C}-\mathrm{O}}\right), 1065\left(\mathrm{v}_{\mathrm{C}-\mathrm{O}}\right)$; Analyses of NMR spectra revealed that this product was a mixture of two rotamers, named $A$ and $B$ with a ratio $A / B=1 / 0.3 .{ }^{1} \mathrm{H} \mathrm{NMR}\left(\mathrm{CDCl}_{3}, 400 \mathrm{MHz}\right)$ $\delta 9.48\left(\mathrm{~s}, 1 \mathrm{H}, \mathrm{H}_{\mathrm{b}(\mathrm{A} / \mathrm{B})}\right), 8.92\left(\mathrm{~s}, 1 \mathrm{H}, \mathrm{H}_{2(\mathrm{~B})}\right), 8.89\left(\mathrm{~s}, 1 \mathrm{H}, \mathrm{H}_{2(\mathrm{~A})}\right), 7.85\left(\mathrm{~m}, 1 \mathrm{H}, \mathrm{H}_{5(\mathrm{~B})}\right), 7.78(\mathrm{~d}, 1 \mathrm{H}$, $\left.\left.{ }^{4} J_{\left.H_{5(A)}\right)^{-H} 7(A)}=1.7 \mathrm{~Hz}, H_{5(A)}\right), 7.68\left(m, 1 H, H_{7(A / B)}\right), 7.08\left(\mathrm{~d}, 1 \mathrm{H},{ }^{4} J_{H^{\prime}(A / B)}\right)^{-H_{6^{\prime}(A / B)}}=2.1 \mathrm{~Hz}, \mathrm{H}_{2^{\prime}(\mathrm{A} / \mathrm{B})}\right)$, $7.03\left(\mathrm{dd}, 1 \mathrm{H},{ }^{3} \mathrm{~J}_{\mathrm{H}^{\prime}(\mathrm{A})-\mathrm{H}_{5^{\prime}(\mathrm{A})}}=8.4 \mathrm{~Hz},{ }^{4} \mathrm{~J}_{\mathrm{H}^{\prime}(\mathrm{A})-\mathrm{H}_{2^{\prime}(\mathrm{A})}}=2.1 \mathrm{~Hz}, \mathrm{H}_{6^{\prime}(\mathrm{A})}\right), 6.89\left(\mathrm{~m}, 1 \mathrm{H}, \mathrm{H}_{6^{\prime}(\mathrm{B})}\right), 6.80(\mathrm{~d}$, $\left.1 \mathrm{H},{ }^{3} J_{\mathrm{H}^{\prime}(\mathrm{A})-\mathrm{H}_{6^{\prime}(\mathrm{A})}}=8.4 \mathrm{~Hz}, \mathrm{H}_{5^{\prime}(\mathrm{A})}\right), 6.78\left(\mathrm{~d}, 1 \mathrm{H},{ }^{3} \mathrm{~J}_{\mathrm{H}^{\prime}(\mathrm{B}) \mathrm{H}_{6^{\prime}(\mathrm{B})}}=8.4 \mathrm{~Hz}, \mathrm{H}_{5^{\prime}(\mathrm{B})}\right), 6.10\left(\mathrm{~m}, 1 \mathrm{H}, \mathrm{H}_{\mathrm{f}(\mathrm{B})}\right)$, $5.65\left(\mathrm{~m}, 1 \mathrm{H}, \mathrm{H}_{\mathrm{f}(\mathrm{A})}\right), 5.50\left(\mathrm{~d}, 1 \mathrm{H},{ }^{3} \mathrm{~J}_{\mathrm{H}_{\mathrm{g}(\mathrm{B})}-\mathrm{H}_{\mathrm{f}(\mathrm{B})}}=17.2 \mathrm{~Hz}, \mathrm{H}_{\mathrm{g}(\mathrm{B})}\right), 5.42\left(\mathrm{~d}, 1 \mathrm{H},{ }^{3} \mathrm{~J}_{\mathrm{Hg}^{\prime}(\mathrm{B})}{ }^{-\mathrm{H}_{\mathrm{f}}(\mathrm{B})}=10.3 \mathrm{~Hz}\right.$, $\left.\mathrm{H}_{\mathrm{g}^{\prime}(\mathrm{B})}\right), 5.02\left(\mathrm{~m}, 3 \mathrm{H}, \mathrm{H}_{\mathrm{g}(\mathrm{A})}, \mathrm{H}_{\mathrm{C}(\mathrm{A} / \mathrm{B})}\right), 4.81\left(\mathrm{~m}, 2 \mathrm{H}, \mathrm{H}_{\mathrm{e}(\mathrm{B})}\right), 4.48\left(\mathrm{~m}, 2 \mathrm{H}, \mathrm{H}_{\mathrm{e}(\mathrm{A})}\right), 4.40\left(\mathrm{~d}, 1 \mathrm{H}^{2}{ }^{2} J_{\mathrm{H}_{\mathrm{c}^{\prime}(B)}}\right.$

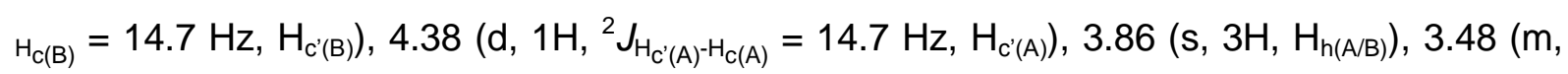
$\left.2 \mathrm{H}, \mathrm{H}_{\mathrm{a}(\mathrm{A} / \mathrm{B})}\right), 3.32\left(\mathrm{q}, 2 \mathrm{H},{ }^{3} \mathrm{~J}_{\mathrm{Hi}(\mathrm{A} / \mathrm{B})-\mathrm{Hj}(\mathrm{A} / \mathrm{B})}=7.5 \mathrm{~Hz}, \mathrm{H}_{\mathrm{i}(\mathrm{A} / \mathrm{B})}\right), 1.39\left(\mathrm{t}, 3 \mathrm{H},{ }^{3} \mathrm{~J}_{\mathrm{Hj}(\mathrm{A} / \mathrm{B})-\mathrm{H}(\mathrm{A} / \mathrm{B})}=7.5 \mathrm{~Hz}\right.$, $\left.\mathrm{H}_{\mathrm{j}(\mathrm{A} / \mathrm{B})}\right) ;{ }^{13} \mathrm{C} \mathrm{NMR}\left(\mathrm{CDCl}_{3}, 100 \mathrm{MHz}\right) \delta 197.0\left(\mathrm{C}_{\mathrm{b}(\mathrm{B})}\right), 196.4\left(\mathrm{C}_{\mathrm{b}(\mathrm{A})}\right), 155.3\left(\mathrm{C}_{4^{\prime}(\mathrm{A} / \mathrm{B})}\right), 154.8$ $\left(\mathrm{C}_{\mathrm{d}(\mathrm{A} / \mathrm{B})}\right), 154.6\left(\mathrm{C}_{2(\mathrm{~A} / \mathrm{B})}\right), 148.6\left(\mathrm{C}_{8 \mathrm{a}(\mathrm{A} / \mathrm{B})}\right), 146.1\left(\mathrm{C}_{8(\mathrm{~A} / \mathrm{B})}\right), 144.5\left(\mathrm{C}_{4(\mathrm{~A} / \mathrm{B})}\right), 131.7\left(\mathrm{C}_{\mathrm{f}(\mathrm{A} / \mathrm{B})}\right), 131.4$ $\left(\mathrm{C}_{2^{\prime}(\mathrm{A} / \mathrm{B})}\right), 129.3\left(\mathrm{C}_{6^{\prime}(\mathrm{A} / \mathrm{B})}\right), 129.0\left(\mathrm{C}_{1^{\prime}(\mathrm{A} / \mathrm{B})}\right), 128.8\left(\mathrm{C}_{5(\mathrm{~A} / \mathrm{B})}\right), 127.1\left(\mathrm{C}_{7(\mathrm{~A} / \mathrm{B})}\right), 125.9\left(\mathrm{C}_{3(\mathrm{~A} / \mathrm{B})}\right), 125.2$ $\left(\mathrm{C}_{4 \mathrm{a}(\mathrm{A} / \mathrm{B})}\right), 122.7\left(\mathrm{C}_{3^{\prime}(\mathrm{A} / \mathrm{B})}\right), 119.9\left(\mathrm{C}_{\mathrm{g}(\mathrm{B})}\right), 119.0\left(\mathrm{C}_{\mathrm{g}(\mathrm{A})}\right), 118.7\left(\mathrm{CN}_{(\mathrm{A} / \mathrm{B})}\right), 112.2\left(\mathrm{C}_{5^{\prime}(\mathrm{A} / \mathrm{B})}\right), 111.3$ $\left(\mathrm{C}_{6(\mathrm{~A} / \mathrm{B})}\right), 67.8\left(\mathrm{C}_{\mathrm{e}(\mathrm{B})}\right), 67.3\left(\mathrm{C}_{\mathrm{e}(\mathrm{A})}\right), 56.3\left(\mathrm{C}_{\mathrm{h}(\mathrm{A} / \mathrm{B})}\right), 53.5\left(\mathrm{C}_{\mathrm{c}(\mathrm{B})}\right), 53.4\left(\mathrm{C}_{\mathrm{c}(\mathrm{A})}\right), 43.8\left(\mathrm{C}_{\mathrm{a}(\mathrm{B})}\right), 43.5$ $\left(\mathrm{C}_{\mathrm{a}(\mathrm{A})}\right), 24.7\left(\mathrm{C}_{\mathrm{i}(\mathrm{B})}\right), 24.6\left(\mathrm{C}_{\mathrm{i}(\mathrm{A})}\right), 14.8\left(\mathrm{C}_{\mathrm{j}(\mathrm{B})}\right), 14.6\left(\mathrm{C}_{\mathrm{j}(\mathrm{A})}\right)$; ESI-MS calculated for $\mathrm{C}_{26} \mathrm{H}_{24}{ }^{35} \mathrm{CIN}_{3} \mathrm{O}_{4}$ 
$[\mathrm{M}+\mathrm{H}]^{+} \mathrm{m} / \mathrm{z} 478.15$, found $\mathrm{C}_{26} \mathrm{H}_{24}{ }^{35} \mathrm{CIN}_{3} \mathrm{O}_{4}[\mathrm{M}+\mathrm{H}]^{+} \mathrm{m} / \mathrm{z} 478.05(100 \%) ; \mathrm{C}_{26} \mathrm{H}_{24}{ }^{37} \mathrm{CIN}_{3} \mathrm{O}_{4}[\mathrm{M}+\mathrm{H}]^{+}$ $\mathrm{m} / \mathrm{z} 480.11$ (33\%).

4.1.17.

4-[(3-Chloro-4-methoxybenzyl)amino]-8-cyclopropyl-3-(2-

hydroxyethyl)quinoline-6-carbonitrile (21a). A $1.1 \mathrm{M}$ solution of lithium tri-tertbutoxyaluminum hydride in tetrahydrofuran $(1.7 \mathrm{~mL}, 1.87 \mathrm{mmol}, 3.0$ eq.) was added, under argon and stirring, to a solution of $20 \mathrm{a}$ (300 $\mathrm{mg}, 0.61 \mathrm{mmol}, 1.0$ eq.) in anhydrous tetrahydrofuran $(30 \mathrm{~mL})$. The resulting mixture was stirred at $60^{\circ} \mathrm{C}$ for 20 hours. After cooling to rt, water $(50 \mathrm{~mL})$ was slowly added under stirring. This aqueous layer was then extracted with dichloromethane $(100 \mathrm{~mL})$ using a Soxhlet extractor for 20 hours. The organic layer was concentrated under reduced pressure. The residue was purified by column chromatography $\left(\mathrm{SiO}_{2}\right.$, ethanol/dichloromethane, 1/9, v/v) to give the desired product 21a (130 mg, 0.32 mmol, 52\%) as a yellow oil. $\mathrm{R}_{\mathrm{f}}\left(\mathrm{SiO}_{2}\right.$, dichloromethane/ethanol, 9/1, v/v): 0.20; IR $\left(\mathrm{cm}^{-1}\right): 2226$ $\left(\mathrm{v}_{\mathrm{C} \equiv \mathrm{N}}\right), 1500\left(\mathrm{v}_{\mathrm{C}=\mathrm{C}}\right), 1257\left(\mathrm{v}_{\mathrm{C}-\mathrm{O}}\right), 1062\left(\mathrm{v}_{\mathrm{C}-\mathrm{O}}\right), 1020\left(\mathrm{v}_{\mathrm{C}-\mathrm{O}}\right) ;{ }^{1} \mathrm{H} \mathrm{NMR}\left(\mathrm{CDCl}_{3}, 400 \mathrm{MHz}\right) \delta 8.56(\mathrm{~s}$, $\left.1 \mathrm{H}, \mathrm{H}_{2}\right), 8.20\left(\mathrm{~d}, 1 \mathrm{H},{ }^{4} \mathrm{~J}_{\mathrm{H}_{5}-\mathrm{H}_{7}}=1.7 \mathrm{~Hz}, \mathrm{H}_{5}\right), 7.29\left(\mathrm{~d}, 1 \mathrm{H},{ }^{4} J_{\mathrm{H}_{2}-\mathrm{H}_{6^{\prime}}}=2.2 \mathrm{~Hz}, \mathrm{H}_{2^{\prime}}\right), 7.17\left(\mathrm{~d}, 1 \mathrm{H},{ }^{4} J_{\mathrm{H}^{-}}\right.$ $\left.\mathrm{H}_{5}=1.7 \mathrm{~Hz}, \mathrm{H}_{7}\right), 7.09\left(\mathrm{dd}, 1 \mathrm{H},{ }^{3} J_{\mathrm{H}_{6^{\prime}} \mathrm{H}^{\prime}}=8.4 \mathrm{~Hz},{ }^{4} \mathrm{~J}_{\mathrm{H}^{\prime} \mathrm{H}^{\prime} \mathrm{H}^{\prime}}=2.2 \mathrm{~Hz}, \mathrm{H}_{6^{\prime}}\right), 6.86\left(\mathrm{~d}, 1 \mathrm{H},{ }^{3} J_{\mathrm{H}_{5^{\prime}} \cdot \mathrm{H}_{6^{\prime}}}=\right.$ $\left.8.4 \mathrm{~Hz}, \mathrm{H}_{5}\right), 4.48\left(\mathrm{~s}, 2 \mathrm{H}, \mathrm{H}_{\mathrm{c}}\right), 3.86\left(\mathrm{~s}, 3 \mathrm{H}, \mathrm{H}_{\mathrm{d}}\right), 3.83\left(\mathrm{t}, 2 \mathrm{H},{ }^{3} \mathrm{~J}_{\mathrm{H}_{\mathrm{b}}-\mathrm{H}_{\mathrm{a}}}=5.8 \mathrm{~Hz}, \mathrm{H}_{\mathrm{b}}\right), 2.92(\mathrm{~m}, 1 \mathrm{H}$, $\left.\mathrm{H}_{\mathrm{e}}\right), 2.80\left(\mathrm{t}, 2 \mathrm{H},{ }^{3} \mathrm{~J}_{\mathrm{H}_{\mathrm{a}}-\mathrm{H}_{\mathrm{b}}}=5.8 \mathrm{~Hz}, \mathrm{H}_{\mathrm{a}}\right), 1.15\left(\mathrm{~m}, 2 \mathrm{H}, \mathrm{H}_{\mathrm{f}}\right.$ or $\left.\mathrm{H}_{\mathrm{f}}\right), 0.77\left(\mathrm{~m}, 2 \mathrm{H}, \mathrm{H}_{\mathrm{f}}\right.$ or $\left.\mathrm{H}_{\mathrm{f}}\right) ;{ }^{13} \mathrm{C} N M R$ $\left(\mathrm{CDCl}_{3}, 100 \mathrm{MHz}\right) \delta 154.7\left(\mathrm{C}_{4^{\prime}}\right), 153.4\left(\mathrm{C}_{2}\right), 153.0\left(\mathrm{C}_{4}\right), 149.0\left(\mathrm{C}_{8 \mathrm{a}}\right), 144.4\left(\mathrm{C}_{8}\right), 132.1\left(\mathrm{C}_{1^{\prime}}\right)$, $129.4\left(\mathrm{C}_{2^{\prime}}\right), 127.8\left(\mathrm{C}_{5}\right), 127.0\left(\mathrm{C}_{6^{\prime}}\right), 123.8\left(\mathrm{C}_{7}\right), 122.8\left(\mathrm{C}_{3^{\prime}}\right), 121.0\left(\mathrm{C}_{4 \mathrm{a}}\right), 120.8\left(\mathrm{C}_{3}\right), 119.4$ $(\mathrm{CN}), 112.4\left(\mathrm{C}_{5^{\prime}}\right), 107.8\left(\mathrm{C}_{6}\right), 63.2\left(\mathrm{C}_{\mathrm{b}}\right), 56.3\left(\mathrm{C}_{\mathrm{d}}\right), 53.0\left(\mathrm{C}_{\mathrm{c}}\right), 32.8\left(\mathrm{C}_{\mathrm{a}}\right), 11.3\left(\mathrm{C}_{\mathrm{e}}\right), 9.6\left(2 \mathrm{C}, \mathrm{C}_{\mathrm{f}}\right.$, $\mathrm{C}_{\mathrm{f}}$ ); HRMS calculated for $\mathrm{C}_{23} \mathrm{H}_{22}{ }^{35} \mathrm{CIN}_{3} \mathrm{O}_{2}[\mathrm{M}+\mathrm{H}]^{+} \mathrm{m} / \mathrm{z} 408.1479$, found $\mathrm{C}_{23} \mathrm{H}_{22}{ }^{35} \mathrm{CIN}_{3} \mathrm{O}_{2}[\mathrm{M}+\mathrm{H}]^{+}$ $\mathrm{m} / \mathrm{z} 408.1478$ (100\%); $\mathrm{C}_{23} \mathrm{H}_{22}{ }^{37} \mathrm{CIN}_{3} \mathrm{O}_{2}[\mathrm{M}+\mathrm{H}]^{+} \mathrm{m} / \mathrm{z} 410.1430$ (33\%).

\subsubsection{4-[(3-Chloro-4-methoxybenzyl)amino]-8-ethyl-3-(2-hydroxyethyl)quinoline-6-} carbonitrile (21b). A $1.1 \mathrm{M}$ solution of lithium tri-tert-butoxyaluminum hydride in tetrahydrofuran ( $0.63 \mathrm{~mL}, 0.69 \mathrm{mmol}, 3.0$ eq.) was added, under argon and stirring, to a solution of $20 \mathrm{~b}$ (110 mg, $0.23 \mathrm{mmol}, 1.0$ eq.) in anhydrous tetrahydrofuran (15 mL). The resulting mixture was stirred at $60{ }^{\circ} \mathrm{C}$ for 20 hours. After cooling to rt, water $(3 \mathrm{~mL})$ was added slowly and the mixture was stirred at this temperature for 4 hours. The solid formed was filtered and washed with ethyl acetate $(20 \mathrm{~mL})$. The filtrate was concentrated under reduced pressure. The residue obtained was purified by column chromatography $\left(\mathrm{SiO}_{2}\right.$, ethanol/dichloromethane, $1 / 9, \mathrm{v} / \mathrm{v}$ ) to give the desired product $21 \mathrm{~b}(40 \mathrm{mg}, 0.10 \mathrm{mmol}, 44 \%$ ) as a yellow solid. $\mathrm{R}_{\mathrm{f}}\left(\mathrm{SiO}_{2}\right.$, ethanol/dichloromethane, 1/9, v/v): 0.20; IR $\left(\mathrm{cm}^{-1}\right): 2226\left(\mathrm{v}_{\mathrm{C} \equiv \mathrm{N}}\right)$, $1504\left(\delta_{\mathrm{N}-\mathrm{H}}\right), 1279\left(\mathrm{v}_{\mathrm{C}-\mathrm{O}}\right), 1261\left(\mathrm{v}_{\mathrm{C}-\mathrm{O}}\right), 1048\left(\mathrm{v}_{\mathrm{C}-\mathrm{O}}\right), 1024\left(\mathrm{v}_{\mathrm{C}-\mathrm{O}}\right) ;{ }^{1} \mathrm{H}$ NMR $\left(\mathrm{CDCl}_{3}, 400 \mathrm{MHz}\right) \delta$ $8.55\left(\mathrm{~s}, 1 \mathrm{H}, \mathrm{H}_{2}\right), 8.28\left(\mathrm{~d}, 1 \mathrm{H},{ }^{4} \mathrm{~J}_{\mathrm{H}_{5} \mathrm{H}_{7}}=1.7 \mathrm{~Hz}, \mathrm{H}_{5}\right), 7.54\left(\mathrm{~m}, 1 \mathrm{H}, \mathrm{H}_{7}\right), 7.30\left(\mathrm{~d}, 1 \mathrm{H},{ }^{4} \mathrm{~J}_{\mathrm{H}_{2}-\mathrm{H}_{6^{\prime}}}=2.1\right.$ $\left.\mathrm{Hz}, \mathrm{H}_{2^{\prime}}\right), 7.12\left(\mathrm{dd}, 1 \mathrm{H},{ }^{3} J_{\mathrm{H}_{6^{\prime}}-\mathrm{H}^{\prime}}=8.4 \mathrm{~Hz},{ }^{4} J_{\mathrm{H}^{\prime} \mathrm{H}^{-} \mathrm{H}^{\prime}}=2.1 \mathrm{~Hz}, \mathrm{H}_{6^{\prime}}\right), 6.88\left(\mathrm{~d}, 1 \mathrm{H},{ }^{3} J_{\mathrm{H}^{\prime}{ }^{\prime}-\mathrm{H}_{6^{\prime}}}=8.4 \mathrm{~Hz}\right.$, 
$\left.\mathrm{H}_{5^{\prime}}\right), 4.49\left(\mathrm{~s}, 2 \mathrm{H}, \mathrm{H}_{\mathrm{c}}\right), 3.88\left(\mathrm{~s}, 3 \mathrm{H}, \mathrm{H}_{\mathrm{d}}\right), 3.86\left(\mathrm{t}, 2 \mathrm{H},{ }^{3} \mathrm{~J}_{\mathrm{H}_{\mathrm{b}}-\mathrm{H}_{\mathrm{a}}}=5.8 \mathrm{~Hz}, \mathrm{H}_{\mathrm{b}}\right), 3.19\left(\mathrm{q}, 2 \mathrm{H},{ }^{3} \mathrm{~J}_{\mathrm{H}_{\mathrm{e}}-\mathrm{H}_{\mathrm{f}}}=\right.$ $\left.7.5 \mathrm{~Hz}, \mathrm{H}_{\mathrm{e}}\right), 2.82\left(\mathrm{t}, 2 \mathrm{H},{ }^{3} \mathrm{~J}_{\mathrm{H}_{\mathrm{a}} \mathrm{H}_{\mathrm{b}}}=5.8 \mathrm{~Hz}, \mathrm{H}_{\mathrm{a}}\right), 1.33\left(\mathrm{t}, 3 \mathrm{H},{ }^{3} \mathrm{~J}_{\mathrm{H}_{\mathrm{f}}-\mathrm{H}_{\mathrm{e}}}=7.5 \mathrm{~Hz}, \mathrm{H}_{\mathrm{f}}\right) ;{ }^{13} \mathrm{C} \mathrm{NMR}$ $\left(\mathrm{CDCl}_{3}, 100 \mathrm{MHz}\right) \delta 154.7\left(\mathrm{C}_{4^{\prime}}\right), 153.8\left(\mathrm{C}_{2}\right), 152.7\left(\mathrm{C}_{4}\right), 148.6\left(\mathrm{C}_{8 \mathrm{a}}\right), 144.8\left(\mathrm{C}_{8}\right), 132.3\left(\mathrm{C}_{1^{\prime}}\right)$, $129.5\left(\mathrm{C}_{2^{\prime}}\right), 128.5\left(\mathrm{C}_{5}\right), 127.6\left(\mathrm{C}_{7}\right), 127.0\left(\mathrm{C}_{6^{\prime}}\right), 122.8\left(\mathrm{C}_{3^{\prime}}\right), 121.4\left(\mathrm{C}_{4 \mathrm{a}}\right), 120.9\left(\mathrm{C}_{3}\right), 119.6$ $(\mathrm{CN}), 112.4\left(\mathrm{C}_{5}\right), 107.8\left(\mathrm{C}_{6}\right), 63.4\left(\mathrm{C}_{\mathrm{b}}\right), 56.3\left(\mathrm{C}_{\mathrm{d}}\right), 53.2\left(\mathrm{C}_{\mathrm{c}}\right), 32.8\left(\mathrm{C}_{\mathrm{a}}\right), 24.8\left(\mathrm{C}_{\mathrm{e}}\right), 14.5\left(\mathrm{C}_{\mathrm{f}}\right)$; HRMS calculated for $\mathrm{C}_{22} \mathrm{H}_{22}{ }^{35} \mathrm{CIN}_{3} \mathrm{O}_{2}[\mathrm{M}+\mathrm{H}]^{+} \mathrm{m} / \mathrm{z} 396.1479$, found $\mathrm{C}_{22} \mathrm{H}_{22}{ }^{35} \mathrm{CIN}_{3} \mathrm{O}_{2}[\mathrm{M}+\mathrm{H}]^{+} \mathrm{m} / \mathrm{z}$ $396.1512(100 \%) ; \mathrm{C}_{22} \mathrm{H}_{22}{ }^{37} \mathrm{CIN}_{3} \mathrm{O}_{2}[\mathrm{M}+\mathrm{H}]^{+} \mathrm{m} / \mathrm{z} 398.1501$ (33\%).

\subsubsection{4-[(3-Chloro-4-methoxybenzyl)amino]-8-cyclopropyl-3-(2-fluoroethyl)quinoline-}

6-carbonitrile (22a). Diethylaminosulfur trifluoride (42 $\mu \mathrm{L}, 0.32 \mathrm{mmol}, 2.0 \mathrm{eq}$.) was added at $-78{ }^{\circ} \mathrm{C}$, under argon and stirring, to a solution of $21 \mathrm{a}$ (65 mg, $0.16 \mathrm{mmol}, 1.0$ eq.) in anhydrous dichloromethane $(10 \mathrm{~mL})$. The temperature was slowly increased to rt over 3 hours. The mixture was then cooled to $-10{ }^{\circ} \mathrm{C}$ before addition of a saturated sodium bicarbonate solution $(20 \mathrm{~mL})$. After decantation, the aqueous layer was extracted with dichloromethane $(4 \times 15 \mathrm{~mL})$. The combined organic layers were washed with brine $(50 \mathrm{~mL})$, dried over anhydrous magnesium sulfate, filtered, concentrated under reduced pressure. The mixture was purified by column chromatography $\left(\mathrm{SiO}_{2}\right.$, dichloromethane/ethanol, 9/1, v/v) to give by order of elution: the desired product $22 \mathrm{a}$ (30 mg, $73.2 \mu \mathrm{mol}, 46 \%$ ) as yellow oil and the by-product 1-(3-chloro-4-methoxybenzyl)-6-cyclopropyl-2,3-dihydro-1 $\mathrm{H}$-pyrrolo[3,2c]quinoline-8-carbonitrile $23 \mathrm{a}(10 \mathrm{mg}, 25.6 \mu \mathrm{mol}, 15 \%)$ as yellow oil. 4-[(3-chloro-4methoxybenzyl)amino]-8-cyclopropyl-3-(2-fluoroethyl)quinoline-6-carbonitrile (22a). $\mathrm{R}_{\mathrm{f}}\left(\mathrm{SiO}_{2}\right.$, dichloromethane/ethanol, 9/1, v/v): 0.56; ${ }^{1} \mathrm{H} \mathrm{NMR}\left(\mathrm{CDCl}_{3}, 400 \mathrm{MHz}\right) \delta 8.68\left(\mathrm{~s}, 1 \mathrm{H}, \mathrm{H}_{2}\right), 8.25$ $\left(\mathrm{d}, 1 \mathrm{H},{ }^{4} J_{\mathrm{H}_{5}-\mathrm{H}_{7}}=1.6 \mathrm{~Hz}, \mathrm{H}_{5}\right), 7.31\left(\mathrm{~d}, 1 \mathrm{H},{ }^{4} J_{\mathrm{H}_{2^{\prime}-\mathrm{H}^{\prime}}}=2.2 \mathrm{~Hz}, \mathrm{H}_{2^{\prime}}\right), 7.23\left(\mathrm{~d}, 1 \mathrm{H},{ }^{4} J_{\mathrm{H}_{7}-\mathrm{H}_{5}}=1.6 \mathrm{~Hz}\right.$, $\left.\mathrm{H}_{7}\right), 7.13\left(\mathrm{dd}, 1 \mathrm{H},{ }^{3} \mathrm{~J}_{\mathrm{H}^{\prime} \mathrm{H}_{5^{\prime}}}=8.4 \mathrm{~Hz},{ }^{4} \mathrm{~J}_{\mathrm{H}^{\prime} \mathrm{H}^{-} \mathrm{H}^{\prime}}=2.2 \mathrm{~Hz}, \mathrm{H}_{6^{\prime}}\right), 6.91\left(\mathrm{~d}, 1 \mathrm{H},{ }^{3} J_{\mathrm{H}^{\prime}-\mathrm{H}_{6^{\prime}}}=8.4 \mathrm{~Hz}, \mathrm{H}_{5^{\prime}}\right)$, $4.64\left(\mathrm{dt}, 2 \mathrm{H},{ }^{2} \mathrm{~J}_{\mathrm{H}_{\mathrm{b}} \mathrm{F}}=47.0 \mathrm{~Hz},{ }^{3} \mathrm{~J}_{\mathrm{H}_{\mathrm{b}}-\mathrm{H}_{\mathrm{a}}}=5.8 \mathrm{~Hz}, \mathrm{H}_{\mathrm{b}}\right), 4.52\left(\mathrm{~d}, 2 \mathrm{H},{ }^{3} \mathrm{~J}_{\mathrm{H}_{\mathrm{c}} \mathrm{NH}}=5.9 \mathrm{~Hz}, \mathrm{H}_{\mathrm{c}}\right), 3.91(\mathrm{~s}$, $\left.3 \mathrm{H}, \mathrm{H}_{\mathrm{d}}\right), 3.10\left(\mathrm{~m}, 1 \mathrm{H}, \mathrm{H}_{\mathrm{e}}\right), 3.02\left(\mathrm{dt}, 2 \mathrm{H},{ }^{3} J_{\mathrm{H}_{\mathrm{a}} \mathrm{F}}=26.8 \mathrm{~Hz},{ }^{3} \mathrm{~J}_{\mathrm{H}_{\mathrm{a}}-\mathrm{H}_{\mathrm{b}}}=5.8 \mathrm{~Hz}, \mathrm{H}_{\mathrm{a}}\right), 1.22\left(\mathrm{~m}, 2 \mathrm{H}, \mathrm{H}_{\mathrm{f}}\right.$ or $\left.\mathrm{H}_{\mathrm{f}}\right), 0.84\left(\mathrm{~m}, 2 \mathrm{H}, \mathrm{H}_{\mathrm{f}}\right.$ or $\left.\mathrm{H}_{\mathrm{f}}\right) ;{ }^{13} \mathrm{C} \operatorname{NMR}\left(\mathrm{CDCl}_{3}, 100 \mathrm{MHz}\right) \delta 155.0\left(\mathrm{C}_{4}\right), 154.1\left(\mathrm{C}_{2}\right), 152.2$ $\left(\mathrm{C}_{4}\right), 149.3\left(\mathrm{C}_{8 \mathrm{a}}\right), 145.2\left(\mathrm{C}_{8}\right), 131.9\left(\mathrm{C}_{1^{\prime}}\right), 129.6\left(\mathrm{C}_{2^{\prime}}\right), 127.3\left(\mathrm{C}_{5}\right), 127.1\left(\mathrm{C}_{6^{\prime}}\right), 123.7\left(\mathrm{C}_{7}\right), 123.1$ $\left(\mathrm{C}_{3^{\prime}}\right), 121.1\left(\mathrm{C}_{3}\right), 119.5(\mathrm{CN}), 118.4\left(\mathrm{C}_{4 \mathrm{a}}\right), 112.5\left(\mathrm{C}_{5^{\prime}}\right), 108.4\left(\mathrm{C}_{6}\right), 84.1\left(\mathrm{~d},{ }^{2} \mathrm{~J}_{\mathrm{C}_{\mathrm{b}} \mathrm{F}}=168 \mathrm{~Hz}, \mathrm{C}_{\mathrm{b}}\right)$, $56.4\left(\mathrm{C}_{\mathrm{d}}\right), 53.4\left(\mathrm{C}_{\mathrm{c}}\right), 30.9\left(\mathrm{~d},{ }^{3} \mathrm{~J}_{\mathrm{C}_{\mathrm{a}} \mathrm{F}}=20 \mathrm{~Hz}, \mathrm{C}_{\mathrm{a}}\right), 11.2\left(\mathrm{C}_{\mathrm{e}}\right), 10.0\left(2 \mathrm{C}, \mathrm{C}_{\mathrm{f}}, \mathrm{C}_{\mathrm{f}}\right)$; HRMS calculated for $\mathrm{C}_{23} \mathrm{H}_{21}{ }^{35} \mathrm{CIFN}_{3} \mathrm{O}[\mathrm{M}+\mathrm{H}]^{+} \mathrm{m} / \mathrm{z}$ 410.1435, found $\mathrm{C}_{23} \mathrm{H}_{21}{ }^{35} \mathrm{CIFN}_{3} \mathrm{O}[\mathrm{M}+\mathrm{H}]^{+} \mathrm{m} / \mathrm{z}$ $410.1420 \quad$ (100\%); $\quad \mathrm{C}_{23} \mathrm{H}_{21}{ }^{37} \mathrm{CIFN}_{3} \mathrm{O} \quad[\mathrm{M}+\mathrm{H}]^{+} \quad \mathrm{m} / \mathrm{z} \quad 412.1215 \quad$ (33\%). $\quad$ 1-(3-chloro-4methoxybenzyl)-6-cyclopropyl-2,3-dihydro-1 $\mathrm{H}$-pyrrolo[3,2-c]quinoline-8-carbonitrile (23a). $\mathrm{R}_{\mathrm{f}}$ $\left(\mathrm{SiO}_{2}\right.$, dichloromethane/ethanol, 9/1, v/v): 0.12; IR $\left(\mathrm{cm}^{-1}\right): 2222\left(\mathrm{v}_{\mathrm{C} \equiv \mathrm{N}}\right), 1501\left(\mathrm{v}_{\mathrm{C}=\mathrm{C}}\right), 1294\left(\mathrm{v}_{\mathrm{as}}\right.$ C-O-c), 1252 ( $\left.\mathrm{v}_{\mathrm{s} \text { C-O-C }}\right) ;{ }^{1} \mathrm{H}$ NMR $\left(\mathrm{CDCl}_{3}, 400 \mathrm{MHz}\right) \delta 8.54\left(\mathrm{~s}, 1 \mathrm{H}, \mathrm{H}_{2}\right), 7.94\left(\mathrm{~d}, 1 \mathrm{H},{ }^{4} \mathrm{~J}_{\mathrm{H}_{5}-\mathrm{H}_{7}}=1.7\right.$ $\left.\mathrm{Hz}, \mathrm{H}_{5}\right), 7.31\left(\mathrm{~d}, 1 \mathrm{H},{ }^{4} J_{\mathrm{H}_{2^{\prime}} \mathrm{H}_{6^{\prime}}}=2.2 \mathrm{~Hz}, \mathrm{H}_{2^{\prime}}\right), 7.15\left(\mathrm{dd}, 1 \mathrm{H},{ }^{3} J_{\mathrm{H}_{6^{\prime}} \mathrm{H}_{5^{\prime}}}=8.5 \mathrm{~Hz},{ }^{4} J_{\mathrm{H}_{6^{\prime}} \mathrm{H}_{2^{\prime}}}=2.2 \mathrm{~Hz}\right.$, 
$\left.\mathrm{H}_{6^{\prime}}\right), 7.09\left(\mathrm{~d}, 1 \mathrm{H},{ }^{4} \mathrm{~J}_{\mathrm{H}_{7}-\mathrm{H}_{5}}=1.7 \mathrm{~Hz}, \mathrm{H}_{7}\right), 6.91\left(\mathrm{~d}, 1 \mathrm{H},{ }^{3} \mathrm{~J}_{\mathrm{H}^{\prime} \mathrm{H}_{6^{\prime}}}=8.5 \mathrm{~Hz}, \mathrm{H}_{5^{\prime}}\right), 4.78\left(\mathrm{~s}, 2 \mathrm{H}, \mathrm{H}_{\mathrm{c}}\right)$, $3.85\left(\mathrm{~m}, 5 \mathrm{H}, \mathrm{H}_{\mathrm{d}}, \mathrm{H}_{\mathrm{b}}\right), 3.24\left(\mathrm{t}, 2 \mathrm{H},{ }^{3} \mathrm{~J}_{\mathrm{H}_{\mathrm{a}}-\mathrm{H}_{\mathrm{b}}}=9.4 \mathrm{~Hz}, \mathrm{H}_{\mathrm{a}}\right), 2.92\left(\mathrm{~m}, 1 \mathrm{H}, \mathrm{H}_{\mathrm{e}}\right), 1.14\left(\mathrm{~m}, 2 \mathrm{H}, \mathrm{H}_{\mathrm{f}}\right.$ or $\left.\mathrm{H}_{\mathrm{f}}\right), 0.73\left(\mathrm{~m}, 2 \mathrm{H}, \mathrm{H}_{\mathrm{f}}\right.$ or $\left.\mathrm{H}_{\mathrm{f}}\right) ;{ }^{13} \mathrm{C} \operatorname{NMR}\left(\mathrm{CDCl}_{3}, 100 \mathrm{MHz}\right) \delta 155.3\left(\mathrm{C}_{4^{\prime}}\right), 154.7\left(\mathrm{C}_{4}\right), 149.3\left(\mathrm{C}_{8 \mathrm{a}}\right)$, $145.8\left(\mathrm{C}_{2}\right), 144.3\left(\mathrm{C}_{8}\right), 129.3\left(\mathrm{C}_{1^{\prime}}\right), 128.2\left(\mathrm{C}_{2^{\prime}}\right), 126.5\left(\mathrm{C}_{5}\right.$ or $\left.\mathrm{C}_{6^{\prime}}\right), 125.8\left(\mathrm{C}_{5}\right.$ or $\left.\mathrm{C}_{6^{\prime}}\right), 123.8\left(\mathrm{C}_{7}\right)$, $123.3\left(\mathrm{C}_{3^{\prime}}\right), 121.2\left(\mathrm{C}_{3}\right), 119.4(\mathrm{CN}), 115.0\left(\mathrm{C}_{4 \mathrm{a}}\right), 112.7\left(\mathrm{C}_{5^{\prime}}\right), 106.6\left(\mathrm{C}_{6}\right), 56.2\left(\mathrm{C}_{\mathrm{d}}\right), 55.8\left(\mathrm{C}_{\mathrm{b}}\right)$, $53.7\left(\mathrm{C}_{\mathrm{c}}\right), 25.5\left(\mathrm{C}_{\mathrm{a}}\right), 11.8\left(\mathrm{C}_{\mathrm{e}}\right), 9.3\left(2 \mathrm{C}, \mathrm{C}_{\mathrm{f}}, \mathrm{C}_{\mathrm{f}}\right)$; HRMS calculated for $\mathrm{C}_{23} \mathrm{H}_{20}{ }^{35} \mathrm{CIFN}_{3} \mathrm{O}[\mathrm{M}+\mathrm{H}]^{+}$ $\mathrm{m} / \mathrm{z} 390.1373$, found $\mathrm{C}_{23} \mathrm{H}_{20}{ }^{35} \mathrm{CIFN}_{3} \mathrm{O}[\mathrm{M}+\mathrm{H}]^{+} \mathrm{m} / \mathrm{z} 390.1374(100 \%) ; \mathrm{C}_{23} \mathrm{H}_{20}{ }^{37} \mathrm{CIFN}_{3} \mathrm{O}[\mathrm{M}+\mathrm{H}]^{+}$ $\mathrm{m} / \mathrm{z} 392.1176$ (33\%).

\subsubsection{4-[(3-Chloro-4-methoxybenzyl)amino]-8-ethyl-3-(2-fluoroethyl)quinoline-6-} carbonitrile (22b). Diethylaminosulfur trifluoride ( $27 \mu \mathrm{L}, 0.20 \mathrm{mmol}, 2.0$ eq.) was added at $78{ }^{\circ} \mathrm{C}$, under argon and stirring, to a solution of $21 \mathrm{~b}$ (40 mg, $0.10 \mathrm{mmol}, 1.0$ eq.) in anhydrous dichloromethane $(10 \mathrm{~mL})$. After return back to rt over 1.5 hours, a saturated sodium hydrogen carbonate solution $(15 \mathrm{~mL})$ was added slowly at $-10^{\circ} \mathrm{C}$. After decantation, the aqueous layer was extracted with dichloromethane $(4 \times 15 \mathrm{~mL})$. The combined organic layers were washed with brine $(50 \mathrm{~mL})$, dried over anhydrous magnesium sulfate, filtered, and concentrated under reduced pressure. The residue was purified by column chromatography $\left(\mathrm{SiO}_{2}\right.$, dichloromethane/ethanol, $\left.9 / 1, \mathrm{v} / \mathrm{v}\right)$ to give, by order of elution: the desired product 22b $(6.0 \mathrm{mg}, 15.1 \mu \mathrm{mol}, 15 \%)$ as a yellow oil and the by-product 1-(3-chloro4-methoxybenzyl)-6-ethyl-2,3-dihydro-1 $H$-pyrrolo[3,2-c]quinoline-8-carbonitrile 23b (25 mg, $66.2 \mu \mathrm{mol}, 68 \%)$ as yellow oil. 4-[(3-chloro-4-methoxybenzyl)amino]-8-ethyl-3-(2fluoroethyl)quinoline-6-carbonitrile (22b); $\mathrm{R}_{\mathrm{f}}\left(\mathrm{SiO}_{2}\right.$, dichloromethane/ethanol, 93/7, v/v): 0.51; ${ }^{1} \mathrm{H} \mathrm{NMR}\left(\mathrm{CDCl}_{3}, 400 \mathrm{MHz}\right) \delta 8.64\left(\mathrm{~s}, 1 \mathrm{H}, \mathrm{H}_{2}\right), 8.31\left(\mathrm{~d}, 1 \mathrm{H},{ }^{4} \mathrm{~J}_{\mathrm{H}_{5}-\mathrm{H}_{7}}=1.7 \mathrm{~Hz}, \mathrm{H}_{5}\right), 7.63(\mathrm{~m}, 1 \mathrm{H}$, $\left.\mathrm{H}_{7}\right), 7.32\left(\mathrm{~d}, 1 \mathrm{H},{ }^{4} J_{\mathrm{H}_{2^{\prime}} \mathrm{H}_{6^{\prime}}}=2.2 \mathrm{~Hz}, \mathrm{H}_{2^{\prime}}\right), 7.15\left(\mathrm{dd}, 1 \mathrm{H},{ }^{3} J_{\mathrm{H}_{6^{\prime}}-\mathrm{H}_{5^{\prime}}}=8.4 \mathrm{~Hz},{ }^{4} J_{\mathrm{H}_{6^{\prime}} \mathrm{H}_{2}}=2.2 \mathrm{~Hz}, \mathrm{H}_{6^{\prime}}\right)$, $6.93\left(\mathrm{~d}, 1 \mathrm{H},{ }^{3} J_{\mathrm{H}_{5^{\prime}}-\mathrm{H}_{6^{\prime}}}=8.4 \mathrm{~Hz}, \mathrm{H}_{5^{\prime}}\right), 4.65\left(\mathrm{dt}, 2 \mathrm{H},{ }^{2} J_{\mathrm{H}_{\mathrm{b}} \mathrm{F}}=47.0 \mathrm{~Hz},{ }^{3} J_{\mathrm{Hb}_{\mathrm{b}}-\mathrm{H}_{\mathrm{a}}}=5.8 \mathrm{~Hz}, \mathrm{H}_{\mathrm{b}}\right), 4.52(\mathrm{~d}$, $\left.2 \mathrm{H},{ }^{3} \mathrm{~J}_{\mathrm{H}_{\mathrm{c}}-\mathrm{NH}}=5.7 \mathrm{~Hz}, \mathrm{H}_{\mathrm{c}}\right), 3.92\left(\mathrm{~s}, 3 \mathrm{H}, \mathrm{H}_{\mathrm{d}}\right), 3.27\left(\mathrm{q}, 2 \mathrm{H},{ }^{3} \mathrm{~J}_{\mathrm{H}_{\mathrm{e}} \mathrm{H}_{\mathrm{f}}}=7.4 \mathrm{~Hz}, \mathrm{H}_{\mathrm{e}}\right), 3.02\left(\mathrm{dt}, 2 \mathrm{H},{ }^{3} \mathrm{~J}_{\mathrm{H}_{\mathrm{a}}-\mathrm{F}}\right.$ $\left.=27.0 \mathrm{~Hz},{ }^{3} \mathrm{~J}_{\mathrm{H}_{\mathrm{a}}-\mathrm{H}_{\mathrm{b}}}=5.8 \mathrm{~Hz}, \mathrm{H}_{\mathrm{a}}\right), 1.38\left(\mathrm{t}, 3 \mathrm{H},{ }^{3} \mathrm{~J}_{\mathrm{H}_{\mathrm{f}}-\mathrm{H}_{\mathrm{e}}}=7.4 \mathrm{~Hz}, \mathrm{H}_{\mathrm{f}}\right)$; HRMS calculated for $\mathrm{C}_{22} \mathrm{H}_{21}{ }^{35} \mathrm{CIFN}_{3} \mathrm{O}[\mathrm{M}+\mathrm{H}]^{+} \mathrm{m} / \mathrm{z} 398.1435$, found $\mathrm{C}_{22} \mathrm{H}_{21}{ }^{35} \mathrm{CIFN}_{3} \mathrm{O}[\mathrm{M}+\mathrm{H}]^{+} \mathrm{m} / \mathrm{z} 398.1451$ (100\%); $\mathrm{C}_{22} \mathrm{H}_{21}{ }^{37} \mathrm{CIFN}_{3} \mathrm{O} \quad[\mathrm{M}+\mathrm{H}]^{+} \quad \mathrm{m} / \mathrm{z} \quad 400.1242$ (33\%). 1-(3-chloro-4-methoxybenzyl)-6-ethyl-2,3dihydro-1H-pyrrolo[3,2-c]quinoline-8-carbonitrile (23b). $\mathrm{R}_{\mathrm{f}}\left(\mathrm{SiO}_{2}\right.$, dichloromethane/ethanol, 93/7, v/v): 0.20; IR ( $\left.\mathrm{cm}^{-1}\right): 2219\left(\mathrm{v}_{\mathrm{C} \equiv \mathrm{N}}\right), 1501\left(\mathrm{v}_{\mathrm{C}=\mathrm{C}}\right), 1254\left(\mathrm{v}_{\mathrm{as}} \mathrm{C}-\mathrm{O}\right), 1061\left(\mathrm{v}_{\mathrm{s}} \mathrm{C}-\mathrm{o}\right)$; Analyses of NMR spectra revealed that this product was a mixture of two rotamers, named $A$ and $B$ with a ratio $\mathrm{A} / \mathrm{B}=1 / 0.2 ;{ }^{1} \mathrm{H} \mathrm{NMR}\left(\mathrm{CDCl}_{3}, 400 \mathrm{MHz}\right) \delta 8.62\left(\mathrm{~s}, 1 \mathrm{H}, \mathrm{H}_{2(\mathrm{~B})}\right), 8.52\left(\mathrm{~s}, 1 \mathrm{H}, \mathrm{H}_{2(\mathrm{~A})}\right), 8.31$ $\left(\mathrm{d}, 1 \mathrm{H},{ }^{4} J_{\mathrm{H}_{5(\mathrm{~B})}-\mathrm{H}_{7(B)}}=1.8 \mathrm{~Hz}, \mathrm{H}_{5(\mathrm{~B})}\right), 8.04\left(\mathrm{~d}, 1 \mathrm{H},{ }^{4} J_{\mathrm{H}_{5(\mathrm{~A})}-\mathrm{H}_{7(\mathrm{~A})}}=1.8 \mathrm{~Hz}, \mathrm{H}_{5(\mathrm{~A})}\right), 7.58\left(\mathrm{~m}, 1 \mathrm{H}, \mathrm{H}_{7(\mathrm{~B})}\right)$, $7.47\left(\mathrm{~m}, 1 \mathrm{H}, \mathrm{H}_{7(\mathrm{~A})}\right), 7.36\left(\mathrm{~d}, 1 \mathrm{H},{ }^{4} J_{\mathrm{H}_{2^{\prime}(\mathrm{A})}-\mathrm{H}_{6^{\prime}(\mathrm{A})}}=2.2 \mathrm{~Hz}, \mathrm{H}_{2^{\prime}(\mathrm{A})}\right), 7.32\left(\mathrm{~d}, 1 \mathrm{H},{ }^{4} J_{\left.\mathrm{H}_{2^{\prime}(B)}\right)^{-} \mathrm{H}^{\prime}(B)}=2.2 \mathrm{~Hz}\right.$,

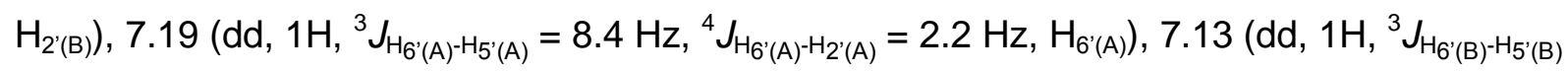


$\left.=8.4 \mathrm{~Hz},{ }^{4} J_{\mathrm{H}^{\prime}(\mathrm{B})-\mathrm{H}_{2^{\prime}(\mathrm{B})}}=2.2 \mathrm{~Hz}, \mathrm{H}_{6^{\prime}(\mathrm{B})}\right), 6.95\left(\mathrm{~d}, 1 \mathrm{H},{ }^{3} J_{\mathrm{H}^{\prime}(\mathrm{A})-\mathrm{H}^{\prime}(\mathrm{A})}=8.4 \mathrm{~Hz}, \mathrm{H}_{5^{\prime}(\mathrm{A})}\right), 6.89(\mathrm{~d}, 1 \mathrm{H}$, $\left.{ }^{3} J_{\left.H_{5^{\prime}(B)}\right)_{6^{\prime}(B)}}=8.4 \mathrm{~Hz}, \mathrm{H}_{5^{\prime}(B)}\right), 4.80\left(\mathrm{~s}, 2 \mathrm{H}, \mathrm{H}_{\mathrm{c}(\mathrm{A})}\right), 4.49\left(\mathrm{~s}, 2 \mathrm{H}, \mathrm{H}_{\mathrm{C}(\mathrm{B})}\right), 3.91\left(\mathrm{~s}, 3 \mathrm{H}, \mathrm{H}_{\mathrm{d}(\mathrm{A})}\right), 3.90(\mathrm{~s}$,

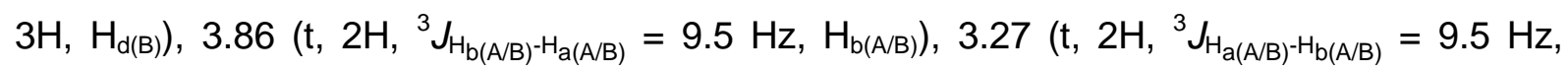
$\left.\mathrm{H}_{\mathrm{a}(\mathrm{A} / \mathrm{B})}\right), 3.19\left(\mathrm{q}, 2 \mathrm{H},{ }^{3} \mathrm{~J}_{\mathrm{H}_{\mathrm{e}}(\mathrm{A} / \mathrm{B})-\mathrm{H}_{\mathrm{f}(\mathrm{A} / \mathrm{B})}}=7.5 \mathrm{~Hz}, \mathrm{H}_{\mathrm{e}(\mathrm{A} / \mathrm{B})}\right), 1.36\left(\mathrm{t}, 3 \mathrm{H},{ }^{3} J_{\mathrm{H}_{\mathrm{f}(B)}-\mathrm{H}_{\mathrm{e}(B)}}=8.4 \mathrm{~Hz}, \mathrm{H}_{\mathrm{f}(\mathrm{B})}\right), 1.34$ $\left(\mathrm{t}, 3 \mathrm{H},{ }^{3} \mathrm{~J}_{\mathrm{H}_{\mathrm{f}}(\mathrm{A})-\mathrm{H}_{\mathrm{e}(\mathrm{A})}}=8.4 \mathrm{~Hz}, \mathrm{H}_{\mathrm{f}(\mathrm{A})}\right) ;{ }^{13} \mathrm{C} \mathrm{NMR}\left(\mathrm{CDCl}_{3}, 100 \mathrm{MHz}\right) \delta 155.2\left(\mathrm{C}_{4}\right), 154.9\left(\mathrm{C}_{4}{ }^{\prime}\right), 149.4$ $\left(\mathrm{C}_{8 \mathrm{a}}\right), 146.9\left(\mathrm{C}_{2}\right), 145.1\left(\mathrm{C}_{8}\right), 129.9\left(\mathrm{C}_{1^{\prime}}\right), 128.5\left(\mathrm{C}_{2^{\prime}}\right), 127.4\left(\mathrm{C}_{5}\right.$ or $\left.\mathrm{C}_{7}\right), 127.3\left(\mathrm{C}_{5}\right.$ or $\left.\mathrm{C}_{7}\right), 126.0$ $\left(\mathrm{C}_{6^{\prime}}\right), 123.5\left(\mathrm{C}_{3^{\prime}}\right), 121.1\left(\mathrm{C}_{3}\right), 119.8(\mathrm{CN}), 115.6\left(\mathrm{C}_{4 \mathrm{a}}\right), 112.9\left(\mathrm{C}_{5^{\prime}}\right), 107.7\left(\mathrm{C}_{6}\right), 56.5\left(\mathrm{C}_{\mathrm{d}}\right), 55.9$ $\left(\mathrm{C}_{\mathrm{b}}\right), 54.1\left(\mathrm{C}_{\mathrm{c}}\right), 25.9\left(\mathrm{C}_{\mathrm{a}}\right), 25.6\left(\mathrm{C}_{\mathrm{e}}\right), 14.4\left(\mathrm{C}_{\mathrm{f}}\right)$; HRMS calculated for $\mathrm{C}_{22} \mathrm{H}_{20}{ }^{35} \mathrm{CIN}_{3} \mathrm{O}[\mathrm{M}+\mathrm{H}]^{+} \mathrm{m} / \mathrm{z}$ 378.1373, found $\mathrm{C}_{22} \mathrm{H}_{20}{ }^{35} \mathrm{CIN}_{3} \mathrm{O}[\mathrm{M}+\mathrm{H}]^{+} \mathrm{m} / \mathrm{z} 378.1392(100 \%) ; \mathrm{C}_{22} \mathrm{H}_{20}{ }^{37} \mathrm{CIN}_{3} \mathrm{O}[\mathrm{M}+\mathrm{H}]^{+} \mathrm{m} / \mathrm{z}$ $380.1329(33 \%)$.

\subsubsection{1.}

4-[(3-Chloro-4-methoxybenzyl)amino]-8-cyclopropyl-3-[(2fluoroethoxy)methyl]quinoline-6-carbonitrile (24a). A solution of 4a [12] (150 mg, 0.38 mmol, 1.0 eq.) in thionyl chloride ( $4 \mathrm{~mL})$ was stirred at $\mathrm{rt}$, under argon, for 30 minutes. The solvent was then removed under reduced pressure for at least 3 hours. The residue was dissolved in anhydrous $N, N$-dimethylformamide $(5 \mathrm{~mL})$ under argon before addition of 2fluoroethanol $(0.15 \mathrm{~mL}, 2.55 \mathrm{mmol}, 6.7$ eq. $)$ at $\mathrm{rt}$ and the mixture was stirred at $80{ }^{\circ} \mathrm{C}$ for 27 hours. After cooling to $\mathrm{rt}$, a saturated sodium hydrogen carbonate solution $(25 \mathrm{~mL})$ was added. This mixture was extracted with ethyl acetate $(2 \times 20 \mathrm{~mL})$. The combined organic layers were washed with brine $(2 \times 40 \mathrm{~mL})$, dried over anhydrous magnesium sulfate, filtered, and concentrated under reduced pressure. The crude product was purified by column chromatography $\left(\mathrm{SiO}_{2}\right.$, ethyl acetate/cyclohexane, $2 / 8$ to $\left.5 / 5, \mathrm{v} / \mathrm{v}\right)$ to give the desired product 24a (60 mg, $0.14 \mathrm{mmol}, 37 \%)$ as a white solid. $\mathrm{R}_{\mathrm{f}}\left(\mathrm{SiO}_{2}\right.$, cyclohexane/ethyl acetate, 5/5, v/v): 0.50; Mp: 152-154 ${ }^{\circ} \mathrm{C}$; IR $\left(\mathrm{cm}^{-1}\right): 2226\left(\mathrm{v}_{\mathrm{C} \equiv \mathrm{N}}\right), 1506\left(\mathrm{v}_{\mathrm{C}=\mathrm{C}}\right), 1261\left(\mathrm{v}_{\mathrm{C}-\mathrm{O}}\right), 1188\left(\mathrm{v}_{\mathrm{C}-\mathrm{o}}\right)$, $1068\left(\mathrm{v}_{\mathrm{C}-\mathrm{O}}\right), 1021\left(\mathrm{v}_{\mathrm{C}-\mathrm{O}}\right) ;{ }^{1} \mathrm{H} \mathrm{NMR}\left(\mathrm{CDCl}_{3}, 400 \mathrm{MHz}\right) \delta 8.56\left(\mathrm{~s}, 1 \mathrm{H}, \mathrm{H}_{2}\right), 8.25\left(\mathrm{~d}, 1 \mathrm{H},{ }^{4} \mathrm{~J}_{\mathrm{H}_{5}-\mathrm{H}_{7}}=\right.$ $\left.1.5 \mathrm{~Hz}, \mathrm{H}_{5}\right), 7.32\left(\mathrm{~d}, 1 \mathrm{H},{ }^{4} \mathrm{~J}_{\mathrm{H}^{\prime}-\mathrm{H}_{6^{\prime}}}=2.1 \mathrm{~Hz}, \mathrm{H}_{2^{\prime}}\right), 7.19\left(\mathrm{~d}, 1 \mathrm{H},{ }^{4} J_{\mathrm{H}_{7}-\mathrm{H}_{5}}=1.5 \mathrm{~Hz}, \mathrm{H}_{7}\right), 7.15(\mathrm{dd}, 1 \mathrm{H}$, $\left.{ }^{3} J_{\mathrm{H}^{\prime} \mathrm{H}^{\prime}{ }^{\prime}}=8.4 \mathrm{~Hz},{ }^{4} J_{\mathrm{H}_{6^{\prime}}-\mathrm{H}_{2^{\prime}}}=2.1 \mathrm{~Hz}, \mathrm{H}_{6^{\prime}}\right), 6.89\left(\mathrm{~d}, 1 \mathrm{H},{ }^{3} J_{\mathrm{H}^{\prime} \cdot \mathrm{H}_{6^{\prime}}}=8.4 \mathrm{~Hz}, \mathrm{H}_{5^{\prime}}\right), 5.75(\mathrm{~m}, 1 \mathrm{H}, \mathrm{NH})$, $4.70\left(\mathrm{~d}, 2 \mathrm{H},{ }^{3} \mathrm{~J}_{\mathrm{H}_{\mathrm{d}-\mathrm{NH}}}=5.6 \mathrm{~Hz}, \mathrm{H}_{\mathrm{d}}\right), 4.62\left(\mathrm{~s}, 2 \mathrm{H}, \mathrm{H}_{\mathrm{a}}\right), 4.51\left(\mathrm{~m}, 2 \mathrm{H}, \mathrm{H}_{\mathrm{c}}\right), 3.88\left(\mathrm{~s}, 3 \mathrm{H}, \mathrm{H}_{\mathrm{e}}\right), 3.67(\mathrm{~m}$, $\left.2 \mathrm{H}, \mathrm{H}_{\mathrm{b}}\right), 3.09\left(\mathrm{~m}, 1 \mathrm{H}, \mathrm{H}_{\mathrm{f}}\right), 1.18\left(\mathrm{~m}, 2 \mathrm{H}, \mathrm{H}_{\mathrm{g}}\right.$ or $\left.\mathrm{H}_{\mathrm{g}^{\prime}}\right), 0.80\left(\mathrm{~m}, 2 \mathrm{H}, \mathrm{H}_{\mathrm{g}}\right.$ or $\left.\mathrm{H}_{\mathrm{g}^{\prime}}\right) ;{ }^{13} \mathrm{C} \mathrm{NMR}\left(\mathrm{CDCl}_{3}\right.$, $100 \mathrm{MHz}) \delta 154.8\left(\mathrm{C}_{4}\right), 153.1\left(\mathrm{C}_{4}\right), 152.8\left(\mathrm{C}_{2}\right), 150.7\left(\mathrm{C}_{8 \mathrm{a}}\right), 145.3\left(\mathrm{C}_{8}\right), 132.1\left(\mathrm{C}_{1^{1}}\right), 129.4$ $\left(\mathrm{C}_{2^{\prime}}\right), 127.4\left(\mathrm{C}_{5}\right), 126.9\left(\mathrm{C}_{6^{\prime}}\right), 123.7\left(\mathrm{C}_{7}\right), 123.0\left(\mathrm{C}_{3^{\prime}}\right), 120.0\left(\mathrm{C}_{4 \mathrm{a}}\right), 119.5(\mathrm{CN}), 115.1\left(\mathrm{C}_{3}\right)$, $112.5\left(\mathrm{C}_{5^{\prime}}\right), 107.6\left(\mathrm{C}_{6}\right), 82.7\left(\mathrm{~d},{ }^{1} \mathrm{~J}_{\mathrm{C}_{\mathrm{c}} \mathrm{F}}=169 \mathrm{~Hz}, \mathrm{C}_{\mathrm{c}}\right), 70.1\left(\mathrm{C}_{\mathrm{a}}\right), 69.0\left(\mathrm{~d},{ }^{2} \mathrm{~J}_{\mathrm{C}_{\mathrm{b}} \mathrm{F}}=19 \mathrm{~Hz}, \mathrm{C}_{\mathrm{b}}\right)$, $56.3\left(\mathrm{C}_{\mathrm{e}}\right), 52.1\left(\mathrm{C}_{\mathrm{d}}\right), 11.2\left(\mathrm{C}_{\mathrm{f}}\right), 9.9\left(2 \mathrm{C}, \mathrm{C}_{\mathrm{g}}, \mathrm{C}_{\mathrm{g}}\right)$; HRMS calculated for $\mathrm{C}_{24} \mathrm{H}_{23}{ }^{35} \mathrm{CIFN}_{3} \mathrm{O}_{2}[\mathrm{M}+\mathrm{H}]^{+}$ $\mathrm{m} / \mathrm{z} 440.1541$, found $\mathrm{C}_{24} \mathrm{H}_{23}{ }^{35} \mathrm{CIFN}_{3} \mathrm{O}_{2}[\mathrm{M}+\mathrm{H}]^{+} \mathrm{m} / \mathrm{z} 440.1505$ (100\%); $\mathrm{C}_{24} \mathrm{H}_{23}{ }^{37} \mathrm{ClFN}_{3} \mathrm{O}_{2}[\mathrm{M}+\mathrm{H}]^{+}$ $\mathrm{m} / \mathrm{z} 442.1481$ (33\%). 
fluoroethoxy)methyl]quinoline-6-carbonitrile (24b). A solution of $4 \mathrm{~b}(250 \mathrm{mg}, 0.65 \mathrm{mmol}$, 1.0 eq.) in thionyl chloride ( $4 \mathrm{~mL})$ was stirred at rt, under argon, for 30 minutes. The solvent was then removed under reduced pressure for at least three hours. The residue was dissolved in anhydrous $\mathrm{N}, \mathrm{N}$-dimethylformamide $(15 \mathrm{~mL})$ before addition of 2-fluoroethanol ( $0.38 \mathrm{~mL}, 6.47 \mathrm{mmol}, 10.0$ eq.) under stirring and argon at rt. The mixture was stirred at 80 ${ }^{\circ} \mathrm{C}$ for 30 hours. After cooling to rt, a saturated aqueous sodium hydrogen carbonate solution $(30 \mathrm{~mL})$ was added. The mixture was extracted with ethyl acetate $(3 \times 30 \mathrm{~mL})$. The combined organic layers were washed with brine $(2 \times 40 \mathrm{~mL})$, dried over anhydrous magnesium sulfate, filtered and then concentrated under reduced pressure. The crude product was purified by column chromatography $\left(\mathrm{SiO}_{2}\right.$, ethyl acetate/cyclohexane, $2 / 8$ to $\left.5 / 5, \mathrm{v} / \mathrm{v}\right)$ to give the desired product $24 \mathrm{~b}(80 \mathrm{mg}, 0.19 \mathrm{mmol}, 29 \%)$ as a yellow solid. $\mathrm{R}_{\mathrm{f}}\left(\mathrm{SiO}_{2}\right.$, cyclohexane/ethyl acetate, 6/4, v/v): 0.51; Mp: 149-151 ${ }^{\circ} \mathrm{C}$; IR $\left(\mathrm{cm}^{-1}\right): 2229\left(\mathrm{v}_{\mathrm{C} \equiv \mathrm{N}}\right), 1505$ $\left(\mathrm{v}_{\mathrm{C}=\mathrm{C}}\right), 1260\left(\mathrm{v}_{\mathrm{C}-\mathrm{O}}\right), 1104\left(\mathrm{v}_{\mathrm{C}-\mathrm{O}}\right), 1067\left(\mathrm{v}_{\mathrm{C}-\mathrm{O}}\right), 1013\left(\mathrm{v}_{\mathrm{C}-\mathrm{O}}\right) ;{ }^{1} \mathrm{H} \mathrm{NMR}\left(\mathrm{CDCl}_{3}, 400 \mathrm{MHz}\right) \delta 8.53(\mathrm{~s}$, $\left.1 \mathrm{H}, \mathrm{H}_{2}\right), 8.32\left(\mathrm{~d}, 1 \mathrm{H},{ }^{4} \mathrm{~J}_{\mathrm{H}_{5}-\mathrm{H}_{7}}=1.7 \mathrm{~Hz}, \mathrm{H}_{5}\right), 7.59\left(\mathrm{~m}, 1 \mathrm{H}, \mathrm{H}_{7}\right), 7.34\left(\mathrm{~d}, 1 \mathrm{H},{ }^{4} \mathrm{~J}_{\mathrm{H}^{\prime}-\mathrm{H}_{6^{\prime}}}=2.2 \mathrm{~Hz}, \mathrm{H}_{2^{\prime}}\right)$, $7.17\left(\mathrm{dd}, 1 \mathrm{H},{ }^{3} \mathrm{~J}_{\mathrm{H}^{\prime} \mathrm{H}^{-} \mathrm{H}^{\prime}}=8.4 \mathrm{~Hz},{ }^{4} \mathrm{~J}_{\mathrm{H}^{\prime} \mathrm{H}^{\prime} \mathrm{H}^{\prime}}=2.2 \mathrm{~Hz}, \mathrm{H}_{6^{\prime}}\right), 6.91\left(\mathrm{~d}, 1 \mathrm{H},{ }^{3} \mathrm{~J}_{\mathrm{H}^{\prime}-\mathrm{H}_{6^{\prime}}}=8.4 \mathrm{~Hz}, \mathrm{H}_{5^{\prime}}\right), 5.78$ (brs, $1 \mathrm{H}, \mathrm{NH}), 4.71\left(\mathrm{~d}, 2 \mathrm{H},{ }^{3} \mathrm{~J}_{\mathrm{d}_{\mathrm{N}-\mathrm{NH}}}=5.1 \mathrm{~Hz}, \mathrm{H}_{\mathrm{d}}\right), 4.62\left(\mathrm{~s}, 2 \mathrm{H}, \mathrm{H}_{\mathrm{a}}\right), 4.52\left(\mathrm{~m}, 2 \mathrm{H}, \mathrm{H}_{\mathrm{c}}\right), 3.89(\mathrm{~s}$, $3 \mathrm{H}, \mathrm{H}_{\mathrm{e}}$ ), $3.68\left(\mathrm{~m}, 2 \mathrm{H}, \mathrm{H}_{\mathrm{b}}\right), 3.22\left(\mathrm{q}, 2 \mathrm{H},{ }^{3} \mathrm{~J}_{\mathrm{H}_{\mathrm{f}} \mathrm{H}_{\mathrm{g}}}=7.5 \mathrm{~Hz}, \mathrm{H}_{\mathrm{f}}\right), 1.35\left(\mathrm{t}, 3 \mathrm{H},{ }^{3} \mathrm{~J}_{\mathrm{H}_{\mathrm{g}}-\mathrm{H}_{\mathrm{f}}}=7.5 \mathrm{~Hz}, \mathrm{H}_{\mathrm{g}}\right.$ ); ${ }^{13} \mathrm{C}$ NMR $\left(\mathrm{CDCl}_{3}, 100 \mathrm{MHz}\right) \delta 154.8\left(\mathrm{C}_{4}\right), 153.1\left(\mathrm{C}_{4}\right), 152.5\left(\mathrm{C}_{2}\right), 149.8\left(\mathrm{C}_{8 \mathrm{a}}\right), 145.0\left(\mathrm{C}_{8}\right)$, $132.0\left(\mathrm{C}_{1^{\prime}}\right), 129.3\left(\mathrm{C}_{2^{\prime}}\right), 128.2\left(\mathrm{C}_{5}\right), 128.1\left(\mathrm{C}_{7}\right), 126.8\left(\mathrm{C}_{6^{\prime}}\right), 123.0\left(\mathrm{C}_{3^{\prime}}\right), 119.9\left(\mathrm{C}_{4 \mathrm{a}}\right.$ or $\left.\mathrm{CN}\right)$, $119.5\left(\mathrm{C}_{4 \mathrm{a}}\right.$ or $\left.\mathrm{CN}\right), 114.8\left(\mathrm{C}_{3}\right), 112.4\left(\mathrm{C}_{5^{\prime}}\right), 107.5\left(\mathrm{C}_{6}\right), 82.7\left(\mathrm{~d},{ }^{1} \mathrm{~J}_{\mathrm{C}^{-}-\mathrm{F}}=168 \mathrm{~Hz}, \mathrm{C}_{\mathrm{c}}\right), 70.1\left(\mathrm{C}_{\mathrm{a}}\right)$, $69.0\left(\mathrm{~d},{ }^{2} \mathrm{~J}_{\mathrm{C}_{\mathrm{b}} \mathrm{F}}=19 \mathrm{~Hz}, \mathrm{C}_{\mathrm{b}}\right), 56.2\left(\mathrm{C}_{\mathrm{e}}\right), 52.0\left(\mathrm{C}_{\mathrm{d}}\right), 24.9\left(\mathrm{C}_{\mathrm{f}}\right), 14.4\left(\mathrm{C}_{\mathrm{g}}\right)$; HRMS calculated for $\mathrm{C}_{23} \mathrm{H}_{23}{ }^{35} \mathrm{CIFN}_{3} \mathrm{O}_{2}[\mathrm{M}+\mathrm{H}]^{+} \mathrm{m} / \mathrm{z} 428.1541$, found $\mathrm{C}_{23} \mathrm{H}_{23}{ }^{35} \mathrm{CIFN}_{3} \mathrm{O}_{2}[\mathrm{M}+\mathrm{H}]^{+} \mathrm{m} / \mathrm{z} 428.1492(100 \%)$; $\mathrm{C}_{23} \mathrm{H}_{23}{ }^{37} \mathrm{CIFN}_{3} \mathrm{O}_{2}[\mathrm{M}+\mathrm{H}]^{+} \mathrm{m} / \mathrm{z} 430.1510$ (33\%).

Similar experimental protocols used for the synthesis of compounds 26-32 bearing a trifluoromethyl substituent at position C-6 are given in electronic supplementary information.

\subsection{Biology.}

All tests were performed at the SB Drug Discovery company (Glasgow, UK). The phosphodiesterase assays were performed using recombinant human PDE enzymes expressed in a baculoviral system and selected for their similarity to PDE enzymes taken from human tissue using known inhibitor standards. The radiometric assay method was a modification of the two-step method of Thompson and Appleman, ${ }^{37}$ adapted for 96 well plate format.

Compounds were tested at a concentration of $1 \mu \mathrm{M}$ against human PDE2A3, PDE3A, PDE4A1, PDE4C2, PDE6AB, PDE9A1, PDE10A1 and PDE11A1 and at a concentration of $100 \mathrm{nM}$ against human PDE5A1. The percentage of inhibition of the compounds and 
standard inhibitors were determined and compared to historical assay data to ensure that they fell within acceptable ranges. For $\mathrm{IC}_{50}$ values measurements, compounds were tested at concentrations of $1000,100,10,1,0.5,0.25$, and $0.1 \mathrm{nM}$ against PDE5A1. Data generated were analyzed using Prism software (GraphPad Inc)

\section{Acknowledgements}

The authors would like to thank the China Scholarship Council for supporting the PhD thesis of Jianrong Liu. Campus France together with the German Academic Exchange Service-DAAD kindly supported this project with a travel grant (PHC PROCOPE Project ID: 57129895).

\section{References}

[1] G. Cornutiu, The Epidemiological Scale of Alzheimer's Disease, J. Clin. Med. Res. 7 (2015) 657-666.

[2] H. W. Klafki, M. Staufenbiel, J. Kornhuber, J. Wiltfang, Therapeutic approaches to Alzheimer's disease, Brain 129 (2006) 2840-2855.

[3] N. Ullah, N. Muhammad khan, W. Ullah, Alzheimer's disease, Epidemiology, causes, diagnosis and novel treatments: A review, Int. J. Basic Med. Sci. Pharmacy 5 (2015) 50-56.

[4] C. P. Ferri, M. Prince, C. Brayne, H. Brodaty, L. Fratiglioni, M. Ganguli, K. Hall, K. Hasegawa, H. Hendrie, Y. Huang, A. Jorm, C. Mathers, P. R. Menezes, E. Rimmer, M. Scazufca, Alzheimer's Disease International, Global prevalence of dementia: a Delphi consensus study, Lancet 366 (2005) 2112-2117.

[5] S. Weintraub, A. H. Wicklund, D. P. Salmon, The neuropsychological profile of Alzheimer disease, Cold Spring Harb. Perspect. Med. 2 (2012) a006171.

[6] D. H. Maurice, H. Ke, F. Ahmad, Y. Wang, J. Chung, V. C. Manganiello, Advances in targeting cyclic nucleotide phosphodiesterases, Nat. Rev. Drug. Discov. 13 (2014) 290-314.

[7] C. A. Peixoto, A. K. Santana Nunes, A. Garcia-Osta, Phosphodiesterase-5 Inhibitors: Action on the Signaling Pathways of Neuroinflammation, Neurodegeneration, and Cognition, Mediators Inflamm. 940207 (2015) 2015, 17 pages, doi: 10.1155/2015/940207.

[8] J. Kotera, K. Fujishige, K. Omori, Immunohistochemical localization of cGMP-binding cGMP-specific phosphodiesterase (PDE5) in rat tissues, J. Histochem. Cytochem. 48 (2000) 685-693. 
[9] W. C. G. Van Staveren, H. W. M. Steinbusch, M. Markerink-Van Ittersum, D. R. Repaske, M. F. Goy, J. Kotera, K. Omori, J. A. Beavo, J. De Vente, mRNA expression patterns of the cGMP-hydrolyzing phosphodiesterases types 2, 5, and 9 during development of the rat brain, J. Comp. Neurol. 467 (2003) 566-580.

[10] A. Saavedra, A Giralt, H. Arumi, J. Alberch, E. Perez-Navarro, Regulation of hippocampal cGMP levels as a candidate to treat cognitive deficits in Huntington's disease, PLoS ONE 8 (2013) e73664.

[11] A. Garcia-Osta, M. Cuadrado-Tejedor, C. Garcia-Barroso, J. Oyarzabal, R. Franco, Phosphodiesterases as therapeutic targets for Alzheimer's disease, ACS Chem. Neurosci. 3 (2012) 832-844.

[12] J. Fiorito, F. Saeed, H. Zhang, A. Staniszewski, Y. Feng, Y. I. Francis, S. Rao, D. M. Thakkar, S. X. Deng, D. W. Landry, O. Arancio, Synthesis of quinoline derivatives: discovery of a potent and selective phosphodiesterase 5 inhibitor for the treatment of Alzheimer's disease, Eur. J. Med. Chem. 60 (2013) 285-294.

[13] K. U. Domek-Łopacińska, J. B. Strosznajder, Cyclic GMP and nitric oxide synthase in aging and Alzheimer's disease, Mol. Neurobiol. 41 (2010) 129-137.

[14] O. Arancio, E. R. Kandel, R. D. Hawkins, Activity-dependent long-term enhancement of transmitter release by presynaptic 3',5'-cyclic GMP in cultured hippocampal neurons, Nature, 376 (1995) 74-80.

[15] D. Puzzo, O. Vitolo, F. Trinchesse, J. P. Jacob, A. Palmeri, O. Arancio, Amyloidbeta peptide inhibits activation of the nitric oxide/cGMP/cAMP-responsive elementbinding protein pathway during hippocampal synaptic plasticity, J. Neurosci. 25 (2005) 6887-6897.

[16] O. V. Vitolo, A. Sant'Angelo, V. Costanzo, F. Battaglia, O. Arancio, M. Shelanski, Amyloid beta -peptide inhibition of the PKA/CREB pathway and long-term potentiation: reversibility by drugs that enhance cAMP signaling, Proc. Natl. Acad. Sci. USA 99 (2002) 13217-13221.

[17] J. Zhang, J. Guo, X. Zhao, Z. Chen, G. Wang, A. Liu, Q. Wang, W. Zhou, Y. Xu, C. Wang, Phosphodiesterase-5 inhibitor sildenafil prevents neuroinflammation, lowers betaamyloid levels and improves cognitive performance in APP/PS1 transgenic mice, Behav. Brain Res. 250 (2013) 230-237.

[18] A. Ugarte, F. Gil-Bea, C. García-Barroso, Á. Cedazo-Minguez, M. J. Ramírez, R. Franco, A. García-Osta, J. Oyarzabal, M. Cuadrado-Tejedor, Decreased levels of guanosine 3', 5'-monophosphate (cGMP) in cerebrospinal fluid (CSF) are associated with cognitive decline and amyloid pathology in Alzheimer's disease, Neuropathol. Appl. Neurobiol. 41 (2015) 471-482. 
[19] S. Schröder, B. Wenzel, W. Deuther-Conrad, M. Scheunemann, P. Brust, Novel Radioligands for Cyclic Nucleotide Phosphodiesterase Imaging with Positron Emission Tomography: An Update on Developments Since 2012, Molecules 21 (2016) 650-685.

[20] P. Cumming, A business of some heat: molecular imaging of phosphodiesterase 5, J. Neurochem. 136 (2016) 220-221.

[21] S. Jakobsen, G.M. Kodahl, A.K. Olsen, P. Cumming, Synthesis, radiolabeling and in vivo evaluation of $\left[{ }^{11} \mathrm{C}\right] \mathrm{RAL}-01$, a potential phosphodiesterase 5 radioligand, Nucl. Med. Biol. 33 (2006) 593-597.

[22] R. Chekol, O. Gheysens, J. Cleynhens, P. Pokreisz, G. Vanhoof, M. Ahamed, S. Janssens, A. Verbruggen, G. Bormans, Evaluation of PET radioligands for in vivo visualization of phosphodiesterase 5 (PDE5), Nucl. Med. Biol. 41 (2014) 155-162.

[23] V. Gomez-Vallejo, A. Ugarte, C. Garcia-Barroso, M. Cuadrado-Tejedor, B. Szczupak, I.G. Dopeso-Reyes, J.L. Lanciego, A. Garcia-Osta, J. Llop, J. Oyarzabal, R. Franco, Pharmacokinetic investigation of sildenafil using positron emission tomography and determination of its effect on cerebrospinal fluid cGMP levels, J. Neurochem. 136 (2016) 403-415.

[24] M. J. Palmer, A. S. Bell, D. N. A. Fox, D. G. Brown, Design of second generation of phosphodiesterase 5 inhibitors, Curr. Top. Med. Chem. 7 (2007) 405-419.

[25] M. B. Tollefson, B. A. Acker, E. J. Jacobsen, R. O. Hughes, J. K. Walker, D. N. A. Fox, M. J. Palmer, S. K. Freeman, Y. Yu, B. R. Bond, 1-(2-Ethoxyethyl)-1H-pyrazolo[4,3d]pyrimidines as potent phosphodiesterase 5 (PDE5) inhibitors, Bioorg. Med. Chem. Lett. 20 (2010) 3120-3124.

[26] M. B. Tollefson, B. A. Acker, E. J. Jacobsen, R. O. Hughes, J. K. Walker, D. N. A. Fox, M. J. Palmer, S. K. Freeman, Y. Yu, B. R. Bond, 1-(2-(2,2,2-Trifluoroethoxy)ethyl-1Hpyrazolo[4,3- $d$ ]pyrimidines as potent phosphodiesterase 5 (PDE5) inhibitors, Bioorg. Med. Chem. Lett. 20 (2010) 3125-3128.

[27] G. Yu, H. J. Mason, X. Wu, J. Wang, S. Chong, G. Dorough, A. Henwood, R. Pongrac, L. Seliger, B. He, D. Normandin, L. Adam, J. Krupinski, J.E. Macor, Substituted Pyrazolopyridines as Potent and Selective PDE5 Inhibitors: Potential Agents for Treatment of Erectile Dysfunction, J. Med. Chem. 44 (2001) 1025-1027.

[28] N. Watanabe, H. Adachi, Y. Takase, H. Ozaki, M. Matsukura, K. Miyazaki, K. Ishibashi, H. Ishihara, K. Kodama, M. Nishino, M. Kakiki, Y. Kabasawa, 4-(3-Chloro-4methoxybenzyl)aminophthalazines: Synthesis and Inhibitory Activity toward Phosphodiesterase 5, J. Med. Chem. 43 (2000) 2523-2529.

[29] G. Yu, H. J. Mason, K. Galdi, X. Wu, L. Cornelius, N. Zhao, M. Witkus, W. R. Ewing, J. E. Macor, Mono-Chlorination of Electron-Rich Arylalkyl- and Heteroarylalkyl-amines and Amino Acids Using Sulfuryl Chloride, Synthesis 3 (2003) 403-416. 
[30] Y. Bi, P. Stoy, L. Adam, B. He, J. Krupinski, D. Normandin, R. Pongrac, L. Seliger, A. Watson, J.E. Macor, Quinolines as extremely potent and selective PDE5 inhibitors as potential agents for treatment of erectile dysfunction, Bioorg. Med. Chem. Lett. 14 (2004) 1577-1580.

[31] T. Ukita, Y. Nakamura, A. Kubo, Y. Yamamoto, Y. Moritani, K. Saruta, T. Higashijima, J. Kotera, M. Takagi, K. Kikkawa, K. Omori, Novel, potent, and selective phosphodiesterase 5 inhibitors: synthesis and biological activities of a series of 4-aryl-1isoquinolinone derivatives, J. Med. Chem. 44 (2001) 2204-2218.

[32] T. Ukita, Y. Nakamura, A. Kubo, Y. Yamamoto, Y. Moritani, K. Saruta, T. Higashijima, J. Kotera, K. Fujishige, M. Takagi, K. Kikkawa, K. Omori, 1,7- and 2,7naphthyridine derivatives as potent and highly specific PDE5 inhibitors, Bioorg. Med. Chem. Lett. 13 (2003) 2341-2345.

[33] M. P. Giovannoni, C. Vergelli, A. Graziano, V. Dal Piaz, PDE5 inhibitors and their applications, Curr. Med. Chem. 17 (2010) 2564-2587.

[34] I. P. Holmes, Y. Bergman, G. E. Lunniss, M. Nikac, N. Choi, C. F. Hemley, S. R. Walker, R. C. Foitzik, D. Ganame, R. Lessene, FAK INHIBITORS, US Pat. US2013/0017194A (2013).

[35] I. A. Moussa, S. D. Banister, C. Beinat, N. Giboureau, A. J. Reynolds, M. Kassiou, Design, synthesis, and structure-affinity relationships of regioisomeric $N$-benzyl alkyl ether piperazine derivatives as sigma-1 receptor ligands, J. Med. Chem. 53 (2010) 62286239.

[36] J. Liu, B. Wenzel, S. Dukic-Stefanovic, R. Teodoro, F. A. Ludwig, W. DeutherConrad, S. Schröder, J. M. Chezal, E. Moreau, P. Brust, A. Maisonial-Besset, Development of a New Radiofluorinated Quinoline Analog for PET Imaging of Phosphodiesterase 5 (PDE5) in Brain, Pharmaceuticals 9 (2016) E22.

[37] M. M. Appleman, W. J. Thompson, Multiple cyclic nucleotide phosphodiesterase activities from rat brain, Biochemistry 10 (1971) 311-316. 